\title{
The role of nurses in medical end-of-life decisions
}

\author{
Citation for published version (APA):
}

van Bruchem-van Scheur, G. G. (2009). The role of nurses in medical end-of-life decisions. [Doctoral Thesis, Maastricht University]. Datawyse / Universitaire Pers Maastricht. https://doi.org/10.26481/dis.20090116gb

Document status and date:

Published: 01/01/2009

DOI:

10.26481/dis.20090116gb

Document Version:

Publisher's PDF, also known as Version of record

\section{Please check the document version of this publication:}

- A submitted manuscript is the version of the article upon submission and before peer-review. There can be important differences between the submitted version and the official published version of record.

People interested in the research are advised to contact the author for the final version of the publication, or visit the DOI to the publisher's website.

- The final author version and the galley proof are versions of the publication after peer review.

- The final published version features the final layout of the paper including the volume, issue and page numbers.

Link to publication

\footnotetext{
General rights rights.

- You may freely distribute the URL identifying the publication in the public portal. please follow below link for the End User Agreement:

www.umlib.nl/taverne-license

Take down policy

If you believe that this document breaches copyright please contact us at:

repository@maastrichtuniversity.nl

providing details and we will investigate your claim.
}

Copyright and moral rights for the publications made accessible in the public portal are retained by the authors and/or other copyright owners and it is a condition of accessing publications that users recognise and abide by the legal requirements associated with these

- Users may download and print one copy of any publication from the public portal for the purpose of private study or research.

- You may not further distribute the material or use it for any profit-making activity or commercial gain

If the publication is distributed under the terms of Article $25 \mathrm{fa}$ of the Dutch Copyright Act, indicated by the "Taverne" license above, 


\section{The role of nurses in}

medical end-of-life decisions 
(C) Copyright Ada van Bruchem - van de Scheur, Bruchem 2006

Universitaire Pers Maastricht

ISBN 978-90-5278-796-1

Cover photo by Dick and Frieda de Bijl

Layout by Arie van der Arend

Printed by Datawyse Maastricht 


\section{The role of nurses in}

\section{medical end-of-life decisions}

\section{PROEFSCHRIFT}

ter verkrijging van de graad van doctor aan de Universiteit Maastricht, op gezag van de Rector Magnificus, Prof. mr. G.P.M.F. Mols,

volgens het besluit van het College van Decanen,

in het openbaar te verdedigen

op viijdag 16 januari 2009 om 14.00 uur

door

Grada Gosuïna van Bruchem - van de Scheur

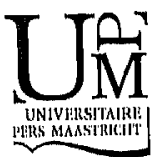




\section{Promotores:}

Prof. dr. R.H.J. ter Meulen Mw. prof. dr. H. Huijer Abu-Saad

\section{Co-promotor:}

Dr. A.J.G. van der Arend

\section{Beoordelingscommissie:}

Mw. prof. dr. A. de Wit

Prof. dr. J.A. Knottnerus

Prof. mr. J. Legemaate

Prof. dr. K.C.P. Vissers

Prof. dr. G.A.M. Widdershoven
University of Bristol, United Kingdom American University of Beirut, Lebanon

voorzitter

VU medisch centrum, Amsterdam UMC St Radboud, Nijmegen 


\section{Contents}

Chapter 1 INTRODUCTION 9

Reason for commissioning the study 9

Aim and research questions of the study 11

$\begin{array}{ll}\text { Aim } & 11\end{array}$

$\begin{array}{ll}\text { Research questions } & 11\end{array}$

Definitions of medical end-of-life decisions 12

The Dutch law on euthanasia and physician-assisted suicide 13

National relevance of the study 13

International relevance of the study 14

$\begin{array}{ll}\text { Outlines of the thesis } & 15\end{array}$

References $\quad 16$

Chapter 2 METHOD OF THE STUDY 19

Introduction 19

The qualitative study 20

Recruitment of respondents and sampling $\quad 20$

$\begin{array}{ll}\text { Data collection } & 21\end{array}$

$\begin{array}{ll}\text { Data-analysis } & 23\end{array}$

Reliability and validity $\quad 23$

Ethical considerations $\quad 24$

Summary of the results of the qualitative study

The role of nurses in euthanasia/physician-assisted suicide 24

The role of nurses in the alleviation of pain and symptoms with a
life-shortening intention

The changeover from the quaiitative study to the quantitative study 26

$\begin{array}{ll}\text { The quantitative study } & 27\end{array}$

$\begin{array}{ll}\text { Recruitment of respondents } & 27\end{array}$

$\begin{array}{ll}\text { Data collection } & 29\end{array}$

$\begin{array}{ll}\text { Data analysis } & 30\end{array}$

Reliability and validity 31

$\begin{array}{ll}\text { Ethical considerations } & 32\end{array}$

References $\quad 32$

Chapter 3 THE ROLE OF NURSES IN EUTHANASIA AND

Abstract PHYSICIAN-ASSISTED SUICIDE IN THE NETHERLANDS

Participants

Contact persons in the organisations recruited the respondents $\quad 37$

$\begin{array}{ll}\text { Data collection } & 37\end{array}$ 
Results

Requests for euthanasia or physician-assisted suicide

The decision-making process

Administering the euthanatics

Discussion

Study limitations and strengths

Requests for euthanasia and physiclan

Conclusions

Administering the euthanatics 42

References

Chapter 4 EUTHANASIA AND PHYSICIAN-ASSISTED SUICIDE IN THE DUTCH HOMECARE SECTOR: THE ROLE OF THE DISTRICT NURSE

Abstract

introduction

Literature review

46

The study

Aim

46

Design

Participants

47

Data collection

Validity and reliability

Ethical considerations Data analysis

Results

Description of participants

Requests for euthanasia or physician-assisted suicides

The decision-making process

Administering lethal drugs

Aftercare

Discussion

Study strengths and limitations

Requests for euthanasia and physician-assisted suicide

The decision-making process

Administering the lethal drugs

Aftercare

Conclusion

References

Chapter 5 EUTHANASIA AND PHYSICIAN-ASSISTED SUICIDE IN

Abstract DUTCH HOSPITALS: THE ROLE OF NURSES

Introduction

Literature review

The study

Aim 
$\begin{array}{ll}\text { Validity and reliability } & 60\end{array}$

Ethical considerations $\quad 61$

Data analysis $\quad 61$

Results

Description of participants

Requests for euthanasia or physician-assisted suicides

The decision-making process 62

$\begin{array}{ll}\text { Administering the euthanatics } & 62\end{array}$

Euthanasia guidelines in hospitals 63

Discussion

Requests for euthanasia and physician-assisted suicide 63

The decision-making process 64

Administering the euthanatics $\quad 65$

Euthanasia guidelines $\quad 66$

Conclusions 66

References $\quad 67$

$\begin{array}{ll}\text { Chapter } 6 & \text { DUTCH NURSES' ATTITUDES TOWARDS EUTHANASIA } \\ & \text { AND PHYSICIAN-ASSISTED SUICIDE }\end{array}$

Abstract $\quad 69$

Introduction 70

Conceptual issues $\quad 70$

The Dutch law on euthanasia and physician-assisted suicide $\quad 70$

Attitudes of nurses $\quad 70$

Method

Aim

Design

Recruitment of participants

Data collection $\quad 72$

Validity and reliability 73

Ethical considerations

Results

Data analysis

Characteristics of respondents

Membership of nurses on regional euthanasia review committees

A legal regulation to oblige physicians to consult a nurse $\quad 74$

Preparatory activities for the administration of euthanatics 75 Discussion

Membership of nurses on regional euthanasia review committees 75

A legal regulation to objige physicians to consult a nurse 76

$\begin{array}{ll}\text { Preparatory activities for the administration of euthanatics } & 77\end{array}$

Conclusion

References

Chapter 7 ALLEVIATION OF PAIN AND SYMPTOMS WITH A LIFE-SHORTENING INTENTION

Abstract

Introduction: conceptual issues

Literature review $\quad 82$

Methods 83

Aim 83 
Recruitment of respondents 83

Data collection 84

Validity and reliability 84

Ethical considerations

Data analysis $\quad 85$

Results

Respondents' characteristics 85

Patients' characteristics 85

Reasons for deciding on APS with a life-shorlening intention 87

The decision making 88

Administering the medication $\quad 88$

Discussion $\quad 89$

Methodological aspects 89

Reasons for deciding on APS with a life-shortening intention 90

The decision making 90

Administering the medication 91

Conclusion $\quad 92$

References $\quad 92$

Chapter 8 CONCLUSIONS AND DISCUSSION

Introduction 95

Conclusions and discussion with regard to the role of nurses in authanasia and

Conclusions and discussion with regard to attitudes of nurses concorning

euthanasia/physician-assisted suicide 102

Conclusions and discussion with regard to the role of nurses in the alleviation
of pain and symptoms with a life-shortening intention

Conclusions and discussion with regard to the methodology of the study 108

References 109

Chapter 9 RECOMMENDATIONS $\$ 11$

Introduction 111

Recommendations with regard to euthanasia and physician-assisted suicide 111

$\begin{array}{ll}\text { Nursing practice } & 111\end{array}$

$\begin{array}{ll}\text { Nursing education } & 112 \\ & 113\end{array}$

Institutional guidelines $\quad 113$

$\begin{array}{ll}\text { Legislation } & 114\end{array}$

Recommendation with regard to alleviation of pain and symploms with a

Follow-up research $\quad 116$

$\begin{array}{ll}\text { References } & 117\end{array}$

ENGLISH SUMMARY

NEDERLANDSE SAMENVATTING

DANKWOORD 131

CURRICULUM VITAE

LIST OF PUBLICATIONS 


\section{Chapter 1}

\section{Introduction}

\section{Reason for commissioning the study}

Medical end-of-life decisions, particularly euthanasia and physician-assisted suicide, have received much attention in the Dutch society for many years. The debate, which started at the beginning of the Seventies, focuised mainiy on the ethical and legal responsibilities of physicians. Especially after 1990, a number of survey studies among physicians were conducted to determine the rate and main characteristics of euthanasia, physician-assisted suicide and other medical end-of-life decisions (Van der Maas et al. 1996, Onwuteaka-Philipsen et al. 2003). In these studies, physicians provided some information about the role of nurses, but their role was never quantitatively investigated from the nurses' own perspective.

While the political, social and professional debates about life ending activities lay emphasis on the role of physicians, the nursing profession in the Netherlands witnessed a number of developments and took position on a number of issues. The following highlights the most relevant of these.

\section{5}

The role of nurses was recognized for the first time by the Dutch state committee on euthanasia in 1985. This committee, whose task it was to advise on future government policies, did not consider it necessary to include the role of nurses in the law (Staatscommissie Euthanasie, 1985). The national nurses' association (then called 'Het Beterschap') made known its dissatisfaction with the committee's opinion. The association argued that nurses being closely involved in the guidance of dying patients in their daily practise, should have adequate legal protection (Beterschap, 1985).

\section{7}

The Royal Dutch Medical Association (KNMG) and the national nurses' association 'Het Beterschap' published their joint guidelines on the collaboration and demarcation of tasks in euthanasia between physicians and nurses. In 1991 and 1997, these guidelines were revised by the KNMG and by the newly formed nurses' association called Nieuwe Unie ' 91 . In 2006, the fourth revised edition was published jointly by the General Asso- 
ciation of Nurses and Caretakers (AVWV), the nurses' association Nieuwe Unie ' 91 (NU'91), and the KNMG (AWV et al. 2006) which was based, among other things, on the results of the study presented here. In the Netherlands, joint guidelines of physicians and nurses have played an important role in clarifying the role of nurses. These guidelines describe the collaboration and demarcation of tasks between physicians and nurses/caregivers in the various stages of the euthanasia process. The guidelines state, for example: 'when a nurse is involved in the daily care of a patient who makes a request for euthanasia, it is highly desirable that the nurse be involved in the decision-making process. Because of her daily involvement and her specific expertise, she could contribute to a careful decision-making of the physician' (AVVV et al. 2006, p. 35).

1993

The government repeated its position that nurses involved in euthanasia did not need legal regulation. In the government's opinion, only physicians can be responsible for performing euthanasia. Nurses can never be held jointly responsible for the decision, although they are frequently involved in the decision-making process (Eerste Kamer der Staten Generaal, 1993). The notification procedure, in force since November 1990, was regulated by law. Under this procedure, physicians are required to report the termination of the life of a patient. In conformity with the government's standpoint concerning the role of nurses, the following question was included in the notification form of the physician: 'Did you consult the nursing staff/the patient's caretakers about terminating the patient's life? If so, who did you consult and what was their view? If not, why not?'

\section{8}

With the establishment of five Regional euthanasia review committees in the Netherlands, discussion arose about whether nursing should be represented in these committees. The task of these committees is to review reported cases of euthanasia and physician-assisted suicide on the basis of the due care requirements of law (see page 13 of this chapter.

Nurses associations argued that nurses should be members of the review committees, because of their extensive experience in observing and supporting patients. Their membership would be an acknowledgment of the fact that nurses observe closely how a patient comes to the decision to request euthanasia. Nurses are well-trained professionals and their expertise and experience should be used (LCVV, 1998).

The Minister of Health decided, however, not to include nurses in the committees for the following reasons (Borst-Eilers, 1998): 1. The involvement of the nurse within the reviewing process has already been guaran-
teed by means of:

a. The form physicians are obliged to complete and send to the regional euthanasia review committee where physicians must indicate if a nurse was consulted and the nurse's view.

b. The committee's ability to obtain information from the concerned caregiver at a later date, when needed to correctly assess the physician's actions.

2. Not in all cases was a nurse involved in euthanasia or physician-assisted suicide. Particularly in the home situation, the nurse is frequently less involved and often only the physician and patient talk about the decision.

3. An even number of committee members would not facilitate its decision-making. $A$ further extension to an odd number of members would also not be desirable. This would not positively influence the effectiveness of the committee or the balance
within the committee. 
The Minister did consider it important, however, to give attention to the role of nurses in requests for euthanasia. For this purpose, the Minister commissioned a study in order to advise the Dutch government in legislation and policy-making concerning such role. Should this study reveal that participation of the nurse in the committee be advisable, the original decision would be reconsidered.

2001

Following the commission of the Ministry of Health, Welfare and Sports, the study into the role of nurses in medical end-of-life decisions began January 2001. It should be noted that the political lobby of the nurses' association Nieuwe Unie '91 (NU'91) and the General Association of Nurses and Caretakers (AVW) contributed to the realization of this study. For many years, they lobbied for adequate legal protection regarding the role of nurses in euthanasia/physician-assisted suicide.

Also the relationship between the researcher and the study should be mentioned here. In 1997, the researcher wrote her MSc dissertation based on a qualitative study into the role of nurses in euthanasia within one hospital (Van de Scheur \& Van der Arend, 1998). In 1998, she proposed to her present promotor to conduct a national study into the role of nurses in euthanasia/physician-assisted suicide. The submitted research proposal was accepted and subsequently financed by the Ministry of Health, Welfare and Sports. In addition to euthanasia and physician-assisted suicide, other medical end-of-life decisions were included: ending of life without an explicit request of the patient, alleviation of pain and symptoms with a life-shortening intention, not starting or stopping treatments which have no prospect or are futile in conformity with actual medical knowledge, and withholding artificial administration of fluids and food. Nurses could also be involved in these other medical end-of-life decisions and their position and responsibilities might be different from those in euthanasia and physician-assisted suicide.

The results of the study were published in August 2004 (Van Bruchem-van de Scheur et al. 2004). This thesis focuses on the main outcomes of that study.

\section{Aim and research questions of the study}

Aim

The aim of the study was to investigate the role, perceptions, responsibilities, and problems of nurses in medical end-of-life decisions in order to advise the Dutch government in legislation and policy-making concerning the role of nurses.

\section{Research questions}

Based on the aim of the study, the following research questions were formulated:

- What is the role of nurses in medical end-of-life decisions in hospitals, homecare organizations and nursing homes?

- What are their responsibilities?

- What attitudes do nurses have with regard to their responsibilities?

- What obstacles do nurses experience and how can these be resolved?

The following sub questions have been formulated:

1. What is the role of nurses in the various stages of medical end-of-life decisions, which may be chronologically divided: observing a request or a situation which gives reason for ending the life of a patient; decision-making; performing and aftercare, and is there a difference regarding this role between nurses employed in hospitals, homecare organizations and nursing homes? 
2. What attitudes do nurses hold regarding to their role in medical end-of-life decisions, and is there a difference with regards to these attitudes between nurses employed in hospitals, homecare organizations and nursing homes?

3. What obstacles can be observed between the actual role of nurses, their responsibilities and their views about their role and responsibilities? Do the obstacles vary between nurses employed in hospitals, homecare organizations and nursing homes?

4. What obstacles can be observed in the role, attitudes and responsibilities of nurses, physicians and other persons involved with regard to task demarcation and collaboration, and how can these be resolved?

\section{Definitions of medical end-of-life decisions}

The study considered the following six medical end-of-life decisions, which are defined in accordance with previous Dutch studies into medical end-of-life decisions and the Royal Dutch Medical Association (KNMG):

1. Euthanasia: the administration of drugs by a person other than the patient with the explicit intention of ending the patient's life on his or her explicit request (Onwuteaka-Philipsen et al. 2003).

2. Physician-assisted suicide: the prescribing or supplying of drugs with the explicit intention of enabling the patient to end his or her own life. (Onwuteaka-Philipsen ef al. 2003). The concepts euthanasia and physician-assisted suicide are different in the way in which they are carried out. In euthanasia, someone other than the patient administers the euthanatics. In physician-assisted suicides, the patients themselves take the lethal drugs, as prescribed by their physician. In our study, euthanasia and physician-assisted suicide are morally different. However, for practical reasons in this study they are taken together as one phenomenon.

3. Ending of life without an explicit request of the patient: this medical end-of-life decision distinguishes itself from euthanasia and physician-assisted suicide on the point of the request of the patient. It concerns activities with the explicit aim of ending the life and to which a drug is administered without an explicit request of the patient (Van der Wal \& Van der Maas, 1996).

4. Alleviation of pain and symptoms with a life-shortening intention: in the last stage of life it is not uncommon to intensify the treatment of pain and other symptoms with the purpose to relieve suffering. A shortening of life is possible and justifiable because the administration of drugs is not intended to cause death but to intensify the alleviation of symptoms.

'When deliberate doses are used, which from the viewpoint of necessary pain/symptom alleviation cannot be justified, then the purpose has obviously shifted towards hastening the end of the life of the patient' (KNMG, 2003, p. 5). In our study, we limited ourselves to situations where, according to the nurse, life-shortening was an intention of the administering of medication.

5. Not starting or stopping treatments which are without prospect or futile in conformity with actual medical knowledge: situations where on the basis of medical criteria, it is decided not to start or to stop a treatment whereas it is medically-technically possible to keep someone alive, but which serves no medical purpose, namely the improving or relieving the illness and/or suffering (KNMG, 1995).

6. Withholding artificial administration of fluids and food: situations in which a patient does not or hardly takes in fluids and/or food and the decision is taken not to start or to stop with artificial administration of fluids and food (Pasman et al. 2003). 
Choice of types of decisions in the study

In the qualitative part of the study, all types of named medical decisions were included. The quantitative part of the study was limited to three medical decisions: euthanasia, physician-assisted suicide, and alleviation of pain and symptoms with a life-shortening intention. In chapter 2 this choice is justified.

\section{The Dutch law on euthanasia and physician-assisted suicide}

After 30 years of public discussion in the Netherlands, the Law on the Termination of Life on Request and Assisted Suicide (Euthanasia Act) came into force in April 2002. It confirms that physicians, who perform euthanasia or assist in a suicide, are exempted from prosecution and punishment when their actions meet two conditions:

1. They fulfil the due care requirements which stipulate that the physician

a. is convinced that the patient's request is voluntary and well considered,

b. is convinced that the patient's suffering is hopeless and unbearable,

c. has informed the patient about his/her situation and prospects,

d. is convinced, together with the patient, that there is no other reasonable solution,

e. has consulted at least one other independent physician, who has also seen the patient, and has provided a written assessment of the due care requirements listed in a. to d. above,

f. has carried out the termination or assisted in the suicide with due medical care.

2. They report an unnatural death to the Municipal Coroner and submit a reasoned report on the euthanasia or physician-assisted suicide to a Regional euthanasia review committee. This committee, consisting of a legal expert, a physician, and an ethicist, assesses whether the physician has complied with the due care requirements of the law.

\section{National relevance of the study}

In the Netherlands, medical end-of-life decisions have been investigated mainly within the medical profession. A number of survey studies were conducted to determine the rate and main characteristics of euthanasia and physician-assisted suicide in medical practice (Onwuteaka-Philipsen et al. 2003. Onwuteaka-Philipsen ot al. 2007, Van der Heide et al. 2007). As these studies focused on the role of physicians, they provided only marginal information about the role of nurses. Moreover this information was indirect, as it was not gathered by questioning nurses directly. This latter point applies also to the study of Muller et al. (1997).

Apart from the large survey studies among physicians, only a few qualitative studies have provided data from the perspective of nurses. These studies were conducted in single institutions (Pool 1996, The 1997, Van de Scheur \& Van der Arend 1998). The study presented in this thesis is the first large scale survey exploring the role of nurses in medical end-of-life decisions from their own perspective.

The study is relevant from different perspectives:

1. Scientific relevance. The scientific importance fills a gap in empirical knowledge towards the role of nurses in medical end-of-life decisions. The results contribute to further scientific, philosophic and ethical reflection on the quality of professional activities in medical end-of-life decisions. 
2. Social relevance. Medical end-of-life decisions have been the subject of social debate for more than 30 years, with the role of the physician being the main focus. The study will help clarify the role of nurses; help clarify the collaboration and demarcation of responsibilities between physicians and nurses; and aims to influence health care policy in this field. As a result, the trust of the society in the practices concerned and in the applied law and regulations may be nuanced and affirmed or strengthened.

3. Nursing relevance. In 2001, the year that this study began, it was estimated that $44.5 \%$ of all deaths were preceded by a medical end-of-life decision, of which $2.8 \%$ were related to euthanasia/physician-assisted suicide. The number of explicit requests for euthanasia or physician-assisted suicide 'within the foreseeable future' was estimated at 9700 (Onwuteaka-Philipsen et al. 2007).

Nurses are frequently involved in the guidance of dying patients and consequently, they are confronted with medical end-of-life decisions. Therefore, the results of the study are highly relevant for the nursing profession, especially with regard to the quality improvement of the activities of nurses. The results will contribute to further development of the scope of practice of nurses and the development of guidelines in this fieid. It would be very helpful for nurses to have their responsibility, just as that of other concerned parties, as clearly as possible demarcated and described.

It should be noted that in 2005, between publication of the results and the publication of this thesis, the percentage of medical end-of-life decisions $(43.2 \%$ of all deaths, excluding continuous deep sedation) differed not significantly from 2001. However, the percentage euthanasia/physician-assisted suicide decreased to $1.8 \%$ and the number of explicit requests for euthanasia physician-assisted suicide 'within the foreseeable future' decreased to 8400 (Onwuteaka-Philipsen et al. 2007).

This decline may be explained by several trends: firstly, the death rate in 2005 was lower than in 2001. Secondly, as a result of the increase of the ageing population, the percentages of deaths of people of 80 years and older increased. In this age group, euthanasia and physician-assisted suicide occur relatively less frequently. Thirdly, an increase in other methods of controlling pain and other symptoms, such as continuous deep sedation were developed. Fourthly, changes in attitudes of physicians which indicate that they are probably less inclined to attribute life-shortening effects to morphine (Onwuteaka-Philipsen et al. 2007, Van der Heide et al. 2007). In spite of this decrease, which also did not mean an essential change in practice (given the latter argument), the results are undiminishedly relevant for the nursing profession.

\section{International relevance of the study}

In the world-wide debate of euthanasia, the number of publications about nurses and euthanasia/physician-assisted suicide is increasing. However, most studies focus on nurses' attitudes and ideas about euthanasia and their involvement with it as an illegal act (Ryynänen et al. 2002, Verpoort et al. 2004-a, Verpoort et al. 2004-b, Dierckx de Casterle et al. 2006). Although these studies may help define the (future) role of nurses in euthanasia and physician-assisted suicide, the number of empirical studies investigating nurses' actual role in these practices is limited. Moreover it is not exceptional that data come from physicians, as becomes clear from the literature review of De Beer et al. (2004). In this review, six of 15 studies used physician-only samples and provided only indirect information on the role of nurses. 
The thread through several studies is that nurses perform a variety of tasks in the various stages of the euthanasia process, irrespective of the legal status of euthanasia in a country. Nurses are (often) the first caregivers to receive a request for euthanasia ( $\mathrm{De}$ Beer et al. 2004, De Bal et al, 2006).

In the decision-making process, they could have an important role in the analysis of the patients' request, for example to determine whether the request might conceal an appeal for help (De Bal et al. 2006). However, several studies found that it is not self-evident that nurses participated in the decision-making process (Muller et al. 1997, Deliens et al. 2000, Van der Wal et al. 2003, Bilsen et al. 2004, De Beer et al. 2004). Deliens et al. (2000) and De Beer et al. (2004), for example, suggest that in about half of all cases nurses participate in the decision-making process.

Several studies reported that nurses administered the lethal drugs together with or without the physician (Muller et al. 1997, Van de Scheur \& Van der Arend 1998, Bilsen et al. 2004, De Beer et al. 2004). Each of these actions is a punishable offence.

Although the ICN Code of Ethics for Nurses (International Council of Nurses, 2006) does not mention the role of nurses in life ending activities, it can be stated that the four fundamental responsibilities in this code (to promote health, to prevent illness, to restore health and to alleviate suffering) excludes the ending of life of patients as the work of nurses and other caregivers.

The present study raises new questions in the discussion concerning the role of nurses in euthanasia and physician-assisted suicide, such as their role in preparing euthanatics and inserting an infusion needle to administer the euthanatics. Whilst embedded in a Dutch cultural context, but against the above-mentioned background of uncertainty and obscurity, the data of this study may have international relevance. It may help nurses in other countries to define their (future) role in euthanasia and physician-assisted suicide in case this procedure is legalised. The section on the alleviation of pain and symptoms with a life-shortening intention is relevant for all nurses, regardless of whether or not there exists a legal practice of euthanasia. This may raise questions regarding the scope of nurse's practices, legal and ethical, and may lead as such to further collaboration between health care professionals to develop this field further.

\section{Outlines of the thesis}

This thesis has been based on the Dutch study into the role of nurses in medical end-oflife decisions (Van Bruchem-van de Scheur et al. 2004). It reports on the main outcomes of this study.

Chapter 2 describes the method of the study, both with regard to the qualitative and quantitative part of the study. Both parts are described on the basis of the following topics: recruitment of participants, data collection, data analysis, validity and reliability, and ethical considerations.

This thesis is compiled based on articles, which are described in the chapters 3 through 7. These articles have been published separately, which is the reason for some overlap in description of literature, methods and results.

Chapter 3 describes the role of nurses in euthanasia and physician-assisted suicide in three different sectors: hospitals, homecare and nursing homes. Their role is presented with respect to requests for euthanasia/physician-assisted suicide, the decision-making process, and the administration of euthanatics. Subsequently, the role of nurses in euthanasia and physician-assisted suicide in hospitals is worked out in chapter 4 . Their role is presented with respect to requests for euthanasia/physician-assisted suicide, the decision-making process and the administration of euthanatics. Furthermore the role of 
existing guidelines in hospitals on euthanasia and physician-assisted suicide is presented.

The role of district nurses in euthanasia and physician-assisted suicide in homecare is covered in chapter 5 . Their role is presented with respect to: requests for euthanasia/physician-assisted suicide, the decision-making process, the administration of euthanatics, and aftercare.

Chapter 6 presents the attitudes of nurses towards three actual issues of their role in euthanasia and physician-assisted suicide: 1. membership of nurses in Regional euthanasia review committees; 2 . a legal regulation to require physicians to consult a nurse; 3 . nurses' role in preparatory activities for the administration of euthanatics (preparing euthanatics and inserting an infusion needle to administer euthanatics).

Chapter 7 describes the role of nurses in alleviation of pain and symptoms with a lifeshortening intention. After the reasons have been described for alleviation of pain and symptoms with a life-shortening intention, the role of nurses is presented with respect to the decision-making, and the administration of medication in hospitals, homecare and nursing homes.

In chapter 8 , the main conclusions of the study are presented and discussed. Furthermore, the methodology of the study is discussed. In chapter 9 , recommendations are given for nursing practice, nursing education, institutional guidelines, legislation, and follow-up research.

Finally, a summary of the content of this thesis is given in English and Dutch.

\section{References}

AVW, NU'91, KNMG. (2006) Handreiking voor Samenwerking Artsen, Verpleegkundigen en Verzorgenden bij Euthanasie. (Directive for collaboration physicians, nurses, and caretakers in euthanasia). [4 $4^{\text {th }}$ Edition]. Utrecht: AVVV/NU'91/KNMG. (In Dutch).

Bilsen, J.J.R., Vander Stichele, R.H., Mortier, F. \& Deliens, L. (2004). Involvement of nurses in physician-assisted dying. Journal of Advanced Nursing, 47, 583-591.

Borst-Eilers, E. (4 juni 1998). Meldingsprocedure euthanasie. Kamerstuk. (Notification procedure. Letter to the chairman of the Dutch Lower Chamber). Den Haag: Ministerie van Volksgezondheid, Welzijn en Sport. (In Dutch).

De Bal, N., Dierckx de Casterlé, B., De Beer, T. \& Gastmans, C. (2006). Involvement of nurses in caring for patients requesting euthanasia in Flanders (Belgium): A qualitative study. International Journal of Nursing Studies, 43, 589-599.

De Beer, T., Gastmans, C. \& Dierckx de Casterlé, B. (2004). Involvement of nurses in euthanasia: a review of the literature. Joumal of Medical Ethics, 30, 494-498.

Deliens, L., Mortier, F., Bilsen, J., Cosyns, M., Vander Stichele, R., Vanoverloop, J. \& Ingels, K. (2000). End-of-life decisions in medical practice in Flanders, Belgium: a nationwide survey. Lancet, 356, 1806-1811.

Dierckx de Casterlè, B., Verpoort, C., De Bal, N. \& Gastmans, C. (2006). Nurses' views on their involvement in euthanasia: a qualitative study in Flanders (Belgium). Journal of Medical Ethics, 32, 187-192.

Eerste Kamer der Staten-Generaal (the Dutch Upper Chamber). (1993). Wijziging van de Wet op de lijkbezorging: Memorie van antwoord. (Changing of the Burial Act: Memory in reply). Vergaderjaar 1992-1993, 22 572, nr. 275a, 's-Gravenhage: Sdu. (In Dutch).

Het Beterschap. (1985). Rechtsbescherming verpleegkundigen in euthanasjerapport onvoldoende: Beterschapsreactie op Staatcommissie. (Legal protection of nurses in the euthanasia report is insufficient; reaction of Het Beterschap on the Dutch State Commission on Euthanasia). Het Beterschap, 7, 26-27. (In Dutch). 
International Council of Nurses (ICN). (2006). The ICN Code of Ethics for Nurses. Geneva (Switzerland): International Council of Nurses.

KNMG (Royal Dutch Medical Association). (2003). Standpunt Federatiebestuur KNMG inzake euthanasie 2003. (Standpoint of the federation board KNMG concerning euthanasia 2003). Utrecht: KNMG. (In Dutch).

LCVV (National Centre Nursing \& Care). (1998). Verpleegkundigen in regionale toetsingscommissies voor euthanasie: Standpunt LCVV. (Nurses in Regional review committees for euthanasia: Point of view LCVV). Utrecht: LCVV. (In Dutch). The current name of the LCVV is LEVV (The Netherlands Centre for Excellence in Nursing).

Muller, M.T., Pijnenborg, L., Onwuteaka-Philipsen, B.D., van der Wal, G. \& van Eijk, J.T. (1997). The role of the nurse in active euthanasia and physician-assisted suicide. Journal of Advanced Nursing, 26, 424-430.

Onwuteaka-Philipsen, B.D., van der Heide, A., Koper, D., Keij-Deerenberg, I., Rietjens, J.A.C., Rurup, M.L. et al. (2003). Euthanasia and other end-of-life decisions in the Netherlands in 1990, 1995, and 2001. Lancet, 362, 395-399.

Onwuteaka-Philipsen, B.D., Gevers, J.K.M., van der Heide, A., van Delden, J.J.M., Pasman, H.R.W. Rietjens, J.A.C. et al. (2007). Evaluatie Wet toetsing levensbeëindiging op verzoek en hulp bij zelfdoding. (Evaluation of the Law on the Termination of Life on Request and Assisted Suicide). Den Haag: ZonMw. (In Dutch).

Pasman, H.R.W., Onwuteaka-Philipsen, B.D., The, B.A.M., van Wigcheren, P.T., Ooms, M.E., Ribbe, M.W. \& van der Wal, G. (2003). Al dan niet afzien van kunstmatige toediening van vocht en/of voedsel bij psychogeriatrische verpleeghuispatiënten: Bes/uitvorming, klinisch boloop en kwaliteit van sterven. (Yes or No abandonment of artificial administration of fluids and/or food at psycho geriatric nursing home patients: Decision-making, clinical course and quality of dying). Amsterdam: Afdeling Sociale Geneeskunde en afdeling Verpleeghuisgeneeskunde, instituut voor Extramuraal Geneeskundig Onderzoek, VU medisch centrum. (In Dutch).

Pool, R. (1996). Vragen om te sterven: Euthanasie in een Nederlands ziekenhuis (To ask for dying: euthanasia in a Dutch hospital). Rotterdam: WYT Uitgeefgroep. (In Dutch).

Ryynänen, O-P., Myllykangas, M., Viren, M. \& Heino, H. (2002). Attitudes towards euthanasia among physicians, nurses and the general public in Finland. Public Health, 116, 322-331.

Staatscommissie Euthanasie. (1985). Advies: deel 1. (Advice: part 1). Den Haag: Staatsuitgeverij. (In Dutch).

The, A-M. (1997). 'Vanavond om 8 uur...' Verpleegkundige dilemma's bij euthanasie en andere beslissingen rond het levenseinde. ('Tonight at eight o'clock...' Nurse's dilemmas with euthanasia and other end-of-life decisions). Houten/Diegem: Bohn Stafleu Van Loghum. (In Dutch).

Van Bruchem-van de Scheur, A., van der Arend, A., Spreeuwenberg, C., van Wijmen, F. \& ter Meulen, R. (2004). De rol van verpleegkundigen bij medische beslissingen rond het levenseinde. Verslag van een landelijk onderzoek naar betrokkenheid en praktijken. (The role of nurses in medical end-of-life decisions. Report of a national study into involvement and practices). Utrecht: Uitgeverij De Tijdstroom. (In Dutch).

Van der Heide, A., Onwuteaka-Philipsen, B.D., Rurup, M.L., Buiting, H.M., van Delden, J.J.M., Hanssen-de Wolf. J.E. et al. (2007). End-of-Life Practices in the Netherlands under the Euthanasia Act. New England Journal of Medicine, 356, 1957-1965.

Van der Maas, P.J., van der Wal, G., Haverkate, I., de Graaff, C.L., Kester, J.G., OnwuteakaPhilipsen, B.D. et al. (1996). Euthanasia, Physician-Assisted Suicide, and Other Medical Practices Involving the End of Life in the Netherlands, 1990-1995. New England Journal of Medicine, 335, 1699-1705.

Van de Scheur, A. \& van der Arend, A. (1998). The role of nurses in euthanasia: a Dutch study. Nursing Ethics, 5, 497-508. 
Van der Wal, G. \& van der Maas, P.J. (1996). Euthanasie en andere medische beslissingen rond het levenseinde: de praktijk en de meldingsprocedure. (Euthanasia and other medical end-oflife decisions: the practice and the notification procedure). Den Haag: Sdu. (In Dutch).

Van der Wal, G., van der Heide, A., Onwuteaka-Philipsen, B.D. \& van der Maas, P.J. (2003). Medische besluitvorming aan het einde van het leven. De praktijk en de toetsingsprocedure euthanasie. (Medical decision-making at the end of live. The practice and the notification procedure euthanasia). Utrecht: Uitgeverij De Tijdstroom. (In Dutch).

Verpoort, C., Gastmans, C., De Bal, N. \& Dierckx de Casterlè, B. (2004). Nurses' attitudes to euthanasia: a review of the literature. Nursing Ethics, 11, 349-365.

Verpoort, C., Gastmans, C. \& Dierckx de Casterle B. (2004). Palliative care nurses' views on euthanasia. Journal of Advanced Nursing, 47, 592-600. 


\section{Chapter 2}

\section{Method of the study}

\section{Introduction}

Relatively few research results have been published about the role of nurses in medical end-of-life decisions, neither within the Netherlands nor elsewhere. To approach the research question quantitatively was impossible without thorough preliminary study. Moreover, an exclusively quantitative approach ran the risk that unknown aspects would not be considered. Therefore, the study was comprised of two parts:

1. A qualitative study using individual interviews and focus group interviews in order to explore the nurses' practice. The results were important for constructing a questionnaire for the quantitative part of the study.

2. A quantitative study using a questionnaire consisting of a pilot study and main study. Three sectors participaled in the study: hospitals, homecare organizations and nursing homes.

As expected, within these sectors there occurred sufficient medical end-of-life decisions with implications for the role of nurses. This expectation was based on earlier studies among physicians (Van der Maas et al. 1991, Van der Wal \& Van der Maas, 1996).

Though the articles in this thesis (chapters 3 trough 7) focus on the quantitative part of the study, this chapter describes both the qualitative and quantitative methodology of the study.

The method of the qualitative study is described with respect to the recruitment of respondents and sampling, data collection, data analysis, validity and reliability, and ethical considerations, followed by a summary of a part of the results of the qualitative study. Furthermore, choices are discussed with regard to the changeover of the qualitative to the quantitative part of the study. Finally, the method of the quantitative study is described with respect to the recruitment of respondents, data collection, data analysis, validity and reliability, and ethical considerations. 


\section{The qualitative study}

This first part of the study was aimed at studying the nature of the phenomena. It focused on extensively exploring the role of nurses in medical end-of-life decisions and not on obtaining representative figures of the content matter. Such an approach is useful for several reasons. Qualitative research is pre-eminently suitable for mapping out and exploring (differences in) practices of nurses (Philipsen, 1990). Qualitative research is also useful for discovering personal experiences (Baarda et al. 2005, Maso \& Smaling, 1990). Furthermore, qualitative research may reveal unforeseen and unknown aspects of a practice (Parahoo, 2006). These three potential characteristics of qualitative research contributed to the development of a questionnaire for the quantitative part of the study.

\section{Recruitment of respondents and sampling \\ The respondent group consisted of both nurses and non-nurses.}

\section{Nurses}

The recruitment of nurses took place along two lines:

1. An appeal to participate in the study in eight professional magazines: Aaneen (Abvakabo), CFO Magazine, Het Richtsnoer, Nursing, TVZ Tijdschrift voor Verpleegkundigen, Verpleegkunde Nieuws, Verpleging NU (Nieuwe Unie'91) and Zorgpleidooi. This resulted in 96 candidates.

2. A sample of organizations. To obtain a national spreading, organizations were grouped by provinces (The Netherlands has 12 provinces). Organisations were approached by telephone, at the management level, with the request to participate in the study. When interest for participation was shown, the organization was asked to designate a contact person. The contact person then received written information about the study and was requested to recruit two respondents. In total 68 organizations were approached of which $43(63.2 \%)$ agreed to participate: 11 hospitals, 16 homecare organizations, and 16 nursing homes. This resulted in 98 candidates. Most important reasons for non-participation were workload and reorganization.

All candidates $(96+98=194)$ received written information about the study along with a registration form and an informed consent form.

The forms were returned by 151 candidates $(77.8 \%)$ with which their enrolment was confirmed. From this group, 56 respondents participated in the study, which were selected on the basis of sector, experience with types of medical end-of-life decisions, and national spreading. Of the 56, 20 respondents were from 15 hospitals, 20 from 14 homecare organizations, and 16 respondents from 13 nursing homes. The numbers of institutions concern (dis)locations of organizations. From a number of organizations, more than one location participated in the study.

Inclusion criteria were that respondents:

- Had more than two years working experience as a registered nurse;

- Had more than two years bedside experience;

- Were empioyed at least half time (in practice this means 18 till 20 hours per week);

- Had experienced medical end-of-life decisions;

- Had active command of the Dutch language.

Because of an expected poor accrual of nurses in nursing homes, also qualified caregivers in such homes were recruited if they worked as team leaders or coordinators. For these respondents, the first inclusion criterion was changed to 'more than two years working experience as a qualified care-giver'. 


\section{Non-nurses}

Because of the complexity of the subject, also 9 non-nurses were interviewed. Recruitment of non-nurses took place through network contacts. Respondents were eligible for inclusion if they:

- Had experience with and/or involvement in medical end-of-life decisions.

- Had expertise in the role, attitudes and/or responsibilities of nurses with regard to medical end-of-life decisions.

Respondents were approached by telephone with the request to participate in the study.

The respondent group consisted of:

- Three SCEN-physicians (Support and Consultation at Euthanasia in the Netherlands) working as nursing home physician, general practitioner or specialist.

- Three respondents with a legal background, working as nursing home physician, policy advisor or head of a care policy department.

- Three respondents, working as practice instructor, member of the Board of Governors/complaint functionary, and director patient care.

Respondents received in advance written general information about the study, as well as specific additional information during the interview.

\section{Data collection}

Data were collected using both individual semi-structured in-depth interviews and focus group interviews. Individual interviews were conducted first in order to explore the topic area, followed by focus group interviews in order to enhance the depth and spread of data.

Getting valuable data, especially within the limited time available, made focus group interviews a suitable instrument for this research (Parahoo, 2006).

A semi-structured questionnaire was developed based on literature and experiences and insights of the research team. The questionnaire consisted of open-ended questions with attention points for further probing when more detail about the role of nurses was desired (Polit \& Beck, 2008).

It appeared possible to develop one questionnaire for all different sectors. Given the open character of the questions no sector-specific questions needed to be formulated beforehand. This offered the possibility of observing similarities and differences between sectors.

In order to increase content validity, the questionnaire was presented to:

- Five members of the scientific advisory committee;

- Nine members of the sounding board;

- Three nurses, employed in a hospital, a homecare organization, and a nursing home.

The questionnaire was regularly adjusted on the basis of insights from interim analyses. The sequence of the interviews, which were all tape-recorded, was:

a. 14 individual semi-structured in-depth interviews with nurses

As a guideline for the interviews, a semi-structured questionnaire was used. Within such a semi-structured interview, the sequence and the depth is adapted to the responses (Zuuren, 1992). The researcher mainly fulfilled a stimulating role and adopted an empathic attitude, avoiding value judgements towards what was said during the interviews (Evers \& De Boer, 2007). This approach offered respondents the opportunity to answer the questions as openly as possible. Space was given to allow the specific situation of the respondent to be placed within a broader context and to discover new data which could also be useful in the development of the questionnaire for the focus group interm 
views. Interviews, which lasted 1 till $2 \frac{1}{2}$ hours, took place in a private area at the respondent's workplace or at the respondent's home.

b. 6 focus group interviews with nurses

Based on the findings from the individual interviews, the questionnaire was adapted for the focus group interviews. The adaptation mainly consisted in a reduction of the number of questions.

Focus group interviews are group discussions with the specific aim to explore issues. They distinguish themselves from the broader category of group discussions through the explicit use of group interactions to yield data (Kitzinger \& Barbour, 1999). Concerning this interaction, Kitzinger (1995) writes that group processes can be helpful to explore and clarify points of view. When these group dynamics function well, respondents work as if they are on the side of the researcher while giving new and frequently unexpected directions to the research matter.

In each sector, two focus group interviews were held. This division in sectors was made to accommodate expected sector-specific information which respondents would introduce. According to Polit \& Beck (2008), a homogeneous group promotes a comfortable group dynamic. When members share a similar background with other group members, they usually feel more at ease expressing their views.

in total 42 respondents participated in the focus group interviews. Respondents signed a confidentiality statement in which they indicated that nothing in the information during the interview would be mentioned in contacts with third parties, in publications, or otherwise made public.

The group size consisted of a maximum of eight respondents. It followed Morgan (1998) who indicates that a group size of six to ten respondents is common. Reasons given by Morgan to form a smaller group and which also partially applies to our study are: collecting in-depth information, high degree of commitment to and emotional involvement in the subject, participants with much knowledge about the subject, a controversial subject, a complex subject, detailed and personal information.

The placing of respondents in a focus group who were employed in the same organization was avoided as much as possible for reasons of confidentiality and undesirable interactions, but was not always preventable.

In the planning of interviews, a list with reserve candidates was used. It happened that invited respondents withdrew because of: courses, recent death in family as a result of which participation would be emotionally too heavy, removal, honeymoon or work schedule conflicts.

Interviews, which lasted 2 till 3 hours, took place within a separate and quiet room within a hospital, a hotel, and an office of a nursing organization. These locations were determined based on the geographical spreading of respondents. Respondents could claim traveling expenses. Other compensations were not given.

A member of the research team presided over the group interviews. The researcher was observer and took notes to detail who was talking, to summarize content, and to record contextual issues. The chairman and observer met following each session to discuss most important findings.

When respondents during the focus group interviews were not able to express everything they wanted to express, they were invited to contact the researcher regarding an additional interview by telephone. Five respondents used this opportunity.

c. 9 half-structured interviews with non-nurses

On the basis of the findings from both the individual and group interviews, a questionnaire was developed for the interviews with non-nurses. Interviews, which lasted 1 till 2 
hours, took place in a private area at the respondent's workplace or at the respondent's home. The role of the researcher corresponded with the one mentioned under point a above.

\section{Data-analysis}

The aim of the qualitative study was to develop question and answer categories for the questionnaire to be used in the quantitative study. A grounded theory approach was selected (Strauss \& Corbin, 1998) to guide the data collection and analysis. This approach has the potential to develop and refine theoretically relevant concepts leading to a better understanding of the role of nurses in medical end-of-life decisions.

Analysing a group interview does not differ in principle from the analysis of other qualitative data, with regard to assigning codes, discovering patterns and making comparisons (Wester \& Peters, 2004). Although the basic principles are the same, the analysis of focus group interviews has a number of its own attention points, which are explained below within the context of this research. Analysis of transcripts comprised four steps:

1. Interviews with nurses were transcribed verbatim. Participants of the focus group interviews were identified using respondent numbers. Before analysis, the transcripts of the individual interviews were reviewed by respondents for accuracy of content. Because of the confidentially of data this review was not possible with the transcripts of the focus group interviews.

2. Data were ordered on the basis of the questions in the questionnaire (Beukema, 2003). For unexpected relevant information new categories were developed.

3. Within the categories a further refinement was made by highlighting key terms and central concepts which described and characterised the role, attitudes and responsibilities of nurses in medical end-of-life decisions. By following this procedure a framework was construcled of key words and key citations that formed a reflection of the respondent's language concerning the subject and the emphasis laid by rospondents on specific data areas. Data coding was undertaken without the assislance of qualitative analysis computer software.

4. The data were processed into reports and contributed highly to the development of question and answer categories for the quantitative study's questionnaire.

It should be noted that due to time pressures only relevant passages from interviews wilh non-nurses were transcribed verbatim.

Reliability and validity

Reliability concerns the degree to which the research results can be replicated (Wester \& Peters, 2004). Validity means that the research data form a correct reflection of what takes place in practice and that the conclusions have been formulated correctly (Wostor \& Peters, 2004).

The following measures were taken to improve reliability:

- Interviews were tape recorded and transcribed verbatim.

- Much attention was paid to the development of the questionnaire. In order to promote content validity, the questionnaire was presented to a number of experts in difm ferent fields (see page 21). Respondents showed an open attitude and the sensitivity of the subject did not prevent them from elaborating it.

The following measures were taken to improve validity:

- A large number of respondents (56) coming from all intended sectors participated in the study, which contributes to the representativity of the results.

- The transcripts of the individual interviews were reviewed by respondents for accu. racy of content (member check). 
- A part of the interviews were read and interpreted independently by another member of the research team. After each focus group interview, the chairman and observer discussed important findings. They drew the same conclusions (peer debriefing).

- Because of the retrospective nature of the data, which could contribute to information bias, respondents were asked to focus their answers on the most recent case of a medical end-of-life decision in which they were involved.

- During the interviews, much attention was paid to the interpretation of the different types of medical decisions by respondents. For the value of the research results this was very important.

\section{Ethical considerations}

The study was approved by the research ethics committee of the Academic Hospital Maastricht and Maastricht University.

Respondents received written information about the study, and informed consent was obtained.

Anonymity was guaranteed to both organizations and respondents. Moreover, the privacy of respondents was protected through the following measures:

- Respondents who participated in a group interview signed a confidentiality statement in which they indicated that nothing of the information during the interview would be mentioned in contacts with third parties, in publications, or otherwise made public.

- Tape recordings of interviews were numbered, contained no names or addresses and were kept in a closed cupboard under management of the researcher.

- The link between tape recordings and names/addresses of respondents could be made exclusively by the researcher. The lists concerned were kept in a place which was only accessible by the researcher and apart from tape recordings.

- Recordings are to be destroyed 5 years after completion of the study.

\section{Summary of the results of the qualitative study}

As mentioned in the introduction of this chapter, the results of the qualitative part of the study were important for constructing a questionnaire for the quantitative part of the study.

Given that the articles in this thesis (chapters 3 through 7 ) focus on the quantitative part of the study, the results of the qualitative study remain unmentioned. It was decided, therefore, to include a summary of the qualitative study here mentioning the areas relevant to the medical end-of-life-decisions in the quantitative study, namely: euthanasia/physician-assisted suicide and the alleviation of pain and symptoms with a lifeshortening intention.

For more details about the results of the qualitative study, see the Dutch report (Van Bruchem-van de Scheur et al. 2004).

In the quantitative study, a number of the results of the qualitative study are confirmed. For conclusions and discussion about the role of nurses in euthanasia/physician-assisted suicide, see chapters $3,4,5$ and 8 . For conclusions and discussion about the role of nurses in the alleviation of pain and symptoms with a life-shortening intention, see chapter 7 and 8.

The role of nurses in euthanasia/physician-assisted suicide

From the interviews it was not clear with which care provider the patient spoke first about the request for euthanasia or physician-assisted suicide. The impression existed that in 
the majority of homecare cases, the physician was the first person with whom patients discussed their request for euthanasia or physician-assisted suicide.

If the patient spoke first with the nurse then this was related to the easy accessibility of the nurse. Not all expressions concerning euthanasia/physician-assisted suicide resulted in a request to the physician.

Nurses had a role in analyzing the request of the patient, where it concerned aspects such as voluntariness and well-consideredness of the request and possible hidden appeals for help. Furthermore, nurses could have a role in the realization of the contact between physician and patient.

Not all requests for euthanasia/physician-assisted suicide were granted, for example because the physician wanted to give palliative care or because a consistent request was lacking. For nurses in the homecare sector, the reason for not-granting a request was not always clear.

In general nurses felt more satisfied when a request was granted than when it was denied.

During the decision-making process, consultations between physicians and nurses were more frequent in hospitals and nursing homes than in homecare. One of the reasons was that the decision had been taken before the first contact between patient and nurse. Another reason was a lack of collaboration between physician and nurse.

Whereas nurses did not always experience their lack of involvement in the decisionmaking process as problematic, in general they did appreciate that they could give their opinion in the decision-making process.

In hospitals and nursing homes, usually the nurse was present during the administering of euthanatics. In homecare, this was generally not the case. When nurses were present, they mainly had tasks of supporting patients and/or relatives.

Physicians administered the euthanatics. Nurses held the opinion that the administration of euthanatics is a task of the physician.

In a number of cases nurses had a role in preparatory activities, such as preparing the euthanatics and inserting an infusion needle to administer the euthanatics.

Nurses held diverging opinions about the question whether preparatory activities could be a task for nurses.

Nurses experienced the farewell of the patient, whether or not on the day of performing, frequently as a difficult moment. The performing of euthanasia affected the mood on the ward.

Nurses also experienced their presence during the administration of euthanatics as an exceptional moment.

With regard to the aftercare following the death of the patient, nurses in hospitals had frequently no role. Also in nursing homes it was not obvious that nurses had a role. In homecare, nurses frequently paid one or more home visits for a personal talk with the surviving relatives.

Nurses with conscientious objections experienced in practice few problems. Nurses respected each others opinions and mutually sought a solution in case of (possible) problems.

The role of nurses in the alleviation of pain and symptoms with a lifeshortening intention

The results show that nurses are regularly faced with the medical end-of-life decision the alleviation of pain and symptoms with a life-shortening intention.

According to nurses, relatives frequently encouraged hastening the patient's death. Sometimes this resulted from too general information provided by the physician to the relatives. For example when told 'it will not last much longer', relatives might be inclined 
to unrealistic expectations with regard to the moment of death. When such expectations were not realized, some became impatient and insisted on hastening the patient's death. Although nurses were not always involved in the decision-making, they were often charged with activities which strongly resembled euthanasia or ending of life without an explicit request of the patient.

Within a nursing team, nurses had differing opinions about the same situation. On the one hand, there were nurses who agreed with the policy of the physician. They reasoned from the interest of the patient, such as: 'this (suffering) cannot be inflicted onto the patient...'

On the other hand there were nurses who did not agree with the policy of the physician. They reasoned from several (sometimes averlapping) interests:

- importance of acting professionally: the patient had no pain and/or other symptoms, which meant that there was no indication for increasing the medication.

- Importance of observing institutional guidelines: on the ward guidelines were present which stated that the alleviation of pain and other symptom may not be applied with the aim of hastening the patients' death.

- Importance of following the law: the nurse did not dare to administer the medication because by doing so she would be committing a punishable offence.

- Importance of pure intentions: the nurse strived for a pure handling during the aim of alleviation of pain and symptoms. As soon as it concerned life-ending activities, the applicable procedures must be followed.

In a number of cases, the nurse was not willing to administer the medication, putting the responsibility back on the physician. Although it was not always appreciated, this created clarity concerning the nature of the activity.

In other cases, the medication was administered by nurses who agreed with the policy of the physician.

If physician and nurse had divided opinions about the policy, it was not self-evident that this was discussed.

\section{The changeover from the qualitative study to the quantitative study}

As previously mentioned, the aim of the qualitative study was to develop items for the questionnaire of the quantitative study. In collecting data, an adequate saturation level was not reached. Reasons for this were the six different medical end-of-life decisions which were included in the study, and the time factor. However, it was assumed that sufficient data were gathered for developing a relevant questionnaire. Moreover, data from previous studies and literature in ethics and law could also be used for the construction of the questionnaire.

The analysis of the qualitative data resulted in a reduction of the number of medical endof-life decisions to be further investigated. The interviews revealed much conceptual confusion about the ending of life without an explicit request of the patient, not starting or stopping treatments which are prospectless or futile in conformity with actual medical knowledge, and withholding artificial administration of fluids and nutrition.

In a qualitative study, misunderstandings with regard to the interpretation of medical endof-life decisions can be corrected immediately. In the case of a questionnaire, this correction possibility is lacking and should be avoided as much as possible. As a result, the questionnaire in the quantitative study focussed on three medical decisions: euthanasia, physician-assisted suicide, and alleviation of pain and symptoms with a life-shortening intention. 


\section{The quantitative study}

In this second phase of the study, the research questions were designed as much as possible to be numerically measurable (Parahoo, 2006). It did not focus on the nature of phenomena, such as has been described in the first phase of the study, but more on the scope of the study subject.

\section{Recruitment of respondents}

It was important to recruit a large sample of nurses in order to obtain representative results. A large number of organizations in the Netherlands were invited by telephone to participate in the study:

- All general and academic hospitals as mentioned in the directory of Van Schie-Kruyt (2003).

- All accredited homecare organizations according to the list which was received from the Dutch Ministry of Health, Welfare and Sports.

- All somatic nursing homes and combined nursing homes (with somatic and psychogeriatric patients) as mentioned in the above-mentioned directory. Psychogeriatric nursing homes were excluded from participation because of an expected small number of requests for euthanasia/ physician-assisted suicide.

Given the diversity of working structures in institutions, approaching them led to contacts with persons on different levels, such as management, board of directors, ethics committee, nurse advisory council, and policy department. When interest for participation was shown, designation of a contact person for further arrangements was requested.

In order to reach a high uniformity of recruitment, contact persons were asked the following:

- To give the registration forms (which could be copied according to one's needs) to heads or team leaders of wards where requests for euthanasia/physician-assisted suicide take place, and to ask them to recruit nurses/caregivers for participation in the study.

- To agree upon a deadline with the heads/team leaders for the return of the registration forms, and to send these to the researcher. It was also possible for heads/team leaders to return the forms directly to the researcher.

Contact persons in hospitals and homecare organizations were asked to recruit 12 to 25 respondents. In nursing homes, this concerned 6 to 12 respondents, with a maximum of 25 per organization. This reduction was due to the smaller organizations in this sector and the less frequent incidences of cases of euthanasia/physician-assisted suicide. When mentioning these recruitment numbers it was always added: "When this is not feasible, this is not a problem; we are interested in all applications.'

In total 488 locations were approached of which 191 (39.1\%) agreed to participate (see Table 2.1).

The willingness to participate was highest in the hospital sector $(69.5 \%$ of the approached locations) and lowest in the nursing home sector $(22.6 \%)$.

In a number of cases, participation was declined without giving a reason. In other cases, participation was promised but participation did not take place in spite of telephone contact by the researcher.

Reasons for non-participation were: workload; other priorities; swamped with studies; reorganisation; sensitivity of the subject; no interest among nurses; no nurses employed in the organization (most mentioned in the homecare sector); participation in other studies; sickness of the manager; research fatigue; a policy concerning euthanasia was in the making, therefore the organization considered itself not suitable for participation; no or infrequent experience with requests for euthanasia/physician-assisted suicide (most 
mentioned in the nursing home sector), which in a number of cases was related to the philosophical character of an organization and/or the philosophy of life of the patient population.

The research group held the view that a randomly drawn sample would give a limited response to the study. For this reason, the study adopted a purposed sampling approach (Polit \& Beck, 2008), seeking to recruit nurses with experience with euthanasia or physician-assisted suicide.

Table 2.1 Extent of participation in the study through organizations.

\begin{tabular}{lccc} 
& Approached locations* & $\begin{array}{c}\text { Locations which } \\
\text { participated }\end{array}$ & $\begin{array}{c}\text { Response } \\
\text { (\%) }\end{array}$ \\
\hline Hospitals & 105 & 73 & 69.5 \\
Homecare organizations & 104 & 55 & 52.8 \\
Nursing homes & 279 & 63 & 22.6 \\
Total & 488 & 191 & 39.1 \\
\hline
\end{tabular}

*A number of organizations had more than one location.

Table 2.2 Participant's response to the study

\begin{tabular}{lccc}
\hline & Applications & $\begin{array}{c}\text { Absolute response } \\
\text { number (\%) }\end{array}$ & $\begin{array}{c}\text { Useful response } \\
\text { number (\%) }\end{array}$ \\
\hline Hospitals & 692 & $556(80.3)$ & $532(76.9)$ \\
Homecare organizations & 500 & $430(86.0)$ & $408(81.6)$ \\
Nursing homes & 317 & $252(79.5)$ & $239(75.4)$ \\
Total & 1509 & $1238(82.0)$ & $1179(78.1)$ \\
\hline
\end{tabular}

Following the qualitative study, in hospitals and homecare organisations, only nurses could participate in the study. It was decided that in nursing homes also caregivers could participate because in this sector few nurses actually attend to the patient.

Based on the experiences during the qualitative study, the inclusion criteria for nurses were sharpened and separate inclusion criteria were formulated for caregivers. For nurses, inclusion criteria were that they:

1. Had more than two years working experience as a registered nurse;

2. Had more than two years bedside experience;

3. Were employed at least half time;

4. Had experienced a request for euthanasia or physician-assisted suicide and/or its administration within the previous two years.

For caregivers, inclusion criteria were that they:

1. Had more than two years working experience as a qualified caregiver;

2. Were working as a team leader or coordinator of nursing care;

3. Had more than two years bedside experience;

4. Were employed at least half time; and

5. Had experienced a request for euthanasia or physician-assisted suicide and/or its administration no longer than two years previously.

The last criterion was included because the main study was commissioned to research the role of nurses in euthanasia and physician-assisted suicide. The expectation was that a part of the respondents, who had experienced a request for euthanasia/physicianassisted suicide, also had experience with alleviation of pain and symptoms with a lifeshortening intention.

The contact persons recruited 1509 nurses who all received a questionnaire. Each respondent got a respondent number which was attached to the questionnaire. If the questionnaire was not returned in time, respondents received a reminder. 
The absolute response rate was $82.0 \%$, and $78.1 \%$ (1179) could be used for analysis i.e. the percentage of questionnaires containing at least one section suitable for analysis (see Table 2.2).

(Part of) the questionnaire was considered unsuitable for analysis if:

- The questionnaire was returned blank with or without reasons.

- Responses were incomplete making an interpretation impossible.

- An incorrect interpretation of the type of medical end-of-ife decision was made.

- A case was included which had made the most impression instead of the most recent case.

- A case was included from the private situation instead of professional practice.

- The respondent did not work as a nurse, which was an inclusion criterion in hospitals and homecare.

\section{Data collection}

Data were collected using a questionnaire. The results of the qualitative study, together with data from previous studies and insights from ethics and law, formed the basis of the questionnaire.

To increase content validity, the questionnaire was presented to: five members of the scientific advisory group, nine members of the sounding board, a statistician, and two experts in the field of questionnaire construction. It was then tested in a pilot study among 106 nurses, who in the qualitative study had indicated their willingness to test the questionnaire. Reasons for spreading out the questionnaire among such a large group of nurses were:

- The address file of these respondents was more than one and a half year old, which could result in cancellations due to removal or change of employer.

- The questionnaire consisted of several parts. To guarantee enough parts would be completed, a large group of respondents had to be included.

The absolute response rate was $85 \%$ which is related to all returned questionnaires. The useful response rate was $69.8 \%$. A number of questionnaires were returned blank due to removal, change of employer, insufficient experience with the subject, no time and/or sickness.

The research team discussed the outcomes of the questionnaire and adapted it where necessary. Apart from textual changes, the revisions mainly consisted of:

- Shortening the questionnaire. The relevance of a number of questions was again evaluated as a result of their answering.

- Changing the sequence of a number of questions.

- Adding new answer categories as a result of information from respondents.

- Sharpening the definition of alleviation of pain and symptoms with a life-shortening intention. A number of cases appeared difficult to interpret because the purpose of the treatment was unclear.

The revised questionnaire was tested by three more nurses, employed in a hospital, a homecare organization, and a nursing home respectively.

It appeared possible to develop one questionnaire for the three different sectors. This offered the opportunity of comparing results between the sectors which had been formulated as an important part of the research questions (see pages 11-12).

Based on the findings of the qualitative study, a number of sector specific answer categories were included, and for homecare some sector specific questions were included. It was estimated that the time to complete was one hour.

The final version of the questionnaire was divided in two parts. The first (most extensive) part concerned euthanasia and physician-assisted suicide. It started with a definition of the types of medical end-of-life decisions at hand. As the research questions mainly 
focused on actual practices, respondents were asked to place their responses within the context of a case concerning a request for euthanasia or physician-assisted suicide.

In order to limit information bias and to promote the topicality of the results, the cases reported by the respondents had to take place within the last two years. These cases regarded the years 2001-2003. Moreover, in order to prevent respondents from selecting a case with large emotional impact or with many other problems, respondents were asked to base their responses on the most recent case. Because in practice most of the requests for euthanasia/physician-assisted suicide are not carried out, the risk existed that little information would be collected concerning the phase of performing the euthanasia or physician-assisted suicide. For this reason the participants were asked at the beginning of the questionnaire to describe a case they were involved in where the euthanasia or physician-assisted suicide was actually performed.

The questions about the case were arranged in chronological order and followed these stages: the request for euthanasia or physician-assisted suicide, the decision-making process, the administration of euthanatics, and the aftercare.

Respondents were guided through the questionnaire, avoiding sections that were irrelevant because of their previous responses.

Because of the complexity of the subject, and in order to minimize the number of socially desirable answers, a relatively large number of open answer categories and open questions were included.

Along with questions concerning the actual practice, experienced obstacles and the respondent's evaluation of these, questions were also included regarding knowledge of the law, guidelines as weil as attitudes of the respondents towards medical end-of-life decisions. The aim of the 'knowledge questions' was twofold; they offered the respondents information on current developments and they tested whether the respondents were acquainted with this information. Respondents were gradually introduced into the subject, before questions concerning their attitudes were asked.

The second part of the questionnaire concerned the alleviation of pain and symptoms with a life-shortening intention. This section began with a description of the medical endof-life decision at hand. Because misconceptions of this type of medical end-of-life decisions could easily occur, two extra questions were included at the beginning of the questionnaire, just to be sure.

The respondents were asked for the aim of the alleviation of pain and symptoms in the chosen case. The request for choosing a case was similar to the first part of the questionnaire. Here too the questions about the case were arranged in chronological order.

\section{Data analysis}

The data were analysed using SPSS version 11.5 for Windows. The input of data was performed by the researcher herself because of the following reasons:

1. Each case had to be evaluated on the correct interpretation of the type of medical end-of-life decision by the respondent. When in doubt, the researcher consulted one or more members of the research team. An unambiguous interpretation of the different types of medical end-of-life decisions was crucial for the validity of the results and when comparing the results with those of other studies.

2. Many open answer categories and open questions were included in the questionnaire, which needed coding. The answers were recorded in a text file and analyzed in accordance with the principles of the grounded theory approach (Strauss \& Corbin, 1998). Subsequently, answers or clusters of answers were numerically coded in order to analyse these data using SPSS. In doubt about coding and/or clustering of codes, the researcher consulted one or more members of the research team.

With regard to the analysis, the following points were important: 
1. As was expected, some respondents employed in the same organization introduced the same case. Per organization, the cases were checked for overlap by comparing the answers to five questions in the questionnaire:

a. On which ward, the case occurred?

b. What was the diagnosis of the patient?

c. What was the gender of the patient?

d. What was (approximately) the age of the patient?

e. Which final decision was taken by the physician?

When an overlap of cases was identified, the case of the most involved nurse was included in the analysis. Based on this procedure 39 cases were ignored. The procedure was not relevant for questions concerning knowledge and attitudes.

2. The answering of three open questions was not suitable for coding because the answers were too diverse. However, these data were still helpful in interpreting the results.

3. A number of the 1179 respondents indicated that they did not comply with the inclusion criteria 'was employed at least half-time ( $4.2 \%$ of respondents) and/or 'more than two years' experience as a registered nurse/qualified caregiver' $(2.1 \%$ of respondents). In these cases, the research team decided to include the respondents' questionnaires for analysis because of their utility and relevance.

On several occasions during the input and analysis of data, a statistician of Maastricht University was consulted. The questionnaire has not been tested statistically. Descriptive statistics (Polit \& Beck, 2008) were utilized to present the role of nurses in euthanasia/ physician-assisted suicide, and the alleviation of pain and symptoms with a lifeshortening intention.

\section{Reliability and validity}

The following measures were taken to improve the study's reliability:

- The preparation of the quantitative study through qualitative interviews improved the connection of the study to the practice of involved nurses.

- The results of the qualitative preliminarily study and the pilot study contributed significantly to the construction of the questionnaire.

The following measures were taken to improve the study's validity:

- Much attention was paid to the interpretation of the different types of medical end-oflife decisions by respondents. The qualitative preliminary study and the pilot study were important in reducing variations in respondents' interpretation of such decisions in the survey.

- Respondents were offered and made an extensive use of opportunities to express their thoughts and explain their answers, which was helpful in interpreting the cases.

- Doubts about interpreting cases and coding data were discussed with one or more members of the research team.

- The possibility of socially desirable answers was minimised as much as possible by the formulation of open questions.

- Because of the retrospective character of the data, which could contribute to information bias, the cases reported by the respondents had to take place within the last two years. In case respondents were confronted by more cases, they were asked to focus their answers on the most recent case. The latter requirement also reduced selection bias caused by the involvement of contact persons who recruited the respondents. Contact persons were not informed about this procedure.

- Promising anonymity and guaranteeing protection from criminal prosecution may have contributed to honest answering by the respondents. Frequently very sensitive information was provided. 
With regard to the external validity of the study it can be stated that the study got high participation rates, a large number of organisations nationwide were involved, and a large number of cases of high quality (most recent cases) were included. Therefore, although non-response could have affected the results a little, the conclusion may be justified that the study was representative of Dutch nurses who have had experience with euthanasia/physician-assisted suicide. This conclusion applies also to the section concerning the alleviation of pain and symptoms with a life-shortening intention.

\section{Ethical considerations}

The research ethics committee of the Academic Hospital Maastricht and Maastricht University approved the study.

As the subject was considered to be highly sensitive, participation was promoted by:

- The guarantee of confidentiality to both organisations and respondents;

- Both contact persons and respondents received a copy of a letter of the Minister of Justice in which participation was recommended and the explicit promise was made that respondents would be protected against criminal prosecution should they disclose information of illegal practices.

Apart from the guarantee of confidentiality the privacy of respondents was further protected through the following measures:

- Questionnaires were numbered, contained no names/addresses and were kept in a closed cupboard under management of the researcher.

- The link between questionnaires and names/addresses of respondents could be made exclusively by the researcher. The lists concerned were kept in a place which was only accessible by the researcher and apart from questionnaires.

- Questionnaires are to be destroyed 5 years after completion of the study.

\section{References}

Baarda, D.B., de Goede, M.P.M. \& Teunissen, J. (2005). Basisboek kwalitatief onderzoek: handleiding voor het opzetten en uitvoeren van kwalitatief onderzoek. (Introduction to qualitative research: manual for designing and implementing qualitative research). Groningen/Houten: Wolters-Noordhoff bv. (In Dutch).

Beukema, H. (2003). De structuur van het onderzoeksverslag (The structure of the research report). in F. Wester (Ed.). Rapporteren over kwalitatief onderzoek. (Report on qualitative research). Utrecht: Uitgeverij LEMMA BV. (In Dutch).

Evers, J. \& de Boer, F. (2007). Het uitvoeren van een individueel interview (Conducting an individual interview). In J. Evers (Ed.). Kwalitatief interviewen: kunst én kunde. (Qualitative interview: art and science). Den Haag: Uitgeverij LEMMA. (In Dutch).

Kitzinger, J. (1995), Introducing focus groups. British Medical Journal, 311, 299-302.

Kitzinger, J. \& Barbour, R.S. (1999). The challenge and promise of focus groups. In R.S. Barbour \& J. Kitzinger (Eds.). Developing Focus Group Research; Politics, Theory and Practice. London/Thousand Oaks/New Delhi: Sage Publications.

Morgan, D.L. (1998). Planning Focus Groups; Focus Group Kit 2. Thousand Oaks/Lon-don/New Delhi: Sage Publications.

Maso, I. \& Smaling, A. (Eds.). (1990). Objectiviteit in kwalitatief onderzoek. (Objectivity in qualitative research), Meppel/Amsterdam: Boom. (In Dutch).

Parahoo, K. (2006). Nursing research: Principles, Process and Issues. [2 ${ }^{\text {nd }}$ Edition]. Hampshire/New York: Palgrave Macmillan. 
Philipsen, H. (1990). Kwalitatief onderzoek: een plaatsbepaling (Qualitative research: an orientation). In A.L. Francke (Ed.). Kwalitatief onderzoek in de verpleegkunde (Qualitative research in nursing). Amsterdam/Lisse: Swets \& Zeitlinger. (In Dutch).

Polit, D.F. \& Beck, C.T. (2008). Nursing research: generating and assessing evidence for nursing practice. [ $8^{\text {th }}$ Edition]. Philadelphia: Wolters Kluwer / Lippincott Williams \& Wilkins.

Strauss, A. \& Corbin, J. (1998). Basics of qualitative research: techniques and procedures for developing grounded theory. Thousand Oaks: Sage.

Van der Maas, P.J., van Delden, J.J.M. \& Pijnenborg, L. (1991). Medische beslissingen rond het levenseinde: het onderzoek voor de Commissie Onderzoek Medische Praktijk inzake Euthanasie. (Medical end-of-life decisions: the study on behalf of the Commission on Research into Medical practice in Euthanasia). Den Haag: Sdu. (In Dutch).

Van der Wal, G. \& van der Maas, P.J. (1996). Euthanasie en andere medische beslissingen rond het levenseinde: de praktijk en de meldingsprocedure. (Euthanasia and other medical end-oflife decisions: the practice and the notification procedure). Den Haag: Sdu. (In Dutch).

Van Zuuren, F. (1992). Het verzamelen van kwalitatief materiaal: Voorbeelden uit de klinische en gezondheidspsychologie. (Collecting qualitative data: Examples from the clinical health psychology). In A. Smaling \& F. van Zuuren (Eds.). De praktijk van kwalitatief onderzoek; voor. beelden en reflecties. (The practice of qualitative research: examples and reflections). Meppel/Amsterdam: Boom. (In Dutch).

Wester, F. \& Peters, V. (2004). Kwalitatieve analyse: uitgangspunten en procedures (Qualitative analysis: basic assumptions and procedures). Bussum: Coutinho. (In Dutch). 


\title{
Chapter 3
}

\section{The role of nurses in euthanasia and physician-assisted suicide in The Netherlands"}

\begin{abstract}
Background: Issues concerning legislation and regulation with respect to the role of nurses in euthanasia and physician-assisted suicide gave the Minister for Health reason to commission a study of the role of nurses in medical end-of-life decisions in hospitals, home care and nursing homes.

Aim: This paper reports the findings of a study of the role of nurses in euthanasia and physicianassisted suicide, conducted as part of a study of the role of nurses in medical end-of-life decisions. The findings for hospitals, home care and nursing homes are described and compared.

Method: A questionnaire was sent to 1509 nurses, employed in 73 hospitals, 55 home care organisations and 63 nursing homes. 1179 responses $(78.1 \%)$ were suitable for analysis. The questionnaire was pilot-tested among 106 nurses, with a response rate of $85 \%$.

Results: In $37.0 \%$ of cases, the nurse was the first person with whom patients discussed their request for euthanasia or physician-assisted suicide. Consultation between physicians and nurses during the decision-making process took place quite often in hospitals $(78.8 \%)$ and nursing homes $(81.3 \%)$ and less frequently in home care situations $(41.2 \%)$. In some cases $(12.2 \%)$, nurses administered the euthanatics.

Conclusions: The results show substantial differences between the intramural sector (hospitals and nursing homes) and the extramural sector (home care), which are probably linked to the organisational structure of the institutions. Consultation between physicians and nurses during the decislonmaking process needs improvement, particularly in home care. Some nurses had administered euthanatics, although this task is by law exclusively reserved to physicians.
\end{abstract}

\footnotetext{
"The text of this chapter has been published as: GG van Bruchem-van de Scheur, AJG van der Arend, H Huijer Abu-Saad, C Spreeuwenberg, FCB van Wijmen \& RHJ ter Meulen (2008). The role of nurses in euthanasia and physician-assisted suicide in The Netherlands. Journal of Medical Ethics, 34, 254-258.
} 


\section{Introduction}

In The Netherlands, euthanasia and physician-assisted suicide have been investigated mainly within the medical profession. ${ }^{12}$ Euthanasia and physician-assisted suicide are the responsibility of physicians, a role that is legally formalised in the Law on the Termination of Life on Request and Assisted Suicide of $2002 .^{3}$ Nurses are often involved in the euthanasia process, but their role is not enacted in that Law. Their role is clarified and demarcated in joint professional guidelines of physicians and nurses. ${ }^{4}$ Concerned about the lack of legal status of nurses in euthanasia and physician-assisted suicide, nurses' professional organisations raised various issues to be included in the new law. One issue concerned the membership of nurses in the regional euthanasia review committees, whose task is to review reported cases of euthanasia and physician-assisted suicide on the basis of the due care requirements of the law. The associations argued that as nurses are often involved in the euthanasia process and they usually are very close to patients, they should be members of the review committees. Moreover, nurses are welltrained professionals and their expertise and experience should be used. ${ }^{5}$

However, the Health Minister decided that before any decision was taken about regulation of the role of nurses in euthanasia, their factual role in practice should be clarified. Consequently, the minister commissioned a study of the role of nurses in medical end-oflife decisions in hospitals, home care and nursing homes in order to advise the Dutch government on legislation and policy-making concerning the role of nurses. ${ }^{6}$ This article reports the outcomes of this study in three settings: hospitals, home care and nursing homes. The role of nurses is presented with respect to the request by the patient for euthanasia or physician-assisted suicide, the decision-making process and the administration of euthanatics.

We used the definition of euthanasia and physician-assisted suicide as given in previous studies among Dutch physicians. ${ }^{1}$ According to this definition, euthanasia means the administration of drugs with the explicit intention of ending the patient's life on his or her explicit request, and physician-assisted suicide is the prescribing or supplying of drugs with the explicit intention of enabling the patient to end his or her own life.

Attention to the role of nurses in euthanasia and physician-assisted suicide is increasing internationally. De Beer and colleagues ${ }^{7}$ conducted an international literature review of 15 studies published between 1991 and 2002. In six of them the sample consisted of physicians and provided indirect information about the role of nurses.

In all the articles selected, data were gathered at a time when euthanasia was illegal, as was also the case in the Dutch studies. However, at the time of the Dutch studies, euthanasia was not a punishable offence in The Netherlands if the physician fulfilled the due care requirements. Euthanasia was also illegal when the Belgian studies were done. ${ }^{8-9}$ This fact, together with differences in study designs, definitions used and the non-sector-specific description of results in studies, limits a reliable comparison with the results in our study (see Discussion).

\section{Method}

\section{Participants}

All general and academic hospitals, accredited home care organisations, somatic nursing homes and nursing homes with both somatic and psychogeriatric patients in The Netherlands were invited by telephone to participate in the study. Of 488 locations, 191 
(39.1\%) agreed to participate: 73 hospitals, 55 home care organisations and 63 nursing homes.

Reasons for non-participation varied: workload, other priorities, swamped with studies, reorganisation, sensitivity of the subject, no zest among nurses, no nurses employed in the organisation, participation in other studies, sickness of the manager, research tiredness, no or rare experience with requests for euthanasia/physician-assisted suicide.

\section{Contact persons in the organisations recruited the respondents}

When interest in participation was shown, the organisation was asked to designate a contact person to recruit the respondents. This was usually someone working at management or policy level. The research group held the view that a random sample would give a limited response to the study. Therefore, it was decided that the research sample would consist of nurses who had experienced cases of euthanasia or physician-assisted suicide. Participation was further promoted by

- a guarantee of anonymity to both organisations and respondents:

- the provision to both contact persons and respondents of a copy of a letter from the Minister of Justice in which participation was recommended and respondents were explicitly promised protection against criminal prosecution if they disclosed illegal practices.

Because of an expected low recruitment of nurses in nursing homes, caregivers working as team leaders or coordinators in the field of nursing in such homes were also recruited. The contact persons recruited 1509 nurses or caregivers, who all received a questionnaire. The number of responses suitable for analysis-that is, of which one or more parts could be used for analysis-was $1179(78.1 \%)$.

\section{Data collection}

Data were collected using a questionnaire. The results of a qualitative preliminary study, together with data from previous studies and insights from ethics and law, were the basis for the construction of this questionnaire. It was checked by experts on content and on questionnaire construction and statistics. It was then pilot-tested with 106 nurses (85\% response rate). The research team discussed the outcomes, adapted the questionnaire where necessary and again tested it with three other nurses.

The respondents were asked to place their responses within the context of their most recent case of a request for and/or administration of euthanasia or assistance in a suicide within the previous 2 years. These cases took place in 2001, 2002 and 2003.

The respondents were guided through the questionnaire, avoiding sectians that had become irrelevant due to their previous responses. This explains the variability in the number of nurses responding to items in the results section. The next paragraph, for example, begins with 799 cases and ends with 129 cases. Variability is further accounted for in the paragraphs below.

The data were analysed using SPSS version 11.5 for Windows.

\section{Results}

Requests for euthanasia or physician-assisted suicide

In 101 of 900 cases $(11.2 \%$ ), patients had made the request known before admission to the ward (hospitals and nursing homes) or at their first contact with nurses (home care). These cases were not analysed for this part of the study, because the nurse had no opportunity to be the first person with whom patients discussed their request for euthanasia or physician-assisted suicide. 
In $37.0 \%$ of the other 799 cases, the nurse was the first person with whom patients discussed their explicit request for euthanasia or physician-assisted suicide. In $36.8 \%$ of the cases, the patient spoke with the physician first, and in $17.3 \%$ the patient first raised the request when both the physician and the nurse were present-for example during the physician's rounds (table 3.1 ).

The data show considerable differences between hospitals/nursing homes and home care.

When the patient spoke with the nurse first and this concerned the respondents themselves (not a colleague), the five most mentioned, and sometimes overlapping, reasons why patients first raised their request with a nurse $(n=129)$ were that

- the nurse had a confidential relationship with the patient $(42.6 \%)$;

- the nurse had more contact with the patient than the physician (20.1\%);

- the relationship between physician and patient was not confidential enough to allow discussion of the subject $(11.6 \%)$;

- the nurse was easily accessible $(10.9 \%)$;

- the patients first wanted clarity for themselves $(8.5 \%)$.

\section{The decision-making process}

During the decision-making process, consultations between physicians and nurses were more frequent in hospitals and nursing homes than in home care (table 3.2).

The purpose of the consultation between physician and nurse is that the nurse can give and possibly explain her opinion about the specific case.

Table 3.1 Care providers with whom patients first discussed their request for euthanasia or physician-assisted suicide (\%)

\begin{tabular}{lcccc}
\hline Care provider & $\begin{array}{c}\text { Hospltals } \\
(\mathbf{n}=\mathbf{3 8 1})\end{array}$ & $\begin{array}{c}\text { Home care } \\
(\mathbf{n = 2 7 8})\end{array}$ & $\begin{array}{c}\text { Nursing home } \\
(\mathbf{n}=\mathbf{1 4 0})\end{array}$ & $\begin{array}{c}\text { Total } \\
(\mathbf{n}=\mathbf{7 9 9})\end{array}$ \\
\hline Physician & 23.4 & 62.2 & 22.9 & 36.8 \\
Physician + nurse & 22.3 & 8.3 & 21.4 & 17.3 \\
Nurse & 45.1 & 22.3 & 44.3 & 37.0 \\
Other & 3.7 & - & 2.8 & 2.3 \\
Unknown & 5.5 & 7.2 & 8.6 & 6.6 \\
\hline
\end{tabular}

In this analysis, 146 of 900 cases were ignored because the decision-making and the administering of euthanatics did not take place within the same ward or organisation, or the patient died during the decision-making process or the decision had been taken before the patient was admitted to the ward (hospitals and nursing homes) or before the first contact between patient and nurse (home care) and therefore nurses could not have played a role in the decision-making process.

Contrary to what happened in hospitals and nursing homes, in home care only individual consultation generally took place (table 3.3 ).

When respondents themselves were involved in the decision-making process, they indicated which other persons, apart from physician and nurse, participated in the team consultation. In hospitals (87 cases), the four most mentioned persons were pastor/mental attendant (33), social worker (20), psychologist (8) and physiotherapist (5). In nursing homes (53 cases), the four most mentioned persons were pastor/mental attendant (31), psychologist (24), physiotherapist (12) and social worker (11).

In 845 of 900 cases, the physician took the decision to grant or not to grant the patient's request.

It should be noted that 55 cases were ignored because the decision-making and the administering of euthanatics did not take place within the same ward or organisation, the 
patient died during the decision-making process, or nurses discovered afterwards that euthanasia had been performed.

Table 3.2 Role of nurses in the decision-making process (\%)

\begin{tabular}{lcccc}
\hline Consultation & $\begin{array}{c}\text { Hospitals } \\
(\mathbf{n}=\mathbf{3 5 9})\end{array}$ & $\begin{array}{c}\text { Home care } \\
(\mathbf{n = 2 6 7 )}\end{array}$ & $\begin{array}{c}\text { Nursing homes } \\
(\mathbf{n = 1 2 8})\end{array}$ & $\begin{array}{c}\text { Total } \\
(\mathbf{n}=\mathbf{7 5 4})\end{array}$ \\
\hline $\begin{array}{l}\text { Between physician and nurse } \\
\text { None between physician and }\end{array}$ & 78.8 & 41.2 & 81.3 & 65.9 \\
nurse & 14.2 & 49.8 & 10.9 & 26.2 \\
Unknown & 7.0 & 9.0 & 7.8 & 7.8 \\
\hline
\end{tabular}

Table 3.3 Forms of consultation between physician and nurse (\%)

\begin{tabular}{lcccc}
\hline Consultation & $\begin{array}{c}\text { Hospitals } \\
(\mathbf{n}=\mathbf{2 2 4})\end{array}$ & $\begin{array}{c}\text { Home care } \\
(\mathbf{n}=90)\end{array}$ & $\begin{array}{c}\text { Nursing homes } \\
(\mathbf{n}=92)\end{array}$ & $\begin{array}{c}\text { Total } \\
(\mathbf{n}=\mathbf{4 0 6})\end{array}$ \\
\hline Individual only & $41.5(93)$ & $88.9(80)$ & $33.7(31)$ & $50.2(204)$ \\
Team only & $12.5(28)$ & $1.1(1)$ & $4.3(4)$ & $8.1(33)$ \\
Both individual and team & $33.5(75)$ & $3.3(3)$ & $57.6(53)$ & $32.3(131)$ \\
Other or unknown & $12.5(28)$ & $6.7(6)$ & $4.4(4)$ & $9.3(38)$ \\
\hline
\end{tabular}

Table 3.4 Activities of nurses in administering the euthanatics (\%)

\begin{tabular}{lcccc}
\hline Nurse's task & $\begin{array}{c}\text { Hospitals } \\
(\mathbf{n = 8 7 )}\end{array}$ & $\begin{array}{c}\text { Home care } \\
(\mathbf{n}=\mathbf{6})\end{array}$ & $\begin{array}{c}\text { Nursing homes } \\
(\mathbf{n}=\mathbf{1 7})\end{array}$ & $\begin{array}{c}\text { Total } \\
(\mathbf{n}=\mathbf{1 1 0})\end{array}$ \\
\hline $\begin{array}{l}\text { Passing etuthanatics to physician } \\
\text { Checking physician's actlons }\end{array}$ & $40.2(35)$ & $33.3(2)$ & $70.6(12)$ & $44.5(49)$ \\
$\begin{array}{l}\text { Inserting infusion bag with } \\
\text { euthanatics }\end{array}$ & $40.2(35)$ & $16.7(1)$ & $29.4(5)$ & $37.3(41)$ \\
$\begin{array}{l}\text { Showing physician how to insert } \\
\text { infusion bag with euthanatics }\end{array}$ & $28.7(25)$ & $16.7(1)$ & $5.9(1)$ & $24.5(27)$ \\
\hline
\end{tabular}

In 657 cases, physicians had decided to grant a request for euthanasia or physicianassisted suicide. In $88.6 \%$ of these cases, the nurses had agreed with the physiclan's decision, and in $10.8 \%$ nurses disagreed or had doubts about the decision. The three most frequently mentioned reasons for either disagreement or doubts were $(n=69)$ : conscientious objection by the nurse (41); the patient's condition not being serious enough (26); no evidence of unbearable suffering (19).

In 188 cases, physicians decided not to grant a request for euthanasia or physicianassisted suicide. According to the nurses, physicians had various motives for these decisions. The five most frequently mentioned reasons were: wanted to give palliative care $(46.3 \%)$; no evidence of unbearable suffering $(26.6 \%)$; the institution did not allow euthanasia and physician-assisted suicide (18.6\%); conscientious objection (15.9\%); no hopeless suffering existed (14.4\%).

When a request was not granted, $60.1 \%$ of nurses supported the decision and $37.2 \%$ either disagreed or had doubts about it. The three most mentioned reasons for disagreement or doubts were $(n=70)$ : the request was realistic $(49)$; hopeless suffering did exist (39); unbearable suffering existed (31).

Administering the euthanatics

In 610 of 900 cases, euthanasia or physician-assisted suicide was performed. However, the analysis in this paragraph is based on the 205 cases in which respondents themselves were present when euthanatics were administered and therefore could have played a role in administering them. 
When nurses were present $(n=205)$, they mainly had tasks of supporting patients $(85.6 \%)$ or relatives $(92.1 \%)$.

In $53.7 \%$ of the cases, nurses had one or more tasks related to administering the euthanatics. The four most mentioned activities are presented in table 3.4 .

In 5 cases $(2.4 \%)$, nurses administered the euthanatics, in one case $(0.5 \%)$ the nurse anaesthetist administered the euthanatics, and in 19 cases $(9.3 \%)$, nurses administered the euthanatics together with the physician (table 3.5). In these latter cases ( $n=19$ ), nurses opened the infusion with euthanatics or started up the infusion pump with euthanatics (16), or they injected the euthanatics via a gastrostomy drip-feed (1). In two cases, more than one nurse was present and a colleague-nurse performed the activities. The reasons why nurses administered the euthanatics were not investigated, but five nurses indicated that the physician was inexperienced in operating the infusion system.

Table 3.5 Persons who administered the euthanatics (\%)

\begin{tabular}{lcccc}
\hline Person administering & $\begin{array}{c}\text { Hospitals } \\
(\mathbf{n}=143)\end{array}$ & $\begin{array}{c}\text { Home care } \\
(\mathbf{n}=\mathbf{2 4})\end{array}$ & $\begin{array}{c}\text { Nursing homes } \\
(\mathbf{n}=\mathbf{3 8})\end{array}$ & $\begin{array}{c}\text { Total } \\
(\mathbf{n}=\mathbf{2 0 5})\end{array}$ \\
\hline Physician & $83.2(119)$ & $87.5(21)$ & $89.5(34)$ & $84.9(174)$ \\
Physician and patient & - & - & $5.3(2)$ & $1.0(2)$ \\
Patient & $1.4(2)$ & $4.2(1)$ & $2.6(1)$ & $2.0(4)$ \\
Physician and nurse & $11.9(17)$ & $8.3(2)$ & - & $9.3(19)$ \\
Nurse & $3.5(5)$ & - & - & $2.4(5)$ \\
Nurse anaesthetist & - & - & $2.6(1)$ & $0.5(1)$ \\
\hline
\end{tabular}

\section{Discussion}

\section{Study limitations and strengths}

Medical end-of-life decisions such as euthanasia and physician-assisted suicide are sensitive, complex issues that can be difficult to study through quantitative methods. It is difficult to get insight in the reasons or motives for nurses' actions by such an approach. Another limitation of the study is the "fragmented" involvement of nurses, which often had to do with the nurses' changing duties and/or task-orientation. In a number of cases the nurse was not involved in all stages of the process, with the result that some data are missing.

Though only the most recent cases were included, bias could occur because of the retrospective character of the data. Furthermore, nurses could have interpreted a case differently than the physician did, especially when insufficient consultation took place between physician and nurse.

To improve the validity of the results, much attention was paid to the interpretation of the different types of medical end-of-life decisions by the respondents.

The study got high participation rates, many organizations nationwide were involved and many cases of high quality (most recent cases) were included. Therefore, though nonresponse could have affected the results a little, we feel justified in concluding that the study was representative of Dutch nurses who have had experience with euthanasia and physician-assisted suicide.

\section{Requests for euthanasia and physician-assisted suicide}

In $37 \%$ of the cases analysed, the patient spoke first with a nurse about the option of euthanasia or physician-assisted suicide. This result partly contrasts with the results of the literature review by $\mathrm{De}$ Beer and colleagues ${ }^{7}$ which indicated that nurses often are the first caregivers to receive a request. 
Unlike the case in hospitals and nursing homes, in home care the physician was more often the first person with whom patients discussed their request for euthanasia or physician-assisted suicide. An explanation might be that in home care the patient-physician relationship is, generally speaking, more longstanding and confidential than in the other sectors.

Given the intimacy and sensitivity of the subject, it is remarkable that in a significant number of cases $(17.3 \%)$, patients discussed their request simultaneously with the phy" sician and the nurse. As this mainly occurred in hospitals and nursing homes, this phenomenon may be due to working methods, that is, regular rounds. Patients may raise the issue during these visits.

When patients spoke with a nurse first, respondents suggested that patients might sim. ply be seeking orientation and for that reason did not (yet) like to speak with their physicians. An additional reason might be that the patient knows the physician has to agree with the request before euthanasia can be performed at all; fearing a negative or evasive response by the physician, he or she first approaches the nurse.

However, it is desirable that nurses advise patients to discuss their request with the physician as soon as possible in order to clarify each other's expectations and views.

\section{The decision-making process}

In home care, which has by far the largest reported number of cases of euthanasia in The Netherlands, the nurse is considerably less involved in the decision-making process than in the other settings. These differences may be related to the different organisational structure in home care, where physicians and nurses usually do not work in the same organisation. Moreover, they do not generally encounter each other, whether in the presence of the patient or elsewhere.

Other studies have also indicated large differences in the participation of nurses in the decision-making process between hospitals and home care: $83.3 \%$ and $20 \%$ of cases. respectively, in one study ${ }^{8}$ and $78 \%$ and $16 \%$ of cases in another. ${ }^{10}$ However, several reasons hamper the comparison of results with those of other studies: (partial) absence of a sector-specific description; ${ }^{8}{ }^{11}$ analysis of cases regardless of whether nurses provided care during the decision-making process; $;^{10}$ (partial) small study populations; ${ }^{81011}$ analysis only of cases in which euthanasia was performed; ${ }^{81011}$ and carrying out of the study when euthanasia was still fully illegal. ${ }^{811}$

Although physicians are encouraged to involve nurses in decisions about euthanasia in The Netherlands, they are not legally required to do so. The joint guidelines of physicians and nurses ${ }^{4}$ state that if a nurse is involved in the daily care of a patient who has requested euthanasia, it is highly desirable that the physician includes the nurse in the decision-making process. A reference to this role is also made in the physician's report to the regional euthanasia review committee; the physician has to indicate whether a nurse was consulted and what the nurse's view was. This is in contrast to Belgium, where the legal regulation of euthanasia stipulates that the physician must discuss the patient's request for euthanasia with members of the nursing team who are directly involved in caring for the patient. ${ }^{12}$

Another issue is the lack of agreement between nurse and physician in the decisionmaking process. Nurses reported that they felt more satisfied when a request was granted than when it was denied. When nurses disagreed with the physician's decision to refuse a request $(37.2 \%)$, this was often caused by a certain empathy with the patient. However, this type of solidarity with the patient may be misleading if the request is not sufficiently assessed from different perspectives-for example as a hidden appeal for help. Furthermore, nurses may interpret the due care criteria differently from physicians. 
However, it may also be true that physicians ground their decision on conscientious objections while the nurses' arguments are based on the due care criteria only. Physicians and nurses may also interpret requests or the circumstances of requests differently because patients may have expressed themselves differently to the various care providers. Patients may, for example, be positive about the request with the nurse but express doubts to the physician.

\section{Administering the euthanatics}

When nurses checked physician's actions or showed them how to handle an infusion system, this can be considered a way of ensuring a good course. Moreover, nurses are generaily more experienced with infusions, which may be a reason for double-checking the physician's actions or providing instructions.

Sometimes nurses inserted the infusion bag, while the physician opened the infusion. These are not "administering" actions by nurses. In our study, the demarcation between administering and non-administering actions was set by the moment in which the euthanatics flow into the patient.

While the administration of euthanatics is by law exclusively reserved to the physician, in some cases the nurse performed this act. Sometimes this occurred because the physiclan was insufficiently experienced in adequately managing the infusion. As the moment of infusion is important to the patient and/or relatives, nurses may feel compelled at that very moment to take over the procedure. Despite the intentions of nurses to supply "good care", such activitjes are illegal under Dutch law and do not qualify as emergencies.

Other studies ${ }^{813}$ confirm nurses' administration of euthanatics with or without the physician, in home care in $17.2 \%$ and $4.0 \%$ of cases, respectively, and in hospitals in $58.8 \%$ and $21 \%$ of cases. However, comparison is problematic, because in the other studies all cases were analysed regardless of whether a nurse was present as the euthanatics were administered, ${ }^{813}$ or because the demarcation line between administering and nonadministering activities has not been defined ${ }^{8}{ }^{13}$ or because a sector-specific description is (partially) missing. ${ }^{8}$

As the last lawsuit in this area in The Netherlands dates from 1995, physicians probably have since then not officially reported the administering of euthanatics by nurses. However, nurses who administer euthanatics or assist in a suicide risk both criminal prosecution and disciplinary measures. Moreover, physicians should be aware of their responsibilities and not leave such activities to nurses. It is important that physicians and nurses discuss and review each other's responsibilities and tasks before taking action.

\section{Conclusions}

This is the first Dutch survey exploring the role of nurses in euthanasia and physicianassisted suicide from the nurses' perspective. The study also indirectly offers insight in the approach by physicians, to which the role of nurses is closely related.

The study clearly shows that the role of nurses needs further specification. First, a sector-specific description of it is necessary, given the large differences between the intramural (hospitals and nursing homes) and extramural (home care) sectors.

Second, a stage-specific description of the role of nurses is necessary, as their role varies in the various stages of the euthanasia process. For instance, in the decisionmaking process the consultation between physicians and nurses needs improvement, while in administering euthanatics nurses performed illegal actions by administering euthanatics. 
In the policy advice to government, it has been emphasised that multidisciplinary institutional guidelines could play an important role in improving collaboration between physicians and nurses and in preventing procedural misunderstandings that could lead to ethical problems and legal offences. However, in homecare it may be difficult to develop joint guidelines for physicians and nurses, because in general they work from different organisations. Nevertheless, especially in this sector nurses could benefit from guidelines in which their role and responsibilities are clearly described.

With regard to the demarcation of responsibilities and tasks between physicians and nurses concerning euthanasia and physician-assisted suicide in other countries than The Netherlands, the Dutch data may provide relevant information.

\section{References}

1. Onwuteaka-Philipsen BD, van der Heide A, Koper D, et al. Euthanasia and other end-of-life decisions in the Netherlands in 1990, 1995, and 2001. Lancet 2003;362:395-9.

2. Van der Maas PJ, van der Wal G, Haverkate I, ef al. Euthanasia, physiclan-assisted suicide, and other medical practices involving the end of life in the Netherlands, 1990-1995. N Engl J Med 1996;335:1699-705.

3. De Haan J. The new Dutch law on euthanasia. Med Law Rev 2002;10:57-75.

4. AVVV, NU'91, KNMG. Guidelines to support the collaboration of physicians, nurses and caretakers in euthanasia procedures. (in Dutch.) 4th edn. Utrecht: AVVV, NU'91, KNMG, 2006.

5. LCVV (National Centre Nursing \& Care). Nurses in regional review committees for euthanasia. Point of View LCVV. (In Dutch.) Utrecht: LCVV, 1998 (The current name of the LCVV is LEVV (The Netherlands Centre for Excellence in Nursing).)

6. Van Bruchem-van de Scheur $A$, van der Arend A, Spreeuwenberg $C$, et ai. The role of nurses in medical end-of-life decisions. Report of a national study into involvement and practices. (In Dutch.) Utrecht: De Tijdstroom, 2004.

7. De Beer T, Gastmans C, Dierckx de Casterle' B. Involvement of nurses in euthanasia: a review of the literature. J Med Ethics 2004;30:494-8.

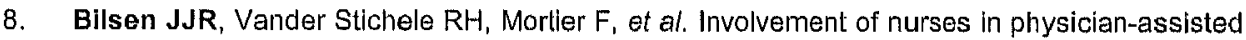
dying. J Adv Nurs 2004;47:583-91.

9. De Bal N, Dierckx de Casterle' B, De Beer T, et al. Involvement of nurses in caring for patients requesting euthanasia in Flanders (Belgium): a qualitative study. Int $J$ Nurs Stud 2006;43:589-99.

10. Van der Wal G, van der Heide A, Onwuteaka-Philipsen BD, et al. Modical decisionmaking at the end of life: the practice and the notification procedure for euthanasia. (In Dutch.) Utrecht: Uitgeverij De Tijdstroom, 2003.

11. Deliens $L$, Mortier F, Bilsen $J$, et al. End-of-life decisions in medical practice in Flanders, Belgium: a nationwide survey. Lancet 2000;356:1806-11.

12. Gastmans $C$, Van Neste $F$, Schotsmans P. Facing requests for euthanasia: a clinical practice guideline. J Med Ethics 2004;30:212-7.

13. Muller MT, Pljnenborg L, Onwuteaka-Philipsen BD, et al. The role of the nurse in active euthanasia and physician-assisted suicide. J Adv Nurs 1997;26:424-30. 


\title{
Chapter 4
}

\author{
Euthanasia and physician-assisted \\ suicide in the Dutch homecare \\ sector: the role of the district nurse
}

\begin{abstract}
Aim. This paper is a report of the findings of a study into the role of district nurses in euthanasia ard physician-assisted suicide in homecare organizations, conducted as part of a study into the role of nurses in medical end-of-life decisions.

Background. Issues concerning legislation and regulation with respect to the role of nurses euthanasia and physician-assisted sulcide gave the Minister for Health reason to commission a study into the role of nurses in medical end-of-life decisions in hospitals, nursing homes and home. care organizations. This is the first quantitative study from the perspective of nurses. Previous quantitative studies were conducted under physicians and information on the role of nurses wats obtained indirectly.

Method. A questionnaire was sent in 2003 to 500 district nurses employed in 55 homecare organ zations. The absolute response rate was $86.0 \%$ and $81.6 \%(408)$ could be used for analysis.

Results. In $22.3 \%$ of 278 cases, the district nurse was the first with whom patients discussed the request for euthanasia or physician-assisted suicide. In about half $(49.8 \%)$ of 267 cases nurses were not involved in the general practitioner's decision-making process, and in only $13.3 \%$ of 26.4 cases, did they attend the administration of the lethal drugs. District nurses had provided somet degree of aftercare to the surviving relatives in $80.3 \%$ of 264 cases.

Conclusion. Collaboration between general practitioners and district nurses needs improvernent particularly in relation to decision-making. Our Dutch data could help nurses in other countries to define their (future) role in euthanasia and physician-assisted suicide.
\end{abstract}

\footnotetext{
"The text of this chapter has been published as: GG van Bruchem-van de Scheur, AJG van der Arend, C Spreeuwenberg, H Huijer Abu-Saad \& RHJ ter Meulen (2007). Eutha nasia and physician-assisted suicide in the Dutch homecare sector: the role of the district nurse. Journal of Advanced Nursing, 58, 44-52.
} 


\section{Introduction}

After 30 years of public debate in the Netherlands, the law on euthanasia (Law on the Termination of Life on Request and Assisted Suicide) came into force in April 2002 (De Haan 2002).

The law does not regulate the role of nurses. Their role is clarified and demarcated in professional guidelines published by the General Association of Nurses and Caretakers (AVW), the nurses' association Nieuwe Unie '91 (NU'91), and the Royal Dutch Medical Association (KNMG) (AVW et al. 2006). The guidelines state that when nurses are involved in the daily care of patients who make a request for euthanasia, it is highly desirable that they are involved in the decision-making process.

The decision to terminate a patient's life is the responsibility of physicians. Only they have the appropriate medical expertise (regarding diagnosis, prognosis and treatment options) and legally recognized authority to make such a decision. Furthermore, the law states that they are the only people who can administer lethal drugs. Delegation of this task to nurses is forbidden: nurses who administer lethal drugs, or assist in a suicide, risk both criminal prosecution and disciplinary measures. Although these points are clearly stated, uncertainty surrounds what they mean in practice. The Health Minister therefore decided that, before any decision could be taken about legislation and regulation of the role of nurses in euthanasia, their factual role should be clarified. Consequently, the Minister commissioned a study into the role of nurses in medical end-of-life decisions in hospitals, nursing homes and homecare (Van Bruchem-van de Scheur et al. 2004).

Our paper focuses on a part of this study: namely, the role of district nurses in euthanasia and physician-assisted suicide in homecare. The nurse's role is presented in four stages, with respect to:

- requests for euthanasia and physician-assisted suicide;

- the decision-making process;

- the administration of lethal drugs and

- aftercare.

In our study, the following concepts of euthanasia and physician-assisted suicide have been used. Euthanasia is defined as the administration of drugs by a person other than the patient with the explicit intention of ending the patient's life at their explicit request. Physician-assisted suicide is defined as the prescribing or supplying of drugs with the explicit intention of enabling the patient to end their own life. The difference between these concepts lies in the way they are carried out: in euthanasia, a person other than the patient administers the lethal drugs, while in physician-assisted suicide, the patient takes the lethal drugs prescribed by their physician. Although there are moral and legal differences between them, for the purposes of our study we grouped together euthanasia and physician-assisted suicide as one phenomenon because nurses were often not present during the administration of the lethal drugs in either case.

\section{Literature review}

There is a growing international literature about nurses and euthanasia or physicianassisted suicide. However, most studies focus on nurses' attitudes and ideas about euthanasia and their involvement with it as an illegal act (Ryynänen et al. 2002, Verpoort define the (future) role of nurses in define the (future) role of nurses in euthanasia and physician-assisted suicide, the num- 
ber of empirical studies investigating nurses' actual role in these practices is limited (Bilsen et al. 2004, De Beer et al. 2004, De Bal et al. 2006). Three important issues emerge from the factual studies into nurses' roles. Firstly, the definitions of euthanasia and/or physician-assisted suicide do not always match with the definitions we have used in our study. Asch (1996), for example, understands euthanasia as active termination of life as well as the practice of withholding or withdrawing life-sustaining treatments. Secondly, in some studies, data were gathered at a time when euthanasia was illegal, as in the Belgian studies by Bilsen et al. (2004) and De Bal et al. (2006); it could be argued that this biased the responses in these studies and limits their generalizability to a situation where euthanasia is legal. Thirdly, in a number of studies, information on the role of nurses was obtained at second hand. For example, a literature review by De Beer et al. (2004) showed that six of 15 studies reviewed used physician-only samples and provided only indirect information on the role of nurses.

Previous studies indicate that nurses could have a role in various stages of the euthanasia process, irrespective of the legal status of euthanasia in a country. Nurses are often the first caregivers to receive a request for euthanasia (De Beer et al. 2004). Deliens et al. (2000) and De Beer et al. (2004) suggest that in about half of all cases nurses participate in the decision-making process, while Bilsen et al. (2004) relate that in some cases nurses administered the lethal drugs together with, or without, the physician: either of these actions is a punishable offence.

A reliable comparison with the results of our study is limited by several factors:

- The role of nurses needs a sector-specific description. Our study and other studies (Muller et al. 1997, Bilsen et al. 2004) show that the role of nurses can vary enormously between the intramural sector (hospitals and nursing homes) and the extramural sector (homecare organizations).

- The limited number of studies into the role of nurses in homecare have different designs. Two Dutch studies (Muller et al. 1997, Van der Wal et al. 2003) and a Belgian study (Bilsen et al. 2004) provide relevant comparative data, but in all three studies general practitioners provided information about the role of district nurses.

\section{The study}

Aim

The aim of our study was to investigate the role of district nurses in euthanasia and physician-assisted suicide in homecare organizations, conducted as part of a larger study into the role of nurses in medical end-of-life decisions.

\section{Design}

In the main study, we investigated the role of nurses in medical end-of-life decisions in Dutch hospitals, homecare organizations and nursing homes, using both qualitative and quantitative methods. During the qualitative part of the study, we interviewed nurses to explore their practices and used these findings to construct a questionnaire for the quantitative part of the study. The data we present here were collected in 2003 and represent a sub-sample of the quantitative study on the role of nurses in end-of-life decisions. The methodological description will concentrate only on this part of the study: that is, the role of district nurses in euthanasia and physician-assisted suicide in homecare.

\section{Participants}

It was important to recruit a large sample of nurses in order to obtain representative results. We telephoned all accredited homecare organizations in the latest edition of the 
official lists of Dutch healthcare facilities with the request to participate in the study. From the 104 homecare organizations approached, $55(52.8 \%)$ agreed to participate. Reasons for non-participation varied: no nurses employed in the organization; no/little experience with requests for euthanasia/physician-assisted suicide; reorganization; workload; participation in other studies; sickness of the manager.

Contact persons in the organizations agreed to recruit the respondents. We took the view that a randomly drawn sample would give a limited response to the issues to be pursued in the study and, for this reason, decided that the research sample should consist of nurses with experience of euthanasia and physician-assisted suicide. Inclusion criteria were that respondents:

- had more than 2 years experience as a Registered Nurse;

- had more than 2 years' bedside experience;

- were employed at least half time and

- had experienced a request for euthanasia or physician-assisted suicide and/or its administration no longer than 2 years previously.

The contact persons identified 500 Registered Nurses. The absolute response rate was $86.0 \%$ and $81.6 \%$ (408) could be used for analysis (i.e. one or more parts could be used for analysis).

\section{Data collection}

We constructed the questionnaire using the findings from the qualitative study, together with data from previous studies and insights from ethics and law. To promote content validity, we presented the questionnaire to a number of people expert in the subject matter and/or the field of questionnaire construction and statistics. Subsequently, we tested the questionnaire in a pilot study using 106 nurses who had indicated in the qualitative phase that they would be willing to help with this. The response rate was $85.0 \%$. We discussed the outcomes of the questionnaire, adapted it where necessary and again tested it with three nurses.

The final version of the questionnaire was divided into two parts. Part one, the most extensive part, concerned euthanasia and physician-assisted suicide. The second part deait with issues of the treatment of pain and other symptoms with the additional aim of ending the life of the patient. Both started by describing the types of medical decisions at hand. Because of the complexity of the subject matter, and in order to minimize the number of socially desirable answers, we inciuded a relatively large number of open answer categories and open questions. We asked respondents to consider their responses in the context of their most recent case of a request for and/or experience of euthanasia or assisted suicide within the last 2 years; this allowed data to be collected about cases occurring in 2001, 2002 and 2003.

Respondents were guided through the questionnaire avoiding sections that were irrelevant due to their previous responses. This explains the variability in the number of nurses responding to items, as indicated in the results section. The phase 'administering lethal drugs', for example, began with 264 cases and ended with 24 cases.

In the results section, some choices are justified which were made with regard to the number of cases included in the analysis of the various phases. The phase of requests for euthanasia or physician-assisted suicide began with 278 cases, the decision-making process with 267 and administering lethal drugs and aftercare with 264 .

\section{Validity and reliability}

We considered interpretation of the different types of medical decisions by respondents to be a key factor, as it had the potential to affect significantly the validity of the results. Content validity of the questionnaire was ensured to large degree by the qualitative pre- 
study and the pilot study. Because of the retrospective character of the data, we felt it important to guard against information bias; we therefore specified cases had to have taken place within the last 2 years and asked respondents to consider only their most recent case. Promising anonymity and protecting from criminal prosecution may have contributed to honest answering of the questions by respondents. Frequently they provided very sensitive information. Because of the large number of homecare organizations nationwide and the large number of district nurses involved in this study, our results can be considered representative of Dutch district nurses, who have had experience with euthanasia and physician-assisted suicide.

\section{Ethical considerations}

The combined research ethics committee of the Academic Hospital, Maastricht and Maastricht University approved the study. As the subject was considered to be highly sensitive, particular attention was given to guaranteeing anonymity to both organizations and respondents. Both contact persons and respondents received a copy of a letter from the Minister of Justice in which participation was recommended and the explicit promise was made that respondents would be protected against criminal prosecution in the case of disclosure of information about illegal practices.

\section{Data analysis}

The data were analysed using SPSS version 11.5 for Windows (SPSS Inc., Chicago, IL, USA). The questionnaire included many open questions. Responses to these were recorded in a text file and analysed in accordance with the principles of the grounded theory approach (Strauss \& Corbin 1998). Subsequently, responses or clusters of responses were numerically coded in order to analyse them using SPSS.

\section{Results}

\section{Description of participants}

From the 408 questionnaires which contained one or more useful parts for analysis (see above), 351 cases were analysed in which the patient requested for euthanasia or physician-assisted suicide. Participants $(n=351$ ) ranged in age (one missing value) from 23 to 63 years (mean 43.8 years). Twenty-seven men $(7.7 \%)$ and 324 women $(92.3 \%$ ) with an average experience of 18.7 years (three missing values) as a Registered Nurse took part in the study.

\section{Requests for euthanasia or physician-assisted suicides}

In the homecare sector, it was not unusual for the patient to make known the request before their first contact with district nurses; this occurred in 73 of the 351 cases $(20.8 \%)$. These cases were not analysed for this part of the study because the district nurse had no chance to be the first person with whom patients discussed their request for euthanasia or physician-assisted suicide. In $62.2 \%$ of 278 cases, general practitioners were the first person with whom patients discussed their request for euthanasia or physicianassisted suicide. In $22.3 \%$ of cases patients spoke with a district nurse first. When this concerned the respondent themselves (rather than a colleague), the two most frequently cited reasons why patients first raised their request with this person were the following (one missing value, $n=41$ ):

- The district nurse had a confidential relationship with the patient $(46.3 \%)$.

- The relationship between general practitioner and patient was not confidential enough to allow discussion of the subject (29.3\%); for example, the patient had 
changed general practitioner or recently moved to another residence so that patient and practitioner did not know each other well. Sometimes, however, lack of confidence resulted from the fact that the relationship between general practitioner and patient simply did not work.

When the patient spoke with the district nurse first, the six most frequent results were: advised the patient to speak with the general practitioner; checked to determine what the patient had in mind; checked the patient's motives for the request; discussed with the patient who should inform the general practitioner; checked that the request really came from the patient themselves; raised the question with the patient whether the request should be reported in their records (Table 4.1).

Table 4.1 The role of district nurses when the patient spoke with the district nurse first $(n=42)$

\begin{tabular}{lc}
\hline The role of district nurses & $\%(\mathrm{n})$ \\
\hline Advised the palient to speak with the general practitioner & $73.8(31)$ \\
Checked to determine what the patient had in mind & $61.9(26)$ \\
Checked the patient's motives for the request & $45.2(19)$ \\
Discussed with the patient who should inform the general practitioner & $38.1(16)$ \\
Checked that the request really came from the patient themselves & $33.3(14)$ \\
Raised the question with the patient whether the request should be reported in their files & $33.3(14)$ \\
\hline
\end{tabular}

The decision-making process

Consultation between general practitioners and district nurses during the decisionmaking process took place in $41.2 \%$ of 267 cases. It is important to note that in this analysis 84 of 351 cases were omitted from consideration for the following reasons:

- Three cases in which the decision-making and administering of lethal drugs did not take place in the same organization. In such cases, it is conceivable that other factors may have had a role in the decision-making process and this could have influenced the role of district nurses.

- Eleven cases in which the patient died during the decision-making process.

- Seventy cases in which nurses provided no care during the decision-making process, and therefore could have played no role in the process.

The four most frequently mentioned reasons for lack of consultation were, according to the nurses $(n=133)$ :

- the patient's request was so obvious that consultation was unnecessary $(42.9 \%)$;

- it was what the patient really wanted (30.8\%);

- general practitioners regarded euthanasia as a matter between themselves and the patient $(26.3 \%)$;

- lack of collaboration between general practitioner and district nurse (18.8\%).

When district nurses themselves were involved in the decision-making process, $92.2 \%$ (n

$=90$ ) had the impression that they had been taken seriously by general practitioners. In $32.2 \%$ of cases in which district nurses had been involved in the decision-making process, they had taken the initiative by raising the issue with general practitioners. In $63.3 \%$ of cases, general practitioners had initiated the involvement of nurses in the decisionmaking process.

In 333 of 351 cases the general practitioner took the decision to grant or not to grant the patient's request. It should be noted that 18 cases were omitted from consideration for the following reasons:

- Three cases in which the decision-making and administering of lethal drugs did not take place in the same organization. 
- Four cases in which the district nurse discovered afterwards that euthanasia had been performed.

- Eleven cases in which the patient died during the decision-making process.

In 290 cases, general practitioners had decided to honour a request for termination. In $87.9 \%$ of these cases, the district nurses had agreed with the general practitioner's decision; in only $11.0 \%$ of cases had district nurses either disagreed with or had doubts about the decision. The five most frequently mentioned arguments for either disagreement or doubts were: conscientious objections including religious reasons; the patient's condition was not critical; palliative care should first be improved; no evidence of unbearable suffering; no hopeless suffering existed (Table 4.2).

Table 4.2 Arguments of district nurses for either disagreement or doubts about the physician's decision to honour the patient's request for termination of their life $(n=31)$

\begin{tabular}{lc}
\hline Arguments of district nurses & $\%(\mathrm{n})$ \\
\hline Conscientious objections including religious reasons & $51.6(16)$ \\
The patient's condition was not critical & $32.3(10)$ \\
Palliative care should first be improved & $25.8(8)$ \\
No evidence of unbearable suffering & $19.4(6)$ \\
No hopeless suffering existed & $12.9(4)$ \\
\hline
\end{tabular}

Table 4.3 District nurses' reasons for disagreement or doubts about the physician's decision not to grant the patient's request for termination of their life $(n=20)$

\begin{tabular}{lc}
\hline District nurses' reasons & $\%(n)$ \\
\hline The request was realistic & $60.0(12)$ \\
Hopeless suffering did exlst & $50.0(10)$ \\
Unbearable suffering existed & $50.0(10)$ \\
Patients are 'entitled' to euthanasia or physician-assisted sulclde as a maller of principle & $50.0(10)$ \\
\hline
\end{tabular}

In 43 cases, general practitioners decided not to grant a request for euthanasia or physim cian-assisted suicide. According to the district nurses, general practitioners had a variety of reasons for these decisions which included:

- wanted to give palliative care $(41.8 \%)$;

- $\quad$ no evidence of unbearable suffering $(27.9 \%)$;

- no hopeless suffering existed $(18.6 \%)$;

- conscientious objections $(16.3 \%)$;

- euthanasia and physician-assisted suicides not seen as part of their job (11.6\%).

When a request was not granted, $53.5 \%$ of district nurses supported the decision, while $46.5 \%$ either disagreed or had doubts about the decision. The four most mentioned reasons for disagreement or doubt were: the request was realistic; hopeless suffering did exist; unbearable suffering existed; patients were 'entitled' to euthanasia or physiclanassisted suicide as a matter of principle (Table 4.3).

\section{Administering lethal drugs}

In 268 of 351 cases, euthanasia or physician-assisted suicide was performed. However, the analysis in this part of the study is related to 264 cases because in four cases the district nurse discovered only afterwards that euthanasia had been performed.

In $48.9 \%$ of 264 cases, general practitioners and district nurses did not communicate about the moment of administering the lethal drugs. In at least $79.8 \%$ of these cases, patients and/or relatives told district nurses when the lethal drugs would be administered. In two cases, district nurses had gone to patients' homes only to find that the death had already occurred; they found this disturbing and annoying. The presence of a district nurse during administration of the lethal drugs was more the exception $13.3 \%$ of 264 
$c$ ases) than the rule. When district nurses themselves were present ( $n=24)$, they were mainly involved in supporting the patient $(75.0 \%)$ and or the patient's relatives $(91.7 \%)$. in six cases $(25 \%)$, district nurses had been involved in administering the lethal drugs. Their role was passing the lethal drugs to the general practitioner; checking the physician's actions; connecting the infusion system to the infusion bag containing lethal drugs; starting the infusion by injecting lethal drugs; showing the physician how to handle the ir fusion pump or infusion tap; or injecting lethal drugs via a gastrostomy drip-feed (Table 4.4).

Table 4.4 The role of nurses in administering the lethal drugs $(n=6)$

\begin{tabular}{lc}
\hline The role of nurses & $\%(\mathbf{n})$ \\
\hline Passing the lethal drugs to the general practitioner & $33.3(2)$ \\
Cnecking the physician's actions & $16.7(1)$ \\
Connecting the infusion system to the infusion bag containing lethal drugs & $16.7(1)$ \\
Starting the infusion with lethal drugs & $16.7(1)$ \\
Showing the physician how to handle the infusion pump or infusion tap & $16.7(1)$ \\
Injecting lethal drugs via a gastrostomy drip-feed & $16.7(1)$ \\
\hline
\end{tabular}

In 21 of 24 cases $(87.5 \%)$, general practitioners administered the lethal drugs. In one case $(4.2 \%)$, the patient took the lethal drugs as prescribed by the general practitioner. In two of these $(8.3 \%)$, district nurses administered the lethal drugs together with the general practitioner at the latter's request. One of these nurses considered administering lethal drugs a normal nursing procedure comparable with administering other medicines, even though this resulted in death. The other nurse hoped that her actions would have no unwanted legal consequences.

\section{Aftercare}

In the aftercare phase 264 of 351 cases were analysed. In $80.3 \%$ of these, district nurses had provided some degree of aftercare to the surviving relatives. Aftercare was given $(n=212)$ a couple of days or weeks after the death of the patient and took several forms, most commonly attendance at the funeral $(23.1 \%)$, and one or more home visits for a personal talk $(90.1 \%)$. In a number of cases, the general practitioner and/or another care provider had an aftercare talk with the surviving reiatives.

\section{Discussion}

\section{Study strengths and limitations}

We are aware that medical end-of-life decisions such as euthanasia and physicianassisted suicide can be difficult to study using quantitative methods. We believe that by basing our questionnaire on qualitative findings from a relatively large sample, and conoucting a pilot study, we developed an instrument which could deliver useful information Van sensitive topic. By asking nurses to reflect on their own recent experience of a relebilit case, we believe that we further enhanced our study's strength, avoiding the possiespeciallyticipants selecting a case which had had a deep emotional impact or was issecially problematic. Many respondents showed a high degree of engagement in the the questionnaire. Wensive answers to the open questions and open answer categories of me questionnaire. We paid great attention to the interpretation of the different types of the dical decisions made by respondents, as this was considered vital for the validity of wice results. Furthermore, the fact that a large number of homecare organizations nationide participated, allowed us to conclude that the study was representative of district 
nurses with experience of euthanasia and physician-assisted suicide in homecare practice. However, we acknowledge that the data are not representative of the whole population of district nurses, as those with no experience with euthanasia and physicianassisted suicide were not included.

\section{Requests for euthanasia and physician-assisted suicide}

In fewer than half of cases, patients spoke first to a nurse about their wishes. This may be the result of the nature of the relationship between patients and general practitioners, and/or that between patients and district nurses. The patient-general practitioner relationship is, generally speaking, a longstanding and confidential one. By contrast, frequent changes of nurses caused by an increasing number of part-time posts do not help to create trusting, confidential patient-district nurse relationships. Another explanation might be that patients know that their general practitioner is likely to agree with their request for termination of life and, for this reason, are comfortable approaching him/her first. When patients spoke with a district nurse first, most nurses advised them to speak with their general practitioner: indeed, nurses are expected to do this according to interprofessional arrangements. The joint guidelines of the AVVV et al. (2006) state: 'The nurse encourages the patient to discuss the request with the physician. The nurse may offer to the patient her presence, in order to help the patient during the conversation.' In addition, it should be noted that patients who speak first with a nurse may only seek orientation, and not really want to speak with their general practitioner at that moment.

\section{The decision-making process}

District nurses were involved in the decision-making process in fewer than half of the cases $(41.2 \%)$. This rather low percentage is possibly explained by the fact that they usually work separately from general practitioners and do not often see one another either in the presence of the patient or elsewhere. In fact, however, in the studies of Van der Wal et al. (2003) and Bilsen et al. (2004), the percentage of nurses with a role in the decision-making process is considerably lower, $16.0 \%$ of 277 cases and $20.0 \%$ of 12 cases respectively. This difference might be explained by the fact that the analysis in our study was related to cases of euthanasia and physician-assisted suicide in which nurses provided care during the decision-making process, and therefore, could have played a role in this process. Van der Wal et al. (2003) and Bilsen et al. (2004) analysed all cases, regardless of whether nurses provided care during the decision-making process. If district nurses were to wait for general practitioners to initiate a consultation, the number involved in the decision-making process would probably have been lower than the figures presented above. In $32.2 \%$ of the cases, district nurses initiated discussion of patients' wishes with general practitioners. This shows that nurses may increasingly be becoming conscious of the fact that they can act as an important source of information for general practitioners. This is a positive development and one which also displays a professional attitude, especially since the sensitivity of the subject may itself impose a barrier to raising the issue with general practitioners, particularly as general practitioners and district nurses in the homecare sector sometimes do not know each other well.

We would argue that the involvement of nurses in the decision-making process is the responsibility of physician, district nurse and patient. This may mean that if a nurse believes that consultation with the physician is not necessary, because the patient's request is obvious, the matter can be left to the physician. Patients, too, share responsibility for the non-involvement of district nurses as, in a number of cases, they specified that they did not want them to be involved in the decision-making process. This corresponds with the findings of Muller et al. (1997) that 'the patient's wish' could be a reason for not consulting the nurse. The private and sensitive nature of the subject may mean that 
patients wish to limit discussion to a small and intimate circle of people. Therefore, it is important that physicians ask patients whether they want to involve district nurses, thus complying with the joint euthanasia guidelines for physicians and nurses (AVVV et al. 2006), which state that the physician should discuss with the patient which caregivers should be informed, and what information they should receive. Any objections expressed by patients should be taken into account.

Although general practitioners are responsible for the decision whether or not to grant a patient's request, district nurses may have information which can contribute significantly to a considered decision by the general practitioner. District nurses can shed light on issues such as whether the patient's request is voluntary and well considered, or whether there could be a hidden appeal for a different sort of help behind the request. Furthermore, if a general practitioner decides either not to involve the district nurse in the decision-making process and/or not to inform them of the patient's wishes, it makes it harder to gear nursing care to the real needs of the patient.

District nurses reported that they felt more satisfied when a request was granted than when it was denied. This may be explained by their identification with the patient. When nurses disagreed with the physician's decision to refuse a request, many of them argued that the patient has a 'right' to euthanasia or physician-assisted suicide. This is an incorrect argument as euthanasia and physician-assisted suicide are not usual medical activim tles and consequently physicians are not obliged to give their assistance to euthanasia and physician-assisted suicide.

It is important to note, however, that about half the district nurses who did not agree with a decision to grant a request had conscientious objections to the request but, because the decision is the responsibility of the general practitioner, were unable to block the physician's decision. Although they cannot overturn a physician's decision, district nurses may refuse to collaborate in certain activities: in the case of euthanasia, for example, by refusing to take part in the decision-making process or by refusing to attend when lethal drugs are administered. The basic assumption is that somebody with conscientious objections must be able to act according to their conscience.

\section{Administering the lethal drugs}

In some cases, district nurses checked general practitioners' actions or showed them how to handle an infusion system. District nurses working in medical-technical teams are generally more experienced with infusions, a reason why they usually double-check general practitioners' actions or provide instructions. In one case, the district nurse had inserted the infusion bag herself and the general practitioner had then started the infusion. These are not 'administering' actions by nurses. In our study, the demarcation line between administering activities and non-administering activities is set at the moment at which the lethal drugs flow into the patient. Although the administration of lethal drugs should be done exclusively by a physician, in two cases $(8.3 \%)$ a district nurse had done this together with the physician. Other studies (Muller et al. 1997, Bilsen et al. 2004) confirm that nurses administered lethal drugs with or without the physician, in $4.0 \%$ of 139 cases and $17.2 \%$ of 20 cases respectively. However, in both studies all cases were analysed, regardless of whether a nurse was present during administration of the lethal drugs, and the demarcation line between administering activities and non-administering activities was not defined. In our study, the analysis was related to cases in which nurses were present during administration of the lethal drugs and, therefore, could have played an active role in administering them.

Problems may arise when a physician is insufficiently experienced to manage the infusion adequately. Because of the importance of the moment of infusion for the patient and/or relatives, nurses may feel compelled to take over the procedure. Such unauthor- 
ized activities are both illegal and punishable under Dutch law. The arguments provided by nurses to explain their administering of the lethal drugs are striking. One district nurse separated the administrative side from the ultimate aim of the activity: the terminating of a life. One district nurse was confident that her actions would not have harmful legal consequences. This confidence has not been betrayed because no criminal cases regarding administration of lethal drugs by nurses have been brought to court during the last few years; however, the fact remains that such activities are illegal.

\section{Aftercare}

The high rate of aftercare in the homecare sector probably stems, at least partly, from a desire to prevent problems arising through early observation of developing issues. Sometimes, however, institutional regulations could adversely affect the provision of aftercare visits. Administrative blockages were, therefore, one of the limitations to the number of home visits and the support offered to surviving relatives. The policies of institutions sometimes caused district nurses to work out their own policy on home visits; these nurses considered proper care provision more important than their institution's regulations.

\section{Conclusion}

Although district nurses are often intensively involved in the last stage of a patient's life, it appears that they have a limited role in euthanasia/physician-assisted suicide practices in the Dutch homecare setting. This is probably linked with the fact that general practitioners and district nurses do not usually work in the same organization. It is important that tasks, responsibilities and relationships between district nurses and general practitioners are further specified and demarcated. This could lead to improved collaboration and prevention of procedural misunderstandings, as well as ethical problems and legal mistakes. These Dutch data could provide useful information for nurses in other countries to help them define their (future) role in euthanasia and physician-assisted suicide.

\section{References}

Asch D.A. (1996) The role of critical care nurses in euthanasia and assisted suicide. Now England Jounal of Medicino 334, 1374-1379.

AVW, NU'91 \& KNMG (2006) Handreiking voor Samenworking Artsen, Verpleegkundigen on Verzorgenden bij Euthanasio (Guidolines to Support the Collaboration of Physicians, Nurses and Caretakers in Euthanasia Procedures), 4th edn. AVVV, NU'91, KNMG, Utrecht, The Netherlands.

Bilsen J.J.R., Vander Stichele R.H., Mortier F. \& Deliens L. (2004) Involvement of nurses in physician-assisted dying. Jourmal of Advanced Nursing 47(6), 583-591.

De Bal N., Dlerckx de Casterlé B., De Beer T. \& Gastmans C. (2006) Involvement of nurses in caring for palients requesting outhanasia in Flanders (Belgium): a qualitalive study. International Journal of Nursing Studies 43(5), 589-599.

De Beer T., Gastmans C. \& Dierckx de Casterlé B. (2004) Involvement of nurses in euthanasia: a review of the literature. Journal of Medical Ethics 30(5), 494-498.

De Haan J. (2002) The new Dutch law on euthanasia. Medical Law Review 10, 57-75.

Deliens L., Mortier F., Biisen J., Cosyns M., Vander Stichele R., Vanoverloop J. \& Ingels K. (2000) End-of-life decisions in medical practice in Flanders, Belgium: a nalionwide survey. Lancet 356, $1806-1811$ 
Dierckx de Casterlé B., Verpoort C., De Bal N. \& Gastmans C. (2006) Nurses' views on their involvement in euthanasia: a qualitative study in Flanders (Belgium). Journal of Medical Ethics 32(4), 187-192.

Muller M.T., Pijnenborg L., Onwuteaka-Philipsen B.D., van der Wal G. \& van Eijk J.T. (1997) The role of the nurse in active euthanasia and physician-assisted suicide. Journal of Advanced Nursing 26(2), 424-430.

Ryynänen O-P., Myllykangas M., Viren M. \& Heino H. (2002) Attitudes towards euthanasia among physicians, nurses and the general public in Finland. Public Health 116(6), 322-331.

Strauss A. \& Corbin J. (1998) Basics of Qualitative Research: Techniques and Procedures for Developing Grounded Theory. Sage, Thousand Oaks, CA.

Van Bruchem-van de Scheur A., van der Arend A., Spreeuwenberg C., van Wijmen F. \& ter Meulen R. (2004) De rol van verpleegkundigen bij medische beslissingen rond het levenseinde. Verslag van een landelijk onderzoek naar betrokkenheid en praktijken. (The Role of Nurses in Medical End-of-Life Decisions. Report of a National Study into Involvement and Practices). Uitgeverij De Tijdstroom, Utrecht, The Netherlands.

Van der Wal G., van der Heide A., Onwuteaka-Philipsen B.D. \& van der Maas P.J. (2003) Medische besluitvorming aan het einde van het leven. De praktijk en de toetsingsprocedure euthanasie. (Medical Decision-Making at the End of Live. The Practice and the Notification Procedure Euthanasia). Uitgeverij De Tijdstroom, Utrecht, The Netherlands.

Verpoort C., Gastmans C., De Bal N. \& Dierckx de Casterlé B. (2004a) Nurses' attitudes to euthanasia: a review of the literature. Nursing Ethics 11(4), 349-365.

Verpoort C., Gastmans C. \& Dierckx de Casterlé B. (2004b) Palliative care nurses' views on euthanasia. Journal of Advanced Nursing 47(6), 592-600. 


\title{
Chapter 5
}

\section{Euthanasia and assisted suicide in Dutch hospitals: the role of nurses}

\begin{abstract}
Aim. To report a study on the role of nurses in euthanasia and physician-assisted suicide in hospitals, conducted as part of a wider study on the role of nurses in medical and-of-life decisions.

Background. Issues concerning legislation and regulation with respect to the role of nurses in euthanasia and physician-assisted sulcide gave the Dutch Minister for Heallh reason to commission a study on the role of nurses in medical end-ornife decisions in hospitals, homecare and nursing homes.

Method. A questionnaire was sent in 2003 to 692 nurses employed in 73 hospital locations. The response suitable for analysis was from $532(76.9 \%)$ nurses. Data were quantilativoly analysed using SPSS version 11.5 for Windows.

Results. In almost half of the cases (45.1\%), the nurse was the first with whom patients discussed their request for euthanasia or physician-assisted suicide. Consultations between physicians and nurses quite often took place $(78.8 \%)$. In several cases (15.4\%), nurses themselves administered the euthanatics with or without a physician. It is not selfovident that hospitals have guidelines concerning euthanasia/physician-assisted suicide.

Conclusions. In the decision-making process, the consullation between the physician and the nurse noeds improvement. In administering the outhanatics, physicians should take responsibility and should not leave these actions to nurses. Guidelines may play an important role to improve the collaboration between physicians and nurses and to prevent procedural, athicel and legal misunder" standings.

Relevance to clinical practice. Nurses in clinical practice are often closely involved in the last stage of a person's life. Consequently, they are often confronted with caring for patients requesting euthanasia or physician-assisted suicide. The results provide relevant information and may help nurses in defining their role in euthanasia and physician-assisted suicide, especially in caso these practices should become legalised.
\end{abstract}

"The text of this chapter has been published as: GG van Bruchem-van de Scheur, AJG van der Arend, H Huijer Abu-Saad, FCB van Wijmen, C Spreeuwenberg \& RHJ ter Meulen (2008). Euthanasia and assisted suicide in Dutch hospitals: the role of nurses. Jourm nal of Clinical Nursing. 17, $1618 \cdots-1626$. 


\section{Introduction}

To date, the debate concerning euthanasia in the Netherlands has mainly focused on the ethical and legal responsibilities of physicians. Their role is legally formalised in the law on euthanasia and physician-assisted suicide of April 2002 (De Haan 2002). The role of nurses has hardly been discussed in the public arena and has mainly been investigated in the context of research among physicians. It was only on the professional level that the agreements regarding the role of nurses were made by the establishment of joint guidelines of physicians and nurses (AVVV, NU'91 \& KNMG 2006).

Apart from the need to clarify the role of nurses in euthanasia and physician-assisted suicide, several additional issues have arisen. One of these issues raised by professional associations of nurses, concerned the membership of nurses in the regional euthanasia review committees whose task is reviewing of reported cases of euthanasia and physician-assisted suicide based on the due care requirements of law.

However, the Health Minister decided that before any decision was taken about regulation of the role of nurses in euthanasia, their factual role in practice should be clarified. Consequently, the Minister commissioned a study on the role of nurses in medical endof-life decisions in hospitals, homecare and nursing homes (Van Bruchem-van de Scheur et al. 2004). Meanwhile, an article has been published about the role of nurses in euthanasia and physician-assisted suicide in homecare (Van Bruchem-van de Scheur et al. 2007).

This article focuses on the role of nurses in euthanasia and physician-assisted suicide in Dutch hospitals, and presents the role of nurses during the request for euthanasia or physician-assisted suicide, the decision-making process and the administration of euthanatics. Subsequently, the article discusses the role of existing guidelines in hospitals on euthanasia and physician-assisted suicide.

In the present study, euthanasia is defined as the administration of drugs by a person other than the patient with the explicit intention of ending the patient's life at his or her explicit request. Physician-assisted suicide is defined as the prescribing or supplying of drugs with the explicit intention of enabling the patient to end his or her own life. The concepts are different in the way they are carried out. In euthanasia, somebody administers the euthanatics. In physician-assisted suicide, the patient takes the lethal drugs as prescribed by the physician. Although there are moral and legal differences between both acts, in the present study, euthanasia and physician-assisted suicide are considered as one phenomenon. Respondents were not always present during the administering of the lethal drugs (143 times in 262 cases) and, consequently, did not know the ways in which these drugs were administered.

\section{Literature review}

Within the Netherlands, several surveys were conducted to determine the rate and main characteristics of euthanasia and physician-assisted suicide in medical practice (Onwuteaka-Philipsen et al. 2003, Van der Wal et al. 2003). As these studies focused on the role of physicians, they provided only marginal information about the role of nurses. Moreover, this information was indirect, as it was gathered not by asking nurses themselves. This latter point also applies for the study of Muller et al. (1997), this study concentrates on the role of nurses. 
Apart from the large surveys among physicians, only a few qualitative studies have provided data from the perspective of nurses themselves. However, these studies were conducted in single institutions (Pool 1996, The 1997, Van de Scheur \&Van der Arend 1998). The study presented here is the first largescale study exploring the role of nurses in euthanasia and physician-assisted suicide from their perspective.

In Belgium, the role of nurses has been explored in recent years both from the perspective of physicians (Deliens et al. 2000, Bilsen ef al. 2004) and from the perspective of nurses (De Bal et al. 2006). In these studies, data were gathered at a time when euthanasia was illegal. Illegality of euthanasia during data-gathering is not exceptional, as becomes clear from the literature review of the De Beer et al. (2004). This review included 15 studies into the involvement of nurses in euthanasia, published between 1991 and 2002. In all selected articles, data were gathered at a time when euthanasia was illegal such as in Australia (Kuhse \& Singer 1993), Japan (Tanida et al. 2002) and the USA (Asch 1996). Only in the included Dutch studies, euthanasia was not a punishable offence when the physician fulfilled the due care requirements.

The thread of several studies is that nurses, because of their daily involvement and specific expertise, are in a prime position to play a role in the various stages of the euthanasia process. According to De Beer et al. (2004) and De Bal ot al. (2006), nurses are (often) the first caregivers to receive a request for euthanasia. In the decision-making process, they could have an important role in the analysis of the patients' request, for example to determine whether the request concealed an appeal for help (De Bal et al. 2006). However, several studies found that it is not obvious that nurses participated in the decision-making process (Muller et al. 1997, Deliens et al. 2000, Van der Wal et al. 2003, Bilsen et al. 2004, De Beer et al. 2004). Several studies reported that nurses cross the line by administering lethal drugs together with or without the physician (Muller et al. 1997, Van de Scheur \& Van der Arend 1998, Bilsen et al. 2004, De Beer et al. 2004).

A comparison of the results in this article with the studies mentioned earlier is limited, because of differences in study design, definitions used and the absence of a sectorspecific description of results in studies. Moreover, the illegal character of euthanasia during the data gathering could bias the comparison of results (see Discussion).

\section{The study}

Aim

The aim of the study was to investigate the role, perceptions, responsibilities and problems of nurses in medical end-of-life decisions, to advise the Dutch government in legislation and policy-making concerning the role of nurses.

\section{Design}

The role of nurses in medical end-of-life decisions in Dutch hospitals, homecare organisations and nursing homes has been investigated using both qualitative and quantitative methods. During the qualitative part of this study, nurses were interviewed to explore their practices. The results were important for constructing the questionnaire for the quantitative part of the study.

Because the data presented here represent a sub-sample of the quantitative study, the methodology will be focused on this part of the study.

\section{Recruitment of participants}

All general and academic hospitals in the Netherlands were approached through telephone with the request to participate in the study. Of the 105 hospital locations, 73 
(69.5\%) agreed to participate. Reasons for non-participation varied: workload; other priorities, swamped with studies; reorganisation; sensitivity of the subject; no enthusiasm for the study among nurses.

Contact persons in the organisations recruited the respondents. Inclusion criteria were that respondents:

- had more than two years' experience as a registered nurse,

- had more than two years' bedside experience,

- were employed at least half-time and

- had experienced a request for euthanasia or physician-assisted suicide and/or its administration no longer than two years before.

The research group had the view that a randomly drawn sample would give a limited response to the study. For this reason, it was decided that the sample would consist of nurses experienced with euthanasia or physician-assisted suicide.

The contact persons recruited 692 nurses. The response suitable for analysis was from $532(76.9 \%)$ nurses. This concerns the number of questionnaires of which any section was useful for analysis.

\section{Data collection}

Data were collected using a questionnaire. The results of the qualitative study, together with data from previous studies and insights from ethics and law, were the basis for constructing the questionnaire. To promote content validity, the questionnaire was presented to experts, with respect to both content and questionnaire construction and statistics. It was then pilot-tested with 106 nurses who, in the qualitative study, had indicated their willingness to test the questionnaire. The response rate was $85 \%$.

The research team discussed the outcomes of the questionnaire, adapted it where necessary and again tested it with three nurses. In the final version of the questionnaire, the first most extensive part concerned euthanasia and physician-assisted suicide. It started by describing the types of medical decisions at hand.

The part about euthanasia and physician-assisted suicide contained 153 questions. The time to be spent by respondents was estimated as one hour. The questionnaire mainly consisted of closed-ended questions to which an open answer category was added to avoid missing data. The need for this latter category was based on the complexity of the subject. The questionnaire has not been tested statistically. Simple descriptive statistics were used to present the role of nurses in euthanasia and physician-assisted suicide.

Respondents were asked to place their responses within the context of their most recent case of a request for euthanasia or physician-assisted suicide and/or its administration within the last two years. These cases took place in the years 2001-2003.

For respondents, the length of the questionnaire was reduced, because they were guided through the questionnaire, avoiding sections that were irrelevant because of their previous responses. This explains the variability in the number of nurses responding to items in the Results section. The phase 'requests for euthanasia or physician-assisted suicide', for example, begins with 381 cases and ends with 47 cases. Some choices are justified in the Results section.

\section{Validity and reliability}

Attention was paid to the interpretation of the different types of medical decisions by respondents to improve the validity of the results. Because of the retrospective character of the data, which could contribute to information bias, the cases reported by the respondents should have taken place within the last two years. In case respondents were confronted by more cases, they were asked to focus their answers on the most recent case. Promising anonymity and protecting from criminal prosecution may have contributed to 
honest answering by the respondents. Frequently, they provided very sensitive information.

Because of the large number of hospitals nationwide and the large number of nurses involved in the present study, the results may be regarded as representative of Dutch hospital nurses with experience in euthanasia and physician-assisted suicide.

\section{Ethical considerations}

The research ethics committee of the Academic Hospital Maastricht and Maastricht University approved the study.

As the subject was considered to be highly sensitive, participation was promoted by:

- the guarantee of anonymity to both organisations and respondents;

- both contact persons and respondents received a copy of a letter of the Minister of Justice in which participation was recommended and the explicit promise was made that respondents would be protected against criminal prosecution, should they disclose information of illegal practices.

This letter of the Minister of Justice contained, besides information about the study design and the research team, the following information. 'From the conclusions of this study, when necessary and desirable, recommendations may be made with respect to policy-making and/or legislation concerning the role of nurses. For this reason, I request your cooperation to this study. (....) Cooperation to the study is entirely voluntary. Refusing has absolutely no consequence for you. You may decide not to participate in the study at any moment and without giving a reason. The results of the study will not be reducible to individual persons. The information on a specific case, provided by you, will not be reported to the Public Prosecutor.'

\section{Data analysis}

The data were analysed using SPSS version 11.5 for Windows. However, as euthanasia practice can be a complex and sensitive situation, the study included several open answer categories and open questions. The answers were described and coded. They appeared to be helpful in obtaining additional data and interpreting the results.

\section{Results}

\section{Description of participants}

From the 532 questionnaires with one or more parts useful for analysis (see above), 404 cases in which patients requested euthanasia or physician-assisted suicide were analysed.

Participants $(n=404)$ ranged in age from 22 to 59 years (mean 38.1 years). Most of them $(85.4 \%$ ) were women. Participants ( 1 missing value) had a mean 14.0 years of experience as a registered nurse.

From 527 out of 532 questionnaires, the part about 'guidelines' could be analysed. Participants $(n=527)$ ranged in age from $21-59$ years (mean 38.2 years). Most $(85.6 \%)$ were women. Participants ( 1 missing value) had a mean 13.9 years of experience as a registered nurse.

\section{Requests for euthanasia or physician-assisted suicide}

In $23.4 \%$ of 381 cases, physicians were the first person with whom patients discussed their request for euthanasia or physician-assisted suicide. In $45.1 \%$ of cases, patients spoke with the nurse first, and in $22.3 \%$ of cases, patients first raised their request when 
both the physician and the nurse were present, for example during the physician's rounds. In $9.2 \%$ of cases, the category 'other' or 'unknown' was applicable.

In this analysis, 23 of 404 cases were ignored, because the patient expressed the request to the physician in the outpatient clinic, before admission to the ward. The nurse, therefore, had no opportunity to be the first person with whom patients discussed their request for euthanasia or physician-assisted suicide.

When the patient spoke with respondents themselves $(n=60)$, the majority $(78.3 \%)$ of those nurses informed the patient about the procedure around euthanasia/physicianassisted suicide. The three most mentioned aspects were $(n=47)$ :

- the legal due care requirements $(70.2 \%)$,

- the policy/guidelines of the institution concerning euthanasia/physician-assisted suicide $(51.1 \%)$,

- possibilities of palliative care (46.8\%).

The decision-making process

Consultation between physicians and nurses during the decision-making process took place in $78.8 \%$ of 359 cases. In $14.2 \%$, this was not the case and in $7.0 \%$ this was unknown.

In this analysis, 45 of 404 cases were ignored because of the following reasons:

1. Cases in which the decision-making and administering of lethal drugs did not take place within the same organisation. In such cases, it is conceivable that other factors have a role in the decision-making process, which could influence the role of nurses $(n=17)$.

2. A case in which the decision-making and administering of lethal drugs did not take place on the same ward $(n=1)$.

3. Cases in which the patient died during the decision-making process $(n=7)$.

4. Cases in which the decision had been taken before the patient was admitted to the ward. Therefore, nurses could not have played a role in the decision-making process $(n=20)$.

The three most commonly cited reasons for a lack of consultation were $(n=51)$ :

- it was what the patient wanted (35.3\%),

- the patient's request was so obvious that consultation was unnecessary (31.4\%),

- physicians considered euthanasia as a matter between themselves and the patient $(31.4 \%)$.

When a distinction is made between accepted requests $(n=264)$ and not-accepted requests $(n=95)$, then nurses more often had a role in the accepted requests $(81.4 \%)$ than in the not-accepted requests $(71.6 \%)$.

In $29.5 \%$ of 224 cases, in which nurses had been involved in the decision-making process, they had taken the initiative by raising the issue with physicians. In $67.0 \%$ of cases, physicians had initiated the involvement of nurses in the decision-making process and in $3.5 \%$, it was unknown.

Taking into account the distinction between accepted and not-accepted requests, physicians had taken the initiative more often $(73.1 \%)$ than nurses $(23.4 \%)$ in the accepted requests $(n=171)$. In the not-accepted requests $(n=53)$, nurses had taken the initiative more often $(49.1 \%)$ than physicians $(47.2 \%)$, although differences were small.

\section{Administering the euthanatics}

In 262 of 404 cases, in which a request was made, euthanasia or physician-assisted suicide was performed. However, the analysis is limited to 143 cases, because only in these cases respondents themselves were present while administering euthanatics. 
In $80.4 \%$ of 143 cases, the nurse who was present during administering of euthanatics had a role in the decision-making process. In $18.9 \%$, this was not the case and in $0.7 \%$ this was unknown.

In $83.2 \%$ of 143 cases physicians administered the euthanatics. In two cases $(1.4 \%)$, patients took the euthanatics, as prescribed by the physician. In five cases $(3.5 \%)$, nurses administered the euthanatics and in 17 cases $(11.9 \%)$ nurses administered the euthanatics together with the physician.

in $9.8 \%$ of 143 cases, nurses had not been convinced that the physician complied with the due care requirements. The majority of these nurses indicated that they had insufficient knowledge of the due care requirements and/or that it was a matter of having faith in the physician.

\section{Euthanasia guidelines in hospitals}

From 527 of 532 questionnaires which contained one or more useful parts for analysis (see above), the part about 'guidelines' could be analysed. More than half (65.3\%) of 527 nurses said that their hospital had its own written guidelines on dealing with requests for euthanasia and physician-assisted suicide. According to $3.2 \%$ of the nurses, their hospital had no guidelines, $28.1 \%$ of the nurses did not know whether their hospital had guidelines, $2.8 \%$ of the nurses indicated that guidelines were in the making, two nurses $(0.4 \%)$ did not answer the question or gave an answer with an unclassifiable meaning and one nurse $(0.2 \%)$ indicated that only the own ward had guidelines, but not the organisation. When guidelines were available $(n=345)$, a large majority of nurses $(81.7 \%)$ indicated that the guidelines were present on the ward. According to $8.7 \%$ of the nurses, the guidelines were not present on the ward, $9.0 \%$ of the nurses did not know whether the guidelines were present on the ward and some nurses $(0.6 \%)$ did not answer the question or gave an answer with an unclassifiable meaning. More than half of the 345 nurses $(57.1 \%)$ indicated that the guidelines describe their role, $9.9 \%$ of the nurses indicated that the guidelines did not describe their role, $32.2 \%$ of the nurses did not know whether the guidelines described their role and some nurses $(0.9 \%)$ did not answer the question.

\section{Discussion}

Requests for euthanasia or physician-assisted suicide

In less than half of the cases $(45.1 \%$ ), patients spoke with a nurse first. However, it is conceivable that patients did not always deliberately choose to speak first with the physician or the nurse. The patient may suddenly be more inclined to talk about euthanasia/physician-assisted suicide, for example, after a bad news message or after a bad sleep.

When patients spoke with a nurse first, the nurse usually informed the patient about the formal euthanasia procedure, such as the due care requirements $(70.2 \%)$ and/or the policy/guidelines of the institution $(51.1 \%)$. This role is in accordance with the guidelines of the AVVV, NU'91 \& KNMG (2006, p. 26), which state: 'it is the responsibility of the physician to inform the patient fully and in a way understandable for him or her during the different stages of the euthanasia procedure. Both the physician and the patient may ask the nurse for support. Repeated explanation by the physician or the nurse may strongly contribute to good information for the patient.... Preferably, the physician holds conversations in the presence of the nurse.'

When a patient has (cancer) pain or other major problems, it is concelvable that the nurse brings palliative care to the patient's attention. Taking into account the due care requirement that 'the physician should be convinced, together with the patient, that there 
is no other reasonable solution', the offering of solutions other than euthanasia or physician-assisted suicide is important.

\section{The decision-making process}

The high percentage $(78.8 \%)$ of consultations between physicians and nurses is in line with two recent studies among physicians. Van der Wal et al. (2003) and Bilsen et al. (2004) found that physicians consulted nurses in $78 \%$ of Dutch cases and in $83.3 \%$ of Belgian cases, respectively.

However, in comparing results, prudence is needed. Van der Wal et al. (2003) and Bilsen et al. (2004) analysed all cases, regardless of whether or not the nurse provided care during the decision-making process. The analysis in our study has been limited to cases of euthanasia and physician-assisted suicide in which the nurse provided care during the decision-making process and, therefore, could have played a role in this process. Furthermore, the percentages of Van der Wal et al. (2003) and Bilsen et al. (2004) arise in small study populations and the percentage of Bilsen et al. (2004) applies to both hospitals and nursing homes.

The high percentage of consultations may be related to the organisational structure of hospitals, where collaboration between physicians and nurses is usually formalised in several scheduled consultation moments. However, in several cases $(14.2 \%)$, the consultation between physician and nurse was lacking. One of the reasons was that physicians considered euthanasia as their exclusive domain. Moreover, involvement of nurses in the decision-making is not a legal requirement in the Netherlands. However, physicians are encouraged to do so, for example, through a question on such activity in the model of the physician's report to the regional review committee. The physician is asked, 'Did you consult the nursing staff/the patient's carers about terminating the patient's life? If so, who did you consult and what view did they hold? If not, why not?' This is in contrast to Belgium where the legal regulation of euthanasia stipulates that the physician must discuss the patient's request for euthanasia with members of the nursing team who are directly involved in caring for the patient (Gastmans et al. 2004).

Although physicians are responsible for the decision whether or not to accept a patient's request, nurses could provide essential information to the physician, for example about the voluntariness and considered nature of the request. The finding that nurses more often have a role when the request is accepted $(81.4 \%)$ than when it is not accepted $(71.6 \%)$ could be explained as follows. When physicians decide not to accept a request for euthanasia or physician-assisted suicide for reasons such as conscientious objection or the institution's policy (euthanasia/physician-assisted suicide is not permitted), it is conceivable that such reasons are well-known on the ward and physicians will tend not to discuss such reasons first with the nurse.

When physicians decide (still) not to accept a request for euthanasia or physicianassisted suicide, it is important to inform nurses about the arguments for that decision. It is important that questions and doubts can be discussed between physician and nurse. However, it should be emphasized that, in case patients want to keep their discussion with the physician private, the physician has to respect this request.

If nurses were to wait for the physician to initiate a consultation, the percentage of nurses involved in the decision-making process would probably had been lower than the figures presented earlier. In $29.5 \%$ of cases, the nurse initiated discussion of the patient's request with the physician. A reason for such initiative could be their strong emotional bonds with the patient as was found in the qualitative part of the study. The contact with the physician might, then, be helpful in finding a balance between those emotions and the objective aspects of the case. 
A striking outcome is that in the not-accepted requests, nurses took the initiative to contact physicians more often than in the accepted requests $(49.1 \%$ and $23.4 \%$, respectively). In the accepted requests the opposite happened, as in these cases, physicians more often took the initiative to contact nurses $(73.1 \%$ against $47.2 \%)$. An explanation of these differences might be:

- in the accepted requests, physicians may gain a feeling of 'legal security' when the decision is supported by nurses.

- in the not-accepted requests, nurses often take the role of the patient's advocate, trying to represent the patient's interests. From this position, they will contact the physician.

\section{Administering the euthanatics}

It is not self-evident that when a nurse had a role in a case of euthanasia or physicianassisted suicide, she has been involved in the whole process from the beginning to the end of that case. In several cases (18.9\%), the nurse who was present during administering of euthanatics had not had any role in the decision-making process. It is unknown how nurses experienced this. However, a conclusion could be that the involvement of nurses in several cases is 'fragmented'. An important reason might be the changing shifts of nurses.

Although the administration of euthanatics is an exclusive responsibility of physicians, in $15.4 \%$ of cases, nurses themselves administered the euthanatics together with or without a physician. In our study, the demarcation line between administering activities and non-administering activities is defined as the moment at which the euthanatics flow into the patient.

The Dutch study of Muller et al. (1997) and the Belgian study of Bilsen et al. (2004) found that nurses administered the euthanatics in $21 \%$ and $58.8 \%$ of the cases, respectively. The comparison of these figures is problematic. In neither study, the demarcation line between administering activities and non-administering activities is defined. Furthermore, the figure of Bilsen et al. is based on the findings from both hospitals and nursing homes.

According to the Dutch euthanasia law and the abovementioned exclusive responsibility of physicians, a nurse who administers euthanatics, or who assists in a suicide, risks both criminal prosecution and disciplinary measures. Physicians should take their responsibilities and should not leave these activities to nurses.

Some nurses $(9.8 \%)$, who were present during the administering of euthanatics, were not convinced that the physician complied with the due care requirements of law. Explanations for this finding could be that nurses consider the compliance with the due care requirements as a medical responsibility only, and/or that they should exclusively focus on supporting the patients and/or their relatives. However, nurses should be aware of the fact that they always risk prosecution irrespective of the prosecution of the physician in such cases. Furthermore, although the physician is legally responsible for compliance with the due care requirements, it may be expected that nurses have knowledge of these requirements and check whether the physician complies with the requirements. This corresponds with the guidelines of the AVVV, NU'91 \& KNMG (2006), which state that nurses who are involved in a care process around euthanasia should know about the law and legislation concerning euthanasia and about the due care requirements as stated in the law.

Institutional guidelines, to be consulted on the ward, could be helpful in promoting such knowledge and compliance (see the following section). 


\section{Euthanasia guidelines}

It is not self-evident that hospitals have guidelines concerning euthanasia and/or physician-assisted suicide and, if they are present (65.3\%), that they are 'within arm's reach' and describe the nurse's role. Therefore, in many cases nurses are not supported by such guidelines. This is not necessarily the result of a non-availability of guidelines. Nurses may make insufficient efforts to search for or read the guidelines. For example, many nurses $(28.1 \%)$ did not know whether or not their hospitals had developed guidelines and many (32.2\%) of those who acknowledged the existence of guidelines were ignorant about their own role in the guidelines.

There are no figures from other studies to compare with. Nevertheless, Gastmans et al. (2006) provided additional information in a study among general directors of hospitals and nursing homes in Belgium, which showed that $79 \%$ of the hospitals had a written ethics policy on euthanasia and that $87 \%$ of these hospitals gave explicit attention to the role of nurses. It is important that the nurses be supported by guidelines, particularly when euthanasia and physician-assisted suicide are not frequently requested and, consequently, nurses may not have relevant knowledge at hand.

Moreover, institutional guidelines may play an important role in improving collaboration between physicians and nurses and in preventing procedural misunderstandings that could lead to ethical problems and legal offences. Therefore, those guidelines should include a description of the law and regulations and the roles of physicians, nurses and other care providers as well as rules for the communication between them.

During the development or renewing of institutional guidelines, the national joint guidelines of physicians and nurses can be helpful (AVVV, NU'91 \& KNMG 2006). In these guidelines, tasks and responsibilities of both physicians and nurses are clarified and demarcated. In 2006, the fourth revised edition was published, which has been based also on the results of our study. According to Gastmans et al. (2004), who developed a clinical practice guideline, guidelines should build bridges between ethics, law and clinical practice in terms of integrated caring for patients who request euthanasia.

Additionally, it may be important for care providers to be provided with information in the multidisciplinary guidelines on issues such as:

- what $\operatorname{step(s)}$ the nurse can take if a physician does not fulfil the due care requirements;

- in which cases the institution will compensate for the costs of legal assistance in case of criminal prosecution;

- whether the employment contract will be broken in the event of a criminal prosecution.

\section{Conclusions}

Nurses perform a variety of tasks in the various stages of the euthanasia process. However, considerable fragmentation and disproportion exist in their role throughout those stages. During decision-making, the role of nurses could be expanded. Although nurses are consulted in the majority of cases, in about $15 \%$ of cases, there is a lack of consultation between physician and nurses. In the administering of euthanatics, nurses are sometimes involved too strongly, as in $15.4 \%$ of the cases, nurses administered the euthanatics themselves. The latter finding is alarming and contrasts sharply with the legal rules and the professional responsibilities of nurses.

A sound policy could improve the collaboration between nurses and physicians and could strengthen the use of nurses' expertise without crossing legal and professional 
boundaries. Multidisciplinary institutional guidelines should play a more important role to achieve this.

An interesting follow-up study might be the analysis of such institutional guidelines, including the role ascribed to nurses.

While embedded in a Dutch cultural context, the data of this study may have international relevance, even in countries where euthanasia is not permitted by law. The findings of this study may help nurses in other countries to define their role in euthanasia and physician-assisted suicide, should they become legalised.

\section{References}

Asch DA (1996) The role of critical care nurses in euthanasia and assisted suicide. The New England Journal of Medicine 334, 1374-1379.

AVW, NU'91 \& KNMG (2006) Handreiking voor Samenwerking Artsen, Verpleegkundigen en Verzorgenden bij Euthanasie (Guidelines to support the collaboration of physicians, nurses and caretakers in euthanasia procedures), 4th edn. AVVV, NU'91, KNMG, Utrecht, the Netherlands.

Bilsen JJR, Vander Stichele RH, Mortier F \& Deliens $L$ (2004) Involvement of nurses in physicianassisted dying. Journal of Advanced Nursing 47, 583-591.

De Bal N, Dierckx de Casterlé B, De Beer T \& Gastmans C (2006) Involvement of nurses in caring for patients requesting euthanasia in Flanders (Belgium): a qualitative study. International Journal of Nursing Studies 43, 589-599.

De Beer T, Gastmans C \& Dierckx de Casterlé B (2004) involvement of nurses in euthanasia: a review of the literature. Journal of Medical Ethics 30, 494-498.

De Haan J (2002) The New Dutch Law on Euthanasia. Medical Law Review 10, 57-75.

Deliens L, Mortier F, Bilsen J, Cosyns M, Vander Stichele R, Vanoverloop J \& Ingels K (2000) Endof-life decisions in medical practice in Flanders, Belgium: a nationwide survey. Lancet 356 , 1806-1811.

Gastmans C, Van Neste F \& Schotsmans P (2004) Facing requests for euthanasia; a clinical practice guideline. Journal of Medical Ethics 30, 212-217.

Gastmans C, Lemiengre J \& Dlerckx de Casterlé B (2006) Role of nurses in institutional ethics policies on euthanasia. Journal of Advanced Nursing 54, 53-61.

Kuhse H \& Singer P (1993) Voluntary euthanasia and the nurse: an Australian survey. International Journal of Nursing Studies 30, 311-322.

Muller MT, Pijnenborg L, Onwuteaka-Philipsen BD, van der Wal G \& van Eijk JT (1997) The role of the nurse in active euthanasia and physician-assisted suicide. Journal of Advanced Nursing $26,424-430$.

Onwuteaka-Philipsen BD, van der Heide A, Koper D, Keij-Deerenberg I, Rietjens JAC, Rurup ML, Vrakking AM, Georges JJ, Muller MT, van der Wal G \& van der Maas PJ (2003) Euthanasia and other end-of-life decisions in the Netherlands in 1990, 1995 and 2001. The Lancet 362, 395-399.

Pool R (1996) Vragen om te sterven. Euthanasie in een Nederlands zlekenhuis. (To ask for dying: euthanasia in a Dutch hospital). WYT Uitgeefgroep, Rotterdam, the Netherlands.

Tanida N, Asai A, Ohnishi M, Nagata SK, Fukul T, Yamazaki Y \& Kuhse H (2002) Voluntary active euthanasia and the nurse: a comparison of Japanese and Australian nurses. Nursing Ethics 9 , 313-322.

The A-M (1997) 'Vanavond om 8 uur...' Verpleegkundige dilemma's bij euthanasie en andere beslissingen rond het levenseinde. ('Tonight at eight o'clock...' Nurse's dilemmas with euthanasla and other end-of-life decisions). Bohn Stafleu Van Loghum, Houten/Diegem, the Netherlands. 
Van Bruchem-van de Scheur A, van der Arend A, Spreeuwenberg C, van Wijmen F \& Ter Meulen $\mathrm{R}$ (2004) De rol van verpleegkundigen bij medische beslissingen rond het levenseinde. Verslag van een landelijk onderzoek naar betrokkenheid en praktijken. (The role of nurses in medical end-of-life decisions. Report of a national study into involvement and practices). Uitgeverij De Tijdstroom, Utrecht, the Netherlands.

Van Bruchem-van de Scheur GG, van der Arend AJG, Spreeuwenberg C, Huijer Abu-Saad H \& Ter Meulen RHJ (2007) Euthanasia and physician-assisted suicide in the Dutch homecare sector: the role of the district nurse. Journal of Advanced Nursing 58, 44-52.

Van der Wal G, van der Heide A, Onwuteaka-Philipsen BD \& van der Maas PJ (2003) Medische besluitvorming aan het einde van het leven. De praktijk en de toetsingsprocedure euthanasie. (Medical decision-making at the end of life. The practice and the notification procedure euthanasia). Uitgeverij De Tijdstroom, Utrecht, the Netherlands.

Van de Scheur A \& van der Arend A. (1998) The role of nurses in euthanasla: a Dutch study. Nursing Ethics 5, 497-508. 


\title{
Chapter 6
}

\section{Dutch nurses' attitudes towards euthanasia and physician-assisted suicide"}

\begin{abstract}
This article presents the attitudes of nurses towards three issues concerning their role in euthanasia and physician-assisted suicide. A questionnaire survey was conducted with 1509 nurses who were employed in hospitals, home care organizations and nursing homes. The study was conducted in the Netherlands between January 2001 and August 2004. The results show that less than half $(45 \%)$ of nurses would be willing to serve on commlttees reviewing cases of euthanasia and physician-assisted suicide. More than half of the nurses $(58.2 \%)$ found it too far-reaching to obllge physiclans to consult a nurse in the decision-making process. The majority of the nurses stated that preparing euthanatics $(62.9 \%)$ and inserting an infusion needle to administer the euthanatics (54.1\%) should not be accepted as nursing tasks. The findings are discussed in the context of common practices and policies in the Netherlands, and a recommendation is made not to include these three issues in new regulations on the role of nurses in euthanasia and physician-assisted suicide.
\end{abstract}

\footnotetext{
"The text of this chapter has been published as: A van Bruchem-van de Scheur, A van der Arend, F van Wijmen, H Huijer Abu-Saad \& R ter Meulen (2008). Dutch nurses' attitudes towards euthanasla and physician-assisted suicide. Nursing Ethics, 15, 186-198.
} 


\section{Introduction}

\section{Conceptual issues}

In this study, euthanasia was defined as the administration of drugs by a person other than the patient with the explicit intention of ending the patient's life at his or her explicit request. Physician-assisted suicide was defined as the prescribing or supplying of drugs with the explicit intention of enabling the patient to end his or her own life. The concepts are different in the way in which they are carried out. In euthanasia, someone administers the euthanatics. In physician-assisted suicide, the patient himself or herself takes the lethal drugs as prescribed by the physician. In this study, euthanasia and physicianassisted suicide are considered as one phenomenon.

\section{The Dutch law on euthanasia and physician-assisted suicide}

After 30 years of public discussion in the Netherlands, the Law on the Termination of Life on Request and Assisted Suicide (Euthanasia Act) came into force in April 2002. This states that physicians who perform euthanasia or assist in a suicide are exempt from prosecution and punishment if their actions meet two conditions:

1) They fulfil the due care requirements that stipulate the physician must: (a) be convinced that the patient's request is voluntary and well considered; (b) be convinced that the patient's suffering is hopeless and unbearable; (c) have informed the patient about his or her situation and prospects; (d) be convinced, together with the patient, that there is no other reasonable solution; (e) have consulted at least one other independent physician, who has also seen the patient, and has provided a written assessment of the due care requirements listed in points a-d above; and (f) have carried out euthanasia or assisted in the suicide with due medical care.

2) They report an unnatural death to the municipal coroner and submit a reasoned report on the euthanasia or physician-assisted suicide to a regional euthanasia review committee. This committee will consist of a legal expert, a physician and an ethicist, and will assess whether the physician has complied with the due care requirements of the law. ${ }^{1}$

\section{Attitudes of nurses}

The number of publications about the attitudes of nurses towards euthanasia is increasing. Verpoort et al. ${ }^{2}$ conducted a literature review, which included 15 relevant documents published between 1990 and 2002. An important obstacle to inclusion was authors' definition of euthanasia. In all retrieved articles, euthanasia had illegal overtones during the data gathering, including the Dutch study by The. ${ }^{3}$ However, while The ${ }^{3}$ was carrying out her study, euthanasia was decriminalized if physicians fulfilled "the due care requirements'. Euthanasia was still illegal during later quantitative studies carried out by Ryynänen et $a l^{4}$ among physicians, nurses and the general public in Finland, and qualitative studies by Verpoort et al..$^{5}$ and Dierckx de Casterle et al..$^{6}$ among palliative care nurses.

In the nursing literature, ${ }^{2,4-6}$ attitudes are related to two main themes: the legalization of euthanasia with arguments for or against its justification ${ }^{2,4,5}$ and the involvement of nurses in the various stages of the euthanasia process of request, ${ }^{6}$ decision making, ${ }^{6}$ administration ${ }^{2,6}$ and aftercare. ${ }^{6}$

In some articles characteristics are identified that influence nurses' opinions, such as age, ${ }^{2,4}$ religion ${ }^{2,4}$ and nursing specialty. ${ }^{2}$ This complex reality of attitudes has been further developed by Berghs et al. ${ }^{7}$ These authors found that age, nursing specialty and religion 
have important roles in the formation of arguments for or against euthanasia. For example, younger nurses tended to accept euthanasia more often than older nurses. Part of the complexity of nurses' attitudes arises out of their need for education in: palliative care, communication skills, giving a place to emotions, decision making, ethical guidelines, professionalism and policymaking.

In the Netherlands, not much was known about the attitudes of nurses with regard to the acceptability of euthanasia and their role in euthanasia and physician-assisted suicide. Only a few studies indirectly paid attention to the attitudes of nurses in this area. In The's study, $^{3}$ nurses were asked how they viewed their tasks, and in the study by Van de Scheur and Van der Arend, ${ }^{8}$ nurses were asked to identify their ideal role in euthanasia. Although studies into attitudes of nurses with regard to their role may help to define the future role of nurses in euthanasia and physician-assisted suicide, in the Netherlands joint guidelines for physicians and nurses have played an important part in clarifying nurses' role. ${ }^{9}$ These guidelines describe the collaboration and demarcation of tasks between physicians and nurses in the various stages of the euthanasia process.

Apart from the general need to clarify the role of nurses in euthanasia and physicianassisted suicide, the Dutch nursing associations raised three particular issues:

1) With the establishment of five regional euthanasia review committees in 1998, discussion arose about whether nursing should be represented on these committees.

2) During debates related to the Bill on the Termination of Life on Request and Assisted Suicide, the question was raised whether consultation with nurses during the decision-making process should be added to physicians' due care requirements.

3) After the Law on the Termination of Life on Request and Assisted Suicide came into force in April 2002, a debate developed about whether nurses should be allowed to carry out activities such as preparing euthanatics and inserting an infusion needle for their administration.

However, the Minister of Health decided that, before any decision could be made about legislation or regulation of the role of nurses in euthanasia, their actual role should be clarified. For this reason, the Minister commissioned a study into the role of nurses in medical end-of-life decisions in hospitals, home care and nursing homes. Van Bruchemvan de Scheur et al. ${ }^{10}$ described the results of this study in an extensive report (in Dutch) to the Minister, and have since published an article on the role of nurses in euthanasia and physicianmassisted suicide in home care. ${ }^{11}$ Although the study focused on actual practice, the nurses were additionally asked for their attitudes to the three issues noted above, which are now reported in this article.

\section{Method}

\section{Aim}

The aim of the study was to investigate the role, perceptions, responsibilities and problems of nurses in medical end-of-life decisions in order to advise the Dutch government on legislation and policymaking concerning the role of nurses.

\section{Design}

The role of nurses in medical end-of-life decisions in Dutch hospitals, home care organizations and nursing homes was investigated using both qualitative and quantitative research methods. During the qualitative phase of the study, nurses were interviewed to explore their practices and attitudes concerning a number of issues about euthanasia and physician-assisted suicide. The interview data contributed significantly to the construction of a questionnaire used for the quantitative phase of the study, especially with 
regard to the actual role of nurses. Qualitative data about their attitudes were less useful because of limitations in number and scope. A well-considered attitude was often lacking, and some issues appeared to be very remote from the nurses' daily practice.

The quantitative data are presented in this article, thus the methodological description concerns the quantitative part of the study.

\section{Recruitment of participants}

All general and academic hospitals, all accredited home care organizations, all nursing homes caring for medical patients and combined nursing homes (medical and psychogeriatric patients) in the Netherlands were approached by telephone with a request to participate in the study.

A total of 488 institutions were approached; 191 agreed to participate: 73 hospitals, 55 home care organizations and 63 nursing homes.

Reasons given for non-participation were: workload; other priorities; being swamped with studies; reorganization; sensitivity of the subject; no interest among nurses; no nurses employed in the organization; participation in other studies; sickness of the manager; research fatigue; a policy on euthanasia was in the making, therefore the organization considered itself not suitable for participation; no or rare experience with requests for euthanasia/physician-assisted suicide, which in a number of cases were related to the philosophical character of an organization and/or the phitosophy of life of the patient population.

Contact persons in the organizations recruited the respondents. The research group held the view that a randomly drawn sample would give a limited response to the study and therefore decided that the research sample should consist only of nurses with experience with euthanasia or physician-assisted suicide.

The inclusion criteria were that respondents:

1) Had more than two years' working experience as a registered nurse;

2) Had more than two years' bedside experience;

3) Were employed for at least $50 \%$ of a full-time working week;

4) Had experienced a request for euthanasia or physician-assisted suicide and/or its administration no more than two years previously.

This last criterion was expected to be critical in the search for a sufficient number of respondents. However, the Dutch study among physicians by Van der Wal and Van der Maas $^{12}$ indicated that, in 1995, 9700 explicit requests for euthanasia or physicianassisted suicide were made known, of which an estimated $3600(37.1 \%)$ were performed.

The contact persons recruited 1509 nurses, who all received a questionnaire. The absolute response rate was $82.0 \%$, and $78.1 \%$ (1179) were suitable for analysis (i.e. questionnaires with at least one section that could be used for analysis).

There was an expected poor recruitment of nurses in nursing homes. Qualified caregivers were therefore recruited in such homes if they worked as team leaders or coordinators.

\section{Data collection}

Data were collected by questionnaire in 2003 . The results of the qualitative study, data from previous studies, and insights from ethics and law, formed the basis of the questionnaire used in this quantitative study.

In order to promote content validity, the questionnaire was presented to a number of experts in the different fields. It was then tested in a pilot study among 106 nurse volunteers. Their response rate was $85 \%$. The research team discussed the outcomes of the questionnaire, adapted it where necessary, and again tested it with three more nurses. 
The final version of the questionnaire was divided into two parts. Part one, the most extensive, concerned euthanasia and physician-assisted suicide. The second part dealt with issues of pain and other symptom control that had as an additional aim the ending of a patient's life. Both parts indicated the types of medical decisions made at the time. In addition to questions on the actual role of nurses in euthanasia and physician-assisted suicide, the participants were also asked for their attitudes regarding that role, including their participation in the reviewing process, their role in the physician's decision-making process, and their involvement in preparatory activities for the administration of euthanatics.

Validity and reliability

Much attention was paid to interpretation of the different types of medical end-of-life decisions by respondents in order to improve the validity of the results. The qualitative study and the pilot study were important in reducing variation in the respondents' interpretation of such decisions in the survey.

Because of the variety of organizations, their national spread, and the large number of nurses involved in this study, the results were considered to be representative of Dutch nurses who have had experience with euthanasia and physician-assisted suicide.

\section{Ethical considerations}

The research ethics committee of the Academic Hospital Maastricht and Maastricht University approved the study.

As the subject was considered to be highly sensitive, participation was promoted by the guarantee of anonymity for both organizations and respondents, and by contact persons as well as respondents receiving a copy of a letter from the Minister of Justice in which participation was recommended and the explicit promise was given that respondents were protected against criminal prosecution if they disclosed information on illegal practices.

\section{Data analysis}

The data were analysed using SPSS version 11.5 for Windows. The questionnaire included a relatively large number of open answer categories and open questions. These answers were recorded in a text file and subsequently numerically coded to allow analysis. They were very helpful for extracting additional data and interpreting the results.

\section{Results}

\section{Characteristics of respondents}

A total of 1179 of the returned questionnaires included at least one section useful for analysis. In almost all the questionnaires (1172) the section on attitudes could be analysed. The largest group of respondents (527) were employed in hospitals, followed by 407 in home care, and 238 in nursing homes.

The demographic characteristics of the respondents are shown in Table 6.1. Most respondents $(87.9 \%)$ were women, with the highest percentage working in home care (92.4\%). Respondents' ages ranged from 21 to 63 years (mean 40.6); and the highest percentage of respondents aged 50 or more worked in home care. The respondents had a mean of 16.5 years' work experience as registered nurses/qualified caregivers, with the longest work experience being in home care (mean 19.4 years).

The inclusion criteria stipulated more than two years' working experience as a registered nurse/qualified caregiver, but 18 respondents (1.5\%) had less than two years' working 
experience. However, the research team decided to include these questionnaires for analysis because of their utility.

Membership of nurses on regional euthanasia review committees

The nurses held diverging opinions about membership of regional euthanasia review committees: $45 \%$ out of the 1172 nurses supported membership of nurses on these committees, $8.9 \%$ were against, and $41.6 \%$ had no opinion about the issue (Table 6.2). Differences between the work sectors were relatively small.

Table 6.1 Demographic characteristics of respondents

\begin{tabular}{lcccc}
\hline Characteristic & $\begin{array}{c}\text { Hospital } \\
\%(\mathbf{n}=\mathbf{5 2 7})\end{array}$ & $\begin{array}{c}\text { Home care } \\
\%(\mathbf{n}=\mathbf{4 0 7})\end{array}$ & $\begin{array}{c}\text { Nursing home } \\
\%(\mathbf{n = 2 3 8})\end{array}$ & $\begin{array}{c}\text { Total } \\
\%(\mathbf{n}=\mathbf{1 1 7 2})\end{array}$ \\
\hline Sex & & & & 85.3 \\
Female & 85.6 & 92.4 & 13.9 & 11.9 \\
Male & 14.4 & 7.6 & 0.8 & 0.2 \\
Unknown & - & - & & \\
Age (years) & & & 17.6 & 18.7 \\
$21-29$ & 25.2 & 10.8 & 61.8 & 59.7 \\
$30-49$ & 58.8 & 59.7 & 20.2 & 21.3 \\
$50-65$ & 15.9 & 29.0 & 1.4 & 0.3 \\
Unknown & - & 0.5 & $40.4(22-61)$ & $40.6(21-63)$ \\
Mean (range) & $38.2(21-59)$ & $43.8(22-63)$ & & 1.5 \\
Working experience (years) & & & 1.7 & 27.0 \\
$<2$ & 1.9 & 1.0 & 29.8 & 45.9 \\
$2-9$ & 35.3 & 14.7 & 45.0 & 24.8 \\
10-24 & 44.4 & 48.4 & 22.7 & 0.7 \\
$\geq 25$ & 18.0 & 34.9 & 0.8 & $16.5(0-41)$ \\
Unknown & 0.4 & 1.0 & $16.2(0-40)$ & \\
Mean (range) & $14.5(0-38)$ & $19.4(1-41)$ & & \\
\hline
\end{tabular}

Table 6.2 Necessity of nurses' membership of regional euthanasia review committees

\begin{tabular}{lcccc}
\hline Response & $\begin{array}{c}\text { Hospital } \\
\%(\mathbf{n}=\mathbf{5 2 7})\end{array}$ & $\begin{array}{c}\text { Home care } \\
\%(\mathrm{n}=\mathbf{4 0 7})\end{array}$ & $\begin{array}{c}\text { Nursing home } \\
\%(\mathrm{n}=\mathbf{2 3 8})\end{array}$ & $\begin{array}{c}\text { Total } \\
\%(\mathbf{n}=\mathbf{1 1 7 2})\end{array}$ \\
\hline Yes & 47.6 & 43.5 & 41.6 & 45.0 \\
No & 8.9 & 8.1 & 10.5 & 8.9 \\
No opinion & 39.7 & 42.5 & 44.2 & 41.6 \\
Unclear & 2.2 & 2.7 & 1.7 & 2.3 \\
Unknown & 1.5 & 3.2 & 2.1 & 2.2 \\
\hline
\end{tabular}

(Adapted from Van Bruchem-van de Scheur et al. ${ }^{10}$ with permission.)

The nurses' responses showed that many of them had insufficient knowledge to discuss the issue adequately. This was confirmed by the answers to another question, for which $35.5 \%$ of nurses did not know what disciplines were represented on regional euthanasia review committees, and $12.5 \%$ had never heard of such representation.

\section{A legal regulation to oblige physicians to consult a nurse}

Almost a quarter (22.6\%) of the nurses approved of the proposal to regulate physicians' obligation to consult a nurse before making their decisions about situations where a nurse is involved in the daily care of the patient (Table 6.3). More than half of the nurses $(58.2 \%)$ found this too far-reaching, while $14.0 \%$ had either an unclear opinion or an opinion with an unclassifiable meaning. The differences between the work sectors were not large. 
Preparatory activities for the administration of euthanatics

A minority $(40.8 \%)$ of nurses stated that inserting an infusion needle to administer euthanatics could be an acceptable nursing task (Table 6.4). A majority (54.1\%) believed that this should not be part of their role. There were considerable differences between home care and nursing homes on one hand, and hospitals on the other.

Almost one third $(31.9 \%)$ of the nurses stated that preparing euthanatics could be an acceptable nursing task, while the majority $(62.9 \%)$ were opposed to this (Table 6.5). Considerable differences existed between nurses working in home care and nursing homes on one hand, and hospitals on the other.

Table 6.3 Necessity for a legal regulation to oblige physicians to consult a nurse in the decisionmaking process

\begin{tabular}{lcccc}
\hline Response & $\begin{array}{c}\text { Hospltal } \\
\%(\mathbf{n}=\mathbf{5 2 7})\end{array}$ & $\begin{array}{c}\text { Home care } \\
\%(\mathbf{n}=\mathbf{4 0 7})\end{array}$ & $\begin{array}{c}\text { Nursing home } \\
\%(\mathbf{n = 2 3 8})\end{array}$ & $\begin{array}{c}\text { Total } \\
\%(\mathbf{n}=1172)\end{array}$ \\
\hline Yes & 26.8 & 18.2 & 21.0 & 22.6 \\
No & 53.5 & 64.4 & 58.3 & 58.2 \\
No opinion & 4.2 & 3.2 & 7.1 & 4.4 \\
Unclear* & 14.8 & 13.5 & 13.0 & 14.0 \\
Unknown & 0.8 & 0.7 & 0.4 & 0.7 \\
\hline
\end{tabular}

Or an opinion with an unclassifiable meaning.

(Adapted from Van Bruchem-van de Scheur et al., ${ }^{10}$ with permission.)

Table 6.4 Inserting an infusion needle to administer euthanatics as a task for nurses

\begin{tabular}{lcccc}
\hline Response & $\begin{array}{c}\text { Hospital } \\
\%(\mathbf{n}=\mathbf{5 2 7})\end{array}$ & $\begin{array}{c}\text { Home care } \\
\%(\mathbf{n}=\mathbf{4 0 7})\end{array}$ & $\begin{array}{c}\text { Nursing home } \\
\%(\mathbf{n}=\mathbf{2 3 8})\end{array}$ & $\begin{array}{c}\text { Total } \\
\%(\mathbf{n}=\mathbf{1 1 7 2})\end{array}$ \\
\hline Yes & 54.8 & 28.0 & 31.5 & 40.8 \\
No & 41.7 & 66.3 & 60.9 & 54.1 \\
No opinion & 0.9 & 3.2 & 6.3 & 2.8 \\
Unknown & 2.5 & 2.5 & 1.3 & 2.3 \\
\hline
\end{tabular}

(Adapted from Van Bruchem-van de Scheur et al., "with permission.)

Table 6.5 Preparing euthanatics as a task for nurses

\begin{tabular}{lcccc}
\hline Response & $\begin{array}{c}\text { Hospital } \\
\%(n=527)\end{array}$ & $\begin{array}{c}\text { Home care } \\
\%(n=407)\end{array}$ & $\begin{array}{c}\text { Nursing home } \\
\%(n=238)\end{array}$ & $\begin{array}{c}\text { Total } \\
\%(n=1172)\end{array}$ \\
\hline Yes & 39.3 & 24.8 & 27.7 & 31.9 \\
No & 55.2 & 71.3 & 65.5 & 62.9 \\
No opinion & 0.9 & 2.2 & 5.5 & 2.3 \\
Unknown & 4.6 & 1.7 & 1.3 & 2.9 \\
\hline
\end{tabular}

(Adapted from Van Bruchem-van de Scheur ot al., ${ }^{10}$ with permission.)

\section{Discussion}

Membership of nurses on regional euthanasia review committees

Although the nurses' professional organizations were promoting the participation of nurses on regional euthanasia review committees, only a minority of those $(45 \%)$ in our study were in favour of such membership. Their associations argued that nurses should be represented on review committees because of their wide experience in observing and supporting patients. Their membership would be an acknowledgement of the fact that nurses observe from close quarters how patients come to their decision to request euthanasia. Nurses are well-trained professionals and their expertise and experience should be used. ${ }^{13}$ This study confirms the view that nurses in general are closely in- 
volved in the provision of care and support for patients requesting euthanasia or physician-assisted suicide. However, the task of regional euthanasia review committees is to consider only the question of whether physicians have followed the due care requirements, and not to evaluate the process of care and support of patients given by nurses. Their evaluation concerns the legal and moral assessment of a medical action, not the 'ethics of care'. Nurses may therefore be involved in such committees but they have no specific tasks in law that would make their presence necessary.

The relatively high percentage $(41.6 \%)$ of nurses with no opinion about nurses' membership of regional euthanasia review committees may therefore show that the issue is of only moderate interest. However, this is probably only one part of the argument because such issues demand close study before a well-considered point of view can be developed. From a perspective of knowledge it is not surprising that these nurses indicated no opinion. Other data from our study showed that nurses in general lack sufficient knowledge on the subject of euthanasia and physician-assisted suicide.

\section{A legal regulation to oblige physicians to consult a nurse}

A majority of the nurses $(58.2 \%)$ did not consider it necessary to make consultation with a nurse a legal requirement for physicians' decision making. These nurses showed that the decision to grant euthanasia or physician-assisted suicide is a medical one and that a line should be drawn between their areas of responsibility and those of physicians. The nurses may have been aware of the heavy responsibility of physicians in this instance and did not want to interfere by formalizing their input in the decision-making process.

However, there are also practical objections to coercing physicians into consulting a nurse. Such legal constructs may become problematic if the situations on which they are to decide constantly change. Problems of interpretation may easily arise, for example, with regard to unsound definitions or differences of opinion on who is the nurse 'involved' and whether he or she should represent only his or her own opinion or also those of other nurses who had taken part in caring for the patient.

Nevertheless, involvement by nurses in the decision-making process is still preferable, as also stated in joint guidelines for physicians and nurses:

when a nurse is involved in the daily care of a patient who made a request for euthanasia, it is highly desirable that the nurse is involved in the decision-making process. Because of her daily involvement and her specific expertise, she could contribute to a careful decision-making by the physician."

Reference to this role is made on the form that physicians are obliged to complete and to send to the regional euthanasia review committee after performing euthanasia or physician-assisted suicide. Physicians are explicitly asked: 'Did you consult the nursing staff/the patient's carers about terminating the patient's life? If so, who did you consult and what was their view? If not, why not?'

Nurses observe and experience patients daily and have contact with relatives. Their contribution may therefore also concern the social and psychological aspects of a request for euthanasia or physician-assisted suicide. Nurses may be able to answer questions such as:

1) Is the patient's request voluntary and well considered?

- Nurses could check whether the request actually originated with the patient himself or herself. Relatives and others may have influenced the patient's feelings and opinions about terminating his or her life. This may happen, for instance, when relatives are no longer able to cope with the situration.

2) Could there be a hidden appeal for help? Reasons could be related to:

- Physical aspects, such as pain, breathlessness, urinary or faecal incontinence, or ulcerating tumours; 
- Mental aspects, such as fear of future suffering, fear of the unknown, depression, confusion;

- Social aspects, such as loneliness, feeling a burden to relatives, quarrelling;

- Spiritual aspects, such as feelings of aimlessness, bitterness, lass of meaning. ${ }^{14}$ By their professional involvement, nurses may provide essential information in the decision-making process that may substantially differ from information held by physicians. Here the Dutch situation differs from that in Belgium, where the legal regulation of euthanasia stipulates that a physician must discuss a patient's euthanasia request with members of the nursing team who are directly involved in caring for the patient. ${ }^{15}$ However, to date no Belgian evaluation data have become available on this issue.

\section{Preparatory activities for the administration of euthanatics}

The majority of nurses stated that inserting an infusion needle $(54.1 \%)$ and preparing euthanatics $(62.9 \%)$ are not part of their tasks. A frequent argument among nurses is about preparatory activities being part of the administration of euthanatics. The underlying idea is that those who carry out the activity should also make the preparations. The fragmentation of tasks could cause confusion about responsibilities. Another explanation could be that nurses consider preparation for the action too emotionally draining, given its ultimate aim.

The percentages obtained for this issue were much lower in hospitals compared with home care organizations and nursing homes. One explanation for this difference may be that preparatory activities are more common nursing activities in hospitals than elsewhere.

One of the due care requirements in the Dutch Euthanasia Act stipulates that physicians carry out termination of life or assist in a suicide, with due medical care. This clarifies that the administration of euthanatics is the exclusive task and responsibility of physicians. Delegation of this task to a nurse is not legal. Nurses who administer euthanatics or assist in a suicide risk both criminal prosecution and disciplinary measures.

Competence with regard to preparatory activities has not been laid down in law. Physicians and nurses have established their views in joint guidelines. ${ }^{9}$ A distinction is made there between various preparatory activities: preparing euthanatics is not considered a task for nurses, but inserting an infusion needle could be a task for nurses.

The guidelines also state that collaboration between physicians and nurses should be transparent: it is recommended that physicians supply a written assignment to nurses in which openness is observed with regard to the intended euthanasia. This gives nurses the opportunity of appealing to conscientious objection if they wish to do so, and/or assessing whether they are able to assist in the euthanasia. Preferably, nurses who carry out preparatory activities have also been involved in the decision making around the euthanasia request. When this is not possible, nurses should be sufficiently previously informed about the patient by physicians.

The insertion of an infusion needle by nurses often seems a pragmatic choice. An inexperienced physician could always ask a pharmacist to dissolve the solution in advance. However, inserting an infusion needle may create serious practical problems to physicians, especially those who are insufficiently skilled in this activity, such as general practitioners in the Dutch health care system. In these cases, nurses may be asked to insert the infusion needle but there are doubts whether this is morally acceptable. It is argued that physicians, and not nurses, should carry out this preparatory activity because of several contentions.

First, euthanasia and physician-assisted suicide do not belong to regular medical practice. Consequently, nurses' activities in this area are not regular practice either, even when they concern only preparatory activities. Such activities have an extraordinary 
moral character that, strictly speaking, falls outside the professional domain of physicians and nurses. Nevertheless, although they may be practiced under certain conditions, they remain the exclusive task and responsibility of physicians.

Second, from the perspective of article 33 in the Individual Health Care Professions Act, ${ }^{16}$ the area of expertise of nurses is deemed to cover: 'performing procedures in the areas of observation, monitoring, nursing and care; [and] on the instructions of an individual health care professional, performing procedures according to the professional's diagnostic and therapeutic work.' ${ }^{\prime 6}$

Because euthanasia and physician-assisted suicide are neither diagnostic nor therapeutic procedures, preparatory activities in this area do not belong to the professional responsibility of nurses.

Third, the national code of ethics for nurses and caregivers, ${ }^{17}$ which describes the moral aspects of professional practice, states that the work of nurses and caregivers aims to promote and maintain health, to prevent illness and disability, to contribute to restoring health, and to relieve suffering and discomfort. This description excludes the ending of life of patients as the work of nurses and other caregivers.

When nurses refuse to insert an infusion needle for this purpose, they can appeal to their professional responsibility with regard to these three points. Nurses have the right to refuse such activities by means of conscientious objection. The Dutch national code of ethics for nurses and caregivers ${ }^{17}$ states that nurses or caregivers may refuse (assistance with) activities if these bring them into serious conflict with their personal philosophy of life or sense of values and norms.

It should be noted that nurses, when requested by physicians, may be competent and are allowed to insert an infusion needle for regular medical indications or interventions. When the same infusion system is later used for administering euthanatics, inserting such infusion needles is not counted as an activity preparatory to euthanasia. The activity of the nurse is not in any sense related to the administration of the euthanatics.

\section{Conclusion}

This article raises new questions concerning the role of nurses in euthanasia and physician-assisted suicide. As no similar studies have been identified in the literature, the results cannot be compared with data from elsewhere.

The findings show differences between work sectors, especially in the issue of preparative activities. This concerns a concrete activity for which skills and work practice influence the attitude of nurses.

With regard to issues such as a legal regulation to oblige physicians to consult a nurse in the decision-making process and the involvement of nurses in regional euthanasia review committees, the differences between the health care work sectors were small and a relatively large number of nurses did not have an opinion on these topics or had an unclear opinion. This is understandable because these issues, especially involvement of nurses in regional euthanasia review committees, are far removed from daily practice and require close study for developing an opinion. Based on our findings it could be suggested that the nurses gave their opinions about specific issues, but they had insufficient knowledge to discuss them adequately, which might have biased the results.

All respondents had experience of requests for euthanasia or physician-assisted suicide and/or its administration. Although not studied, it is conceivable that such practical experience influenced the attitude of the nurses.

The findings also indicated that the nurses hesitated to extend their role into the issues described. The research team did not discern any necessity to extend the role of nurses, 
partly because the professional responsibility of Dutch nurses is laid down by law. However, this does not change the fact that nurses could have an important role in the various stages of the processes of euthanasia and physician-assisted suicide.

Discussion of the three issues may have relevance for a wider audience than in the Netherlands. It may help nurses in other countries where these issues may become legalized to define their role in euthanasia and physician-assisted suicide.

\section{References}

1. De Haan J. The new Dutch law on euthanasia. Med Law Rev 2002; 10: 57-75.

2. Verpoort C, Gastmans C, De Bal N, Dierckx de Casterlé B. Nurses' attitudes to euthanasia: a review of the literature. Nurs Ethics 2004; 11: 349-65.

3. The A-M. 'Vanavond om 8 uur ...' Verpleegkundige dilemma's bil euthanasie en andere beslissingen rond het levenseinde. ('Tonight at eight o'clock ...' Nurses' dilemmas with euthanasia and other end-of-life decisions.) Houten/Diegem: Bohn Stafleu Van Loghum, 1997 (in Dutch).

4. Ryynänen $O-P$, Myllykangas $M$, Viren $M$, Heino $H$. Attitudes towards euthanasia among physicians, nurses and the general public in Finland. Public Health 2002; 116: 322-31.

5. Verpoort C, Gastmans C, Dierckx de Casterlé B. Palliative care nurses' views on euthanasia $J$ Adv Nurs 2004; 47: 592-600.

6. Dierckx de Casterlé B, Verpoort C, De Bal N, Gastmans C. Nurses' views on their involvement in euthanasia: a qualitative study in Flanders (Belgium). J Med Ethics; 2006; 32: 187-92.

7. Berghs $M$, Dierckx de Casterlé $B$, Gastmans $C$. The complexity of nurses' attitudes toward euthanasia: a review of the literature. J Med Ethics 2005; 31: 441-46.

8. Van de Scheur $A$, van der Arend $A$. The role of nurses in euthanasia: a Dutch study. Nurs Ethics 1998; 5: 497-508.

9. AVVV (General Association of Nurses and Caretakers), NU'91 (New Union'91), KNMG (Royal Dutch Medical Association). Handreiking voor Samenwerking Artsen, Verpleegkundigen en Verzorgenden bij Euthanasie. (Directive for collaboration by physicians, nurses, and caretakers in euthanasia.) Fourth edition. Utrecht: AVVV/NU'91/KNMG, 2006 (in Dutch).

10. Van Bruchem-van de Scheur $A$, van der Arend $A$, Spreeuwenberg $C$, van Wijmen $F$, ter Meulen $R$. De rol van verpleegkundigen bij medische beslissingen rond het levenseinde. Verslag van een landelijk onderzoek naar betrokkenheid en praktijken. (The role of nurses in medical end-of-life decisions. Report of a national study into involvement and practices.) Utrecht: Uitgeverij De Tijdstroom, 2004 (in Dutch).

11. Van Bruchem-van de Scheur GG, van der Arend AJG, Spreeuwenberg C, Huijer Abu-Saad H, ter Meulen RHJ. Euthanasia and physician-assisted suicide in the Dutch homecare sector: the role of the district nurse. J Adv Nurs 2007; 58: 44-52.

12. Van der Wal G, van der Maas PJ. Euthanasie en andere medische besissingen rond het levenseinde: de praktijk en de meldingsprocedure. (Euthanasla and other medical end-oflife decisions: practice and the notification procedure.) Den Haag: Sdu, 1996 (in Dutch).

13. LCVV. (National Centre for Nursing and Care.) Verpleegkundigen in regionale toetsingscommissies voor euthanasie. Standpunt LCVV. (Nurses in regional review committees for euthanasia. Point of view LCVV.) Utrecht: LCVV, 1998 (in Dutch).

14. Van Bruchem-van de Scheur A. Professional responsibility at the end of life. Euthanasia and palliative care. In: Cusveller B, Sutton A, O'Mathúna D eds. Commitment and responsibiity in nursing: a faith-based approach. Sloux Center, IA: Dordt College Press, 2004: 11126.

15. Gastmans $C$, van Neste F, Schotsmans $P$. Facing requests for euthanasia: a clinical practice guideline. J Med Ethics 2004; 30: 212-17. 
80 | Chapter 6

16. The Individual Health Care Professions Act. Den Haag: Ministerie van Volksgezondheid, Welzijn en Sport, 2001. Retrieved 3 October, 2007, from: http://www.minvws.nl/images/bigeng_tcm20-108338.pdf

17. V\&VN (Nurses \& Caregivers Netherlands), NU'91 (New Union'91). Nationale Beroepscode van Verpleegkundigen en Verzorgenden. (National code of ethics for nurses and caregivers.) Hilversum: Van der Weij Drukkerijen BV, 2007 (in Dutch). 


\title{
Chapter 7
}

\section{Alleviation of pain and symptoms with a life-shortening intention}

\begin{abstract}
This article reports the findings of a study into the role of Dutch nurses in the alleviation of pain and symptoms with a life-shortening intention, conducted as part of a study into the role of nurses in medical end-of-life decisions. A questionnaire survey was carried out using a population of 1509 nurses who were employed in hospitals, home care organizations and nursing homes. The response rate was $82.0 \% ; 78.1 \%(1179)$ were suitable for analysis. The results show that in about half of the cases (55.8\%) nurses were involved in the decision making by the physician and that nurses were frequently $(81.5 \%)$ involved in administering the medication. The authors' conclusion is that alleviation of pain and symptoms with a life-shortening intention represents a 'grey' area, in which physicians and nurses act on the basis of personal ethical norms rather than legal rules, professional guidelines or shared moral values.
\end{abstract}

\footnotetext{
"The text of this chapter has been published as: GG van Bruchem-van de Scheur, AJG van der Arend, H Huijer Abu-Saad, FCB van Wijmen, C Spreeuwenberg \& RHJ ter Meulen (2008). Alleviation of pain and symptoms with a life-shortening intention. Nursing Ethics, 15, 682-695.
} 


\section{Introduction: conceptual issues}

In the last stage of life it is not uncommon to intensify the treatment of pain and other symptoms with the purpose of relieving further suffering. The shortening of life is possible and justifiable because the administration of drugs is not intended to cause death but to increase the alleviation of symptoms. In this article, we defined this as 'alleviation of pain and symptoms (APS) without a life-shortening intention'. However, APS may have the purpose of shortening the life of a patient as part of the overall goal of treatment. In these cases death is not only the effect but also the intention of treatment. We focus on this type of medical end-of-life decision and define this as 'APS with a life-shortening intention'.

Euthanasia and physician-assisted suicide are mentioned in this article. Euthanasia means the administration of drugs with the explicit intention of ending the patient's life at his or her unequivocal request, and physician-assisted suicide is the prescribing or supplying of drugs to enable a patient to end his or her own life, also with explicit intent.

The differences between euthanasia, physician-assisted suicide and APS with a lifeshortening intention are, first, in cases of euthanasia/physician-assisted suicide the patient has made an explicit request to end his or her life. Such a request is not always present in cases of APS with a life-shortening intention. Second, in the Netherlands physicians are legally obliged to report cases of euthanasia or physician-assisted suicide to a regional euthanasia review committee. On the basis of reports and submitted documents, the committee assesses whether the physician has complied with the due care requirements according to law. APS is usually subsumed under 'pain alleviation' and has no procedural or legal consequences for the physicians involved. This situation is debatable because APS with a life-shortening intention is a way of actively terminating life and should be dealt with as such by the medical and/or legal system.

\section{Literature review}

A literature search (using MEDLINE and PubMed) was carried out using the key phrase 'medical end-of-life decisions' followed by study of the published references retrieved.

APS that has a potential life-shortening effect has been frequently reported as a medical end-of-life decision. ${ }^{1-9}$ The proportion of deaths noted in one article to be preceded by such a decision varied from $19 \%$ of all deaths in Italy to $26 \%$ in Denmark. ${ }^{1}$

In several studies ${ }^{2-7,9}$ on APS with a potential life-shortening effect, two intentions were distinguished: without life-shortening intention and with life-shortening intention. In the majority of cases, APS did not have a life-shortening intention. In a European study by Bilsen et al., ${ }^{6}$ for example, the prevalence varied from $18 \%$ of all deaths in Italy to $24 \%$ in Denmark (very similar to the data already cited above ${ }^{1}$ ). In only a minority of cases did APS have a life-shortening intention, with prevalence varying from $0.4 \%$ of all deaths in Sweden to $2.9 \%$ in Belgium. ${ }^{6}$ In the Netherlands, the country of our study, the most recent report ${ }^{9}$ indicated that $25 \%$ of all deaths were preceded by APS with a potential lifeshortening effect, of which $1 \%$ had a life-shortening intention.

APS with a potential life-shortening effect has been investigated mainly within the medical profession. Studies among physicians have been conducted to determine the incidence and characteristics of medical end-of-life decisions including APS with a potential life-shortening effect. ${ }^{1-9}$ As these studies focused on the role of physicians, they provided only marginal information about the role of nurses. Some studies ${ }^{2,4,5,7}$ described 
whether or nol decisions were discussed with nursing staff. Bilsen et al. ${ }^{7}$ described the role of nurses in APS with and without a life-shorlening intention for both competent and incompetent patients. For example, in cases of APS with a life-shortening intention, in 2001 physicians consulted nurses in $80 \%$ of cases concerning competent patients. ${ }^{7}$

Other reports describe the role of nurses less explicitly. In the study by Van der Heide ot al. ${ }^{1}$ the role of nurses is related to six types of medical end-of-life decisions, which include APS with a potential life-shortening effect. In Bilsen et al.'s ${ }^{6}$ study the role of nurses is not quite clear; they described the role of caregivers in the decision making about APS with and without a life-shortening intention, but did not specify whether and how nurses were involved.

Our study focused on research on patients of legal age (18 years and older); published reports on minors were not considered. The research, which was commissioned by the Dutch Health Minister. was designed to investigate the role of nurses in medical end-oflife decisions in hospitals, home care and nursing homes. We have already presented our results in an extensive roport (in Dutch) to the Minister. ${ }^{10}$

The reason for including the use of APS with a life-shortening intention was that much uncertainty exists with regard to the role of nurses in this medical end-of-life decision. It is likely that many nurses are confronted and even involved in this act, thus it was thought appropriate to research their role in these decisions.

In this article we have selected the study outcomes regarding the role of nurses in APS with a life-shortening intention. It should be noted that the cases described here concern APS with a lifo-shortoning intention according to murses. It is uncertain whether the ending of lifa was indeod intended by the physicians because their professional interpretations were nol available.

\section{Methods}

\section{Aim}

The aim of the whole study was to investigate the role, perceptions, responsibilities and problems of nurses in modical ond-of-life decisions in order to advise the Dutch government on legislation and policy making concerning the role of nurses.

This article concerns a small part of this aim, namely the role of nurses in medical endof-life decisions about APS with a life-shortening intention.

\section{Design}

The role of nurses in medical and ofmlife decisions in Dutch hospitals, home care organizations and nursing homes was investigated both quallatively and quantitatively. The data presented hero are part of the quantitative study, therefore the methodological description concerns this part of the study only.

\section{Recruitment of respondents}

All general and academic hospitals, accredited home care organizations, nursing homes caring for medical pationts and combined nursing homes (medical and psychogeriatric patients) in the Netherlands were invited by telephone to participate in the study. Of 488 locations, 191 (39.1\%) agread to participale: 73 hospitals, 55 home care organlzations, and 63 nursing homes. Contact persons al each location recruited the respondents. The inclusion criteria were that they:

- Had more than iwo years' working experience as a registered nurse;

- Had more than two yours' bodside experience:

- Wero amployed for at least $50 \%$ of a full-time working week; 
- Had experienced a request for euthanasia or physician-assisted suicide and/or its administration no more than two years previously.

This last criterion was included because the main study was commissioned to research the role of nurses in euthanasia and physician-assisted suicide. The expectation was that a number of the respondents who had experienced a request for euthanasia/physician-assisted suicide had also been involved in APS with a life-shortening intention.

As a result of the last inclusion criterion, the reasons given for non-participation were partly related to euthanasia/physician-assisted suicide; for example, that they had received none or only a few requests for euthanasia/physician-assisted suicide. Other reasons were: workload; other priorities; too many studies; reorganization; no interest among nurses; no nurses employed in the organization; participation in other studies; sickness of the manager; and 'research tiredness'.

Because of an expected low recruitment of nurses in nursing homes, qualified caregivers in such homes were included if they worked as team leaders or coordinators.

The contact persons recruited a total of 1509 nurses/caregivers, who all received a questionnaire. The absolute response rate was $82.0 \%, 78.1 \%(1179)$ of which was suitable for analysis (i.e. the percentage of questionnaires containing at least one section suitable for analysis). In 330 of 1179 questionnaires $(28 \%)$ we were able to analyse the section concerning APS with a life-shortening intention.

\section{Data collection}

The questionnaire data were collected in 2003. The results of a qualitative preliminary study, together with data from previous studies and insights from ethics and law, formed the basis of this questionnaire.

To promote content validity, the questionnaire was checked by experts with respect to its construction and content, and to the statistics employed. It was then pilot tested with a group of 106 nurse volunteers (response rate $85 \%$ ). The research team discussed the outcomes, adapted the questionnaire where necessary, and again tested it with three more nurses. In the final version, the second part concerned APS with a life-shortening intention, commencing by describing the type of medical decision at hand.

The section on APS with a life-shortening intention contained 54 questions. Because of the complexity of the subject matter, and in order to minimize the number of socially desirable answers, we included a relatively large number of structured questions $(n=38)$ to which an open answer category was added, together with six open questions and 10 closed questions.

The participants were asked to place their responses within the context of their most recent experience of APS with a life-shortening intention within the previous two years (2001-2003).

Respondents were guided through the questionnaire, avoiding sections that were irrelevant owing to previous responses. This explains the disparity in the numbers of nurses responding to various items, as indicated in the 'Results' section; for example, 'the decision making' begins with 330 cases and ends with 32 .

\section{Validity and reliability}

Content validity of the questionnaire was promoted to a large degree by the preliminary qualitative study, by the pilot study and by approval of the questionnaire by a number of experts in this field.

Retrospective data can contribute to information bias. Thus, to avoid respondents selecting cases with a high emotional impact or with many other problems, they were asked to 
base their responses on the most recent case, that is, occurring within the previous two years.

The promise of anonymity and protection from criminal prosecution (see below) may have contributed to the respondents' honest answers. They frequently provided very sensitive information, which would possibly not have been mentioned if there had been any fear of criminal proceedings.

To improve the validity of the results, in the data analysis much attention was paid to the respondents' interpretations of medical decisions on APS with a life-shortening intention. When there was doubt about interpreting cases or coding, the researcher consulted one or more members of the research team.

\section{Ethical considerations}

The research ethics committee of the Academic Hospital Maastricht and Maastricht University approved the study.

As the subject was considered to be highly sensitive, participation was promoted by guaranteeing anonymity to organizations and respondents. Both contact persons and respondents received a copy of a letter from the Minister of Justice, in which participation was recommended and the explicit promise was given that all respondents would be protected against criminal prosecution if they should disclose information about illegal practices.

\section{Data analysis}

The data were analysed using SPSS version 11.5 for Windows. Responses to the relatively large number of structured questions with open answer categories and open questions were recorded in a text file and analysed in accordance with the principles of the grounded theory approach. ${ }^{11}$ Subsequently, responses or clusters of responses were coded numerically to allow analysis. These were very helpful for extracting additional data and interpreting the results. In the 'Results' section we have included a number of quotations from the material.

During processing and analysis of the data and describing the results, a statistician from Maastricht University was consulted several times. The questionnaire was not tested statistically. Descriptive statistics were used to present the role of nurses in APS with a life-shortening intention.

\section{Results}

\section{Respondents' characteristics}

A total of 330 cases of APS with a life-shortening intention were analysed. The respondents' demographic characteristics are shown in Table 7.1. Their ages ranged from 21 to 62 years (mean 39.6). Most $(88.5 \%$ ) were women. All respondents were registered nurses or qualified caregivers with a mean of 15.3 years' work experience. The inclusion criteria stipulated more than two years' work experience, but four of $330(1.2 \%)$ respondents had worked in nursing for less than two years. However, the research team decided to include these four questionnaires for analysis because of their utility.

\section{Patients' characteristics}

The cases the respondents described mainly concerned patients who were in the final stage of their disease; 309 of the 330 patients (93.6\%) were terminally ill and $14(4.2 \%)$ were not. In seven cases $(2.1 \%)$ the participants did not answer the question. The con- 
cept 'terminal' was not further specified because these results represent perceptions. Other patients' characteristics are shown in Table 7.2.

Table 7.1 Respondents' characteristics

\begin{tabular}{|c|c|c|c|c|}
\hline Characteristic & $\begin{array}{l}\text { Hospital: } \\
\%(n o .) \\
(n=155)\end{array}$ & $\begin{array}{c}\text { Home care: } \\
\% \text { (no.) } \\
(n=131)\end{array}$ & $\begin{array}{c}\text { Nursing home: } \\
\% \text { (no.) } \\
(n=44)\end{array}$ & $\begin{array}{c}\text { Total: } \\
\%(\text { no. }) \\
(n=330)\end{array}$ \\
\hline \multicolumn{5}{|l|}{$\overline{\operatorname{Sex}}$} \\
\hline Female & $83.9(130)$ & $93.9(123)$ & $88.6(39)$ & $88.5(292)$ \\
\hline Male & $16.1(25)$ & $6.1(8)$ & $11.4(5)$ & $11.5(38)$ \\
\hline \multicolumn{5}{|l|}{ Age (years) } \\
\hline $21-29$ & $29.7(46)$ & $10.7(14)$ & $29.5(13)$ & $22.1(73)$ \\
\hline $30-49$ & $60.0(93)$ & $64.1(84)$ & $56.8(25)$ & $61.2(202)$ \\
\hline $50-65$ & $10.3(16)$ & $25.2(33)$ & $13.6(6)$ & $16.7(55)$ \\
\hline Mean (range) & $37.4(21-57)$ & $43.2(22-62)$ & $36.4(23-56)$ & $39.6(21-62)$ \\
\hline \multicolumn{5}{|c|}{ Work experience (years) } \\
\hline$<2$ & $1.3(2)$ & $1.5(2)$ & - & $1.2(4)$ \\
\hline $2-9$ & $41.3(64)$ & $14.5(19)$ & $59.1(26)$ & $33.0(109)$ \\
\hline $10-24$ & $47.1(73)$ & $53.4(70)$ & $34.1(15)$ & $47.9(158)$ \\
\hline$>25$ & $10.3(16)$ & $29.8(39)$ & $6.8(3)$ & $17.6(58)$ \\
\hline Unknown & - & $0.8(1)$ & - & $0.3(1)$ \\
\hline Mean (range) & $13.8(1-37)$ & $18.4(1-39)$ & $11.1(2-32)$ & $15.3(1-39)$ \\
\hline
\end{tabular}

(Adapled from Van Bruchem-van de Scheur et al., ${ }^{10}$ with permission.)

Table 7.2 Patients' characteristics

\begin{tabular}{|c|c|c|c|c|}
\hline Characteristic & $\begin{array}{c}\text { Hospital: } \\
\% \text { (no.) } \\
(n=155)\end{array}$ & $\begin{array}{c}\text { Home care: } \\
\% \text { (no.) } \\
(n=131)\end{array}$ & $\begin{array}{c}\text { Nursing home: } \\
\% \text { (no.) } \\
(n=44)\end{array}$ & $\begin{array}{c}\text { Total: } \\
\%(\text { no. }) \\
(n=330)\end{array}$ \\
\hline \multicolumn{5}{|l|}{$\overline{\operatorname{Sex}}$} \\
\hline Male & $48.4(75)$ & $49.6(65)$ & $45.5(20)$ & $48.5(160)$ \\
\hline Female & $51.6(80)$ & $49.6(65)$ & $54.5(24)$ & $51.2(169)$ \\
\hline Unknown & - & $0.8(1)$ & - & $0,3(1)$ \\
\hline \multicolumn{5}{|l|}{ Age (years) } \\
\hline $30-64$ & $36.8(57)$ & $43.5(57)$ & $18.2(8)$ & $37.0(122)$ \\
\hline $65-79$ & $43.9(68)$ & $40.5(53)$ & $36.4(16)$ & $41.6(137)$ \\
\hline$>80$ & $17.4(27)$ & $15.3(20)$ & $45.5(20)$ & $20.3(67)$ \\
\hline Unknown & $1.9(3)$ & $0.8(1)$ & - & $1.2(4)$ \\
\hline \multicolumn{5}{|l|}{ Diagnosis } \\
\hline Cancer $^{a}$ & $67.1(104)$ & $95.4(125)$ & $56.8(25)$ & $77.0(254)$ \\
\hline Cardiovascular $^{b}$ disease & $12.9(20)$ & $1.5(2)$ & $11.4(5)$ & $8.2(27)$ \\
\hline $\begin{array}{l}\text { Chronic obstructive pulmonary } \\
\text { disease }\end{array}$ & $7.1(11)$ & $0.8(1)$ & $2.3(1)$ & $4.0(13)$ \\
\hline Other ${ }^{\mathrm{e}}$ & $6.5(10)$ & $2.3(3)$ & $27.3(12)$ & $7.6(25)$ \\
\hline Unknown & $6.5(10)$ & - & $2.3(1)$ & $3,4(11)$ \\
\hline
\end{tabular}

Includes cancer in combination with another diagnosis.

'Includes cerebrovescular disease.

Includes combined diagnoses with the exception of cancer.

(Adapted from Van Bruchem-van de Scheur et al., ${ }^{10}$ with permission.)

APS with a life-shortening intention was more frequent among the female than the male patients, although the difference was small. It occurred most frequently in patients aged under 80 years, and was practised most often on those with cancer $(77.0 \%)$; the lowest frequency was in nursing homes and the highest in home care. 
In explaining such differences, prudence is necessary for two reasons: differences in numbers of respondents between hospitals/home care organizations and nursing homes, and doubts about whether or not the contact persons specifically recruited among nurses who had experience of nursing cancer patients.

Reasons for deciding on APS with a life-shortening intention

The participants introduced 330 cases that, in their opinion, concerned APS with a lifeshortening intention. The six most frequently mentioned reasons for this type of end-oflife decision are presented in Table 7.3.

Table 7.3 The six most frequently mentioned reasons for APS with a life-shortening intention

\begin{tabular}{|c|c|c|c|c|}
\hline Reason & $\begin{array}{l}\text { Hospital: } \\
\% \text { (no.) } \\
(n=155)\end{array}$ & $\begin{array}{c}\text { Home care: } \\
\% \text { (no.) } \\
(n=131)\end{array}$ & $\begin{array}{c}\text { Nursing home: } \\
\% \text { (no.) } \\
(n=44)\end{array}$ & $\begin{array}{c}\text { Total: } \\
\% \text { (no.) } \\
(n=330)\end{array}$ \\
\hline Requested by patient & $29.0(45)$ & $34.4(45)$ & $31.8(14)$ & $31.5(104)$ \\
\hline Requested by both patient and relatives & $12.9(20)$ & $13.7(18)$ & $13.6(6)$ & $13.3(44)$ \\
\hline $\begin{array}{l}\text { Patient had expressed a wish for this in the } \\
\text { past }\end{array}$ & $5.2(8)$ & $15.3(20)$ & $9.1(4)$ & $9.7(32)$ \\
\hline $\begin{array}{l}\text { Patient had expressed a wish for this in the } \\
\text { past, combined with a request from relatives }\end{array}$ & $18.7(29)$ & $12.9(17)$ & $13.6(6)$ & $15.7(52)$ \\
\hline Requested by relatives & $10.3(16)$ & $9.2(12)$ & $6.8(3)$ & $9.4(31)$ \\
\hline $\begin{array}{l}\text { Request for euthanasia/physician-assisted } \\
\text { sulcide refused }\end{array}$ & $17.4(27)$ & $9.9(13)$ & $20.5(9)$ & $14.8(49)$ \\
\hline
\end{tabular}

In 104 of 330 cases $(31.5 \%)$, the patient had made an actual request to hasten the end of his or her life. In $32(9.7 \%)$, patients had expressed a wish in the past and spoken about a situation in the future in which they did not want to live any longer. In $31(9.4 \%)$, relatives requested hastening of the patient's death; in 27 of these cases $(87.1 \%)$ the patient had either only moderate or no communication.

In 49 cases $(14.8 \%)$ the decision about APS with a life-shortening intention was preceded by a request for euthanasia/physician-assisted suicide that had not been granted by the physician. Although such requests also concerned patients $(51 \%)$ and/or relatives $(69.4 \%)$, such a refusal was regarded as a separate reason for deciding to administer APS with life-shortening intent.

It can be shown that, in about half (48.8\%) of the 330 cases, relatives requested to hasten the patients' death or made remarks to this effect. The participants described a great variety of utterances of relatives, about which some reasons were given with regard to the 'why?' of their request.

The relatives believed that the patient had pain or suffered otherwise:

[The family] indicated that they wanted to prevent their mother from suffering any longer. They no longer recognized their mother. She has always been an independent woman, now she is a pitiful scrap of humanity, according to the family, (hospital)

The son found it hard to see his mother wasting away in this way and having so much pain. When morphine was started, he said: 'Thank goodness, I hope that it will not take much longer because I cannot bear to watch this.' (nursing home)

The relatives found that dying took too long:

It was more the children. They had three weeks' holiday, lived elsewhere, and hoped that their father [would die] before they had to start working again. (home care) 
The family wondered how long it would last before the patient would die. They had been called already a number of times because it was thought that the patient would die. (hospital)

The relatives had feelings of powerlessness; they could not bear to watch the situation any longer and sometimes they were at the end of their resources:

We find it terrible to see our mother suffering this way. (nursing home)

The sorrow was for the relatives almost as unbearable as for the patient. They found it hard to see their father suffering this way. (hospital)

\section{The decision making}

When a physician considered APS with a life-shortening intention, consultation with nurses was more frequent in hospitals and nursing homes than in home care (Table 7.4). In 254 of 330 cases $(77.0 \%)$ the respondents had agreed with the physician's decision for APS with a life-shortening intention. The three most frequently mentioned arguments for agreement were:

- The hopelessness of the situation (68.1\%);

- The importance of fulfilling the patient's dying wish $(45.7 \%)$;

- The patient's life had become meaningless (29.5\%).

In 76 cases $(23.0 \%)$, the participants had either disagreed with or had doubts about the physician's decision. The three most frequently mentioned reasons for either disagreement or doubt were:

- Relatives exerted undue influence on the physician (42.1\%);

- Absence of the patient's verbal request and/or written statement $(28.9 \%)$;

- Absence of pain and/or other symptoms (27.6\%).

In 45 of these 76 cases $(59.2 \%$ ), those who disagreed with or had doubts about the decision discussed the case with the physician. In 30 cases $(39.5 \%)$ this did not take place, and one respondent did not answer the question. When the respondents who disagreed or had doubts discussed the case with the physician $(n=32)$, in the majority of cases $(71.9 \%)$ the physician showed sympathy and/or clarified the decision. In eight cases $(25.0 \%)$, the physician showed no sympathy and/or gave an unsatisfactory response, which nurses described as:

The physician assessed it purely medically; the patient would die anyway; when that would happen more rapidly, it would still not make a difference. (hospital)

[The physician] found my opinion nonsense; the patient was terminally ill after all. (hospital)

\section{Administering the medication}

In at least 90 of the 330 cases $(27.3 \%$ ), the physician did not inform nurses about the aim of the medication (i.e. to hasten the patient's death). In 25 of these cases (27.8\%), the respondents were informed by the patient and/or relatives; this mainly took place in home care. In 49 cases (54.4\%) the participants discovered the aim of the medication by noticing that the dosage was increased without pain or other symptoms.

In a majority of cases $(66.1 \%)$, the participants administered the medication, especially in hospitals and nursing homes (Table 7.5 ). In 49 cases $(14.8 \%$ ) the physician administered the medication, more frequently in home care. In 41 cases $(12.4 \%)$ both the physician and the participants administered the medication, especially in home care.

In 190 of 330 cases $(57.6 \%$ ) all involved respondents were willing to administer the medication. Despite this willingness, some had difficulties with the physician's policy, which they described: 
Everyone had doubts but did administer the medication, also because the family desired this. (hospital)

Everyone was willing to administer the medication but some, including myself, had conscientious objections. (home care)

In 62 cases (18.8\%) the respondents had divided opinions about the physician's prescription; some were not willing to administer the medication, but some were. In general, they respected each other's point of view and the medication was administered by nurses who agreed with the physician.

Table 7.4 Physician-nurse/caregiver consultation about APS with a life-shortening intention

\begin{tabular}{lcccc}
\hline & Hospital: & Home care: & Nursing home: & Total: \\
& $\%($ no.) & $\%($ no.) & $\%(n o)$. & $\%($ no.) \\
& $(n=155)$ & $(n=131)$ & $(n=44)$ & $(n=330)$ \\
\hline Physician-nurse/caregiver consultation & $62.6(97)$ & $44.3(58)$ & $65.9(29)$ & $55.8(184)$ \\
No physician-nurse/caregiver consultation & $27.7(43)$ & $48.9(64)$ & $18.2(8)$ & $34.8(115)$ \\
Unknown & $9.7(15)$ & $6.9(9)$ & $15.9(7)$ & $9.4(31)$ \\
\hline (Adapted from Van Bruchem-van de Scheur et al. ${ }^{\text {Tot }}$ with permission.)
\end{tabular}

Table 7.5 Persons who administered the medication

\begin{tabular}{|c|c|c|c|c|}
\hline & $\begin{array}{l}\text { Hospital: } \\
\% \text { (no.) } \\
(n=155)\end{array}$ & $\begin{array}{l}\text { Home care: } \\
\% \text { (no.) } \\
(n=131)\end{array}$ & $\begin{array}{l}\text { Nursing home: } \\
\% \text { (no.) } \\
(n=44)\end{array}$ & $\begin{array}{c}\text { Total: } \\
\% \text { (no.) } \\
(n=330)\end{array}$ \\
\hline Nurse/careglver & $86.5(134)$ & $35.1(46)$ & $86.4(38)$ & $66.1(218)$ \\
\hline Physiclan & $6.5(10)$ & $29.8(39)$ & - & $14.8(49)$ \\
\hline Physician and nurse/caregiver & $5.2(8)$ & $20.6(27)$ & $13.6(6)$ & $12.4(41)$ \\
\hline Relatives & $0.6(1)$ & $4.6(6)$ & - & $2.1(7)$ \\
\hline Physician, nurse/caregiver and relatives & - & $3.8(5)$ & - & $1.5(5)$ \\
\hline Nurse/caregiver and relatives & - & $3.8(5)$ & - & $1.5(5)$ \\
\hline Other/unknown & $1.3(2)$ & $2.3(3)$ & - & $1.5(5)$ \\
\hline
\end{tabular}

(Adapted from Van Bruchem-van de Scheur et al., "with permission.)

\section{Discussion}

\section{Methodological aspects}

APS with a life-shortening intention is a sensitive and complex issue to study quantitatively. It is difficult to obtain insight into the reasons or motives for nurses' ways of acting by such an approach. The inclusion of a number of open answer categories and also open questions appeared to be a meaningful measure with regard to interpretation of the results,

Although only recent cases were included, bias may have occurred because of the retrospective character of the data.

Our findings are based on information provided by nurses and qualified caregivers, which indicated the occurrence of APS with a life-shortening intention. We cannot exclude the possibility that nurses and caregivers could have interpreted a case differently compared with physicians, especially when insufficient consultation took place between them and physicians.

Because of the large number of organizations nationwide, the number of nurses and caregivers involved in the study, and many recent high-quality cases, the results may be regarded as representative of Dutch nurses and caregivers who have experienced APS with a life-shortening intention. Although the cases were introduced by a subgroup of the 
population of participants with experience of euthanasia and/or physician-assisted suicide, there is no reason to believe that research with another (sub)population would lead to a different conclusion.

Reasons for deciding on APS with a life-shortening intention

The results show that in about half of the 330 cases mentioned $(48.8 \%)$ relatives requested to hasten the patient's death or made remarks to that effect. The involvement of relatives also became apparent in studies by Deliens et al. ${ }^{4}$ and Bilsen et al.., which indicates that explicit requests for APS with a potential life-shortening effect were made by close(st) relative(s) in $21 \%$ of 332 cases and $20.5 \%$ of 188 cases respectively. However, in comparing results, prudence is required because in both these studies the role of relatives was based on APS in which shortening life was not intended or only partly or additionally intended. In the present study, according to the participants, a life-shortening effect was intended in all cases.

In a number of cases relatives regarded themselves responsible for taking care of the patient's interests, particularly when the patient had communication difficulties. It is hard to determine to what extent the interests of patients and relatives coincide. Sometimes relatives had their own practical interest, for instance, if they wanted to resume their daily work.

The severity of relatives' situation should not be underestimated. They usually have emotional bonds with the patient and experience an intensive period of distress with regard to the future loss of a dear one. The deathbed, however, could be a helpful period for relatives. Looking forward to the end of life may also be part of the mourning process. With regard to the reasons for APS with a life-shortening intention, it is remarkable that $14.8 \%$ of the cases were preceded by a refused request for euthanasia or physicianassisted suicide. The decision to shorten the life of a patient under the guise of APS could be the result of several facets of the situation, such as fear that reporting the case as euthanasia or physician-assisted suicide would result in prosecution.

\section{The decision making}

During the decision-making process before instituting APS with a life-shortening intention, there was consultation between physician and nurse or caregiver in over half of the cases $(55.8 \%)$. This is considerably higher than in the Dutch study by Van der Wal and Van der Maas, ${ }^{12}$ who conducted a study into the practice of euthanasia and other medical end-of-life decisions, and into the notification procedure for euthanasia. Their study indicates that nurses in 1995 had a role in decision making about APS with a lifeshortening intention in $34 \%$ of cases. In addition, in Belgium there is increased involvement of nurses in the decision making. Bilsen et al. ${ }^{7}$ indicated that, in decision making about APS with a life-shortening intention, nurses were more often consulted in 2001 than in 1998 for both competent ( $80 \%$ versus $46 \%$ ) and incompetent ( $72 \%$ versus $49 \%$ ) patients.

In cases of APS without a life-shortening intention, which belongs to normal medical practice, physicians will generally ask nurses to administer the medication without involving them in the decision making. In contrast, APS with a life-shortening intention does not belong to normal medical practice. In such cases, although they have no obligation, it is desirable that physicians should consult nurses and caregivers during the decisionmaking process, especially when physicians involve them in administering the medication, because this could mean drawing them into a criminal act.

Our study indicated that in $23.0 \%$ of cases the participants disagreed with or had doubts about a physician's decision. Their objections indicated that they considered these activities unprofessional. They mentioned concrete items such as the influence of relatives on 
the physician, and the disproportionate medication dosage in relation to observed pain and/or other symptoms.

When the respondents discussed their differences of opinion or doubts with physicians, the physicians could at times respond in a disagreeable way. It is possible that the physicians felt upbraided and recognized their vulnerable position. The harmful consequences of becoming a whistleblower could prevent nurses and caregivers from discussing the situation higher up in the hierarchy of the organization, for instance with management personnel and/or ethics committees.

When participants agreed with a physician's decision $(77.0 \%)$, this was often because of a certain empathy with the patient. Patients' wishes about their own end of life served as a guideline for the nurses and caregivers, and they defined patients' situations as hopeless and meaningless.

Although not documented in our study, it is also conceivable that relatives can influence the opinion of nurses. In her anthropological study on nurses' dilemmas with euthanasia and other end-of-life decisions, The ${ }^{13}$ described familial pressures as a non-transparent, difficult and regularly occurring phenomenon around the bed of dying patients.

It is important to recognize that nurses are closely involved in patients' situation and relatives' sorrow. This can heighten emotions and feelings of impotence that could change an objective view into a subjective one.

\section{Administering the medication}

It is unknown why, in a number of cases $(27.3 \%)$, physicians did not discuss the intention of the treatment (i.e. to hasten the patient's death) with the respondents. Probably, the illegal character of APS with a life-shortening intention does not contribute to openness. Nurses were frequently $(81.5 \%)$ involved in administering the medication (Table 7.5 ). This result contrasts sharply with the study by Bilsen et al., ${ }^{6}$ who indicated that in the Netherlands and other European countries only physicians administered the medication for APS with a life-shortening intention. However, caution is required when comparing the results because Bilsen et al. ${ }^{6}$ did not report whether or not physicians also involved nurses in administering the medication.

In cases of APS with a life-shortening intention, administration of the medication by nurses is unacceptable from a moral and legal point of view. A nurse who administers medication with a life-shortening intention risks both criminal prosecution and disciplinary measures.

When nurses have clear indications that the intention of APS is to hasten the patient's death, they should demand an explanation from the physician and, when doubts persist, refuse to co-operate.

With regard to administering the medication, the participants held disparate views. Even when they were part of the same nursing team this did not hamper the treatment. In such cases, those who agreed with the treatment ordered by a physician administered the medication. In such cases they presumably acted on their individual values and not on the values that are agreed by their profession as, for example, laid down in the Dutch National code of ethics for nurses and caregivers. ${ }^{14}$ These respondents applied their own values and beliefs above those of their profession. It could also be the case that they do not have sufficient knowledge of the values of their profession.

Although the participants solved disagreements by reasonable consultation with each other, the professional and ethical boundaries of the nursing profession were rarely discussed. When constructive discussions are lacking, indistinctness or unspoken questions and dilemmas may cause or reinforce divisions within the nursing team.

It is important to note that in the Netherlands the number of decisions for APS with a lifeshortening intention has decreased from $4 \%$ of all deaths in 1990 to $1 \%$ in $2005 .^{\circ}$ An 
explanation for this trend could be improvements in palliative care, and a resulting decrease in the number of requests for hastening a patient's death. Another explanation, which is related to recent practice, is the development of other methods of APS, such as continuous deep sedation until death occurs. ${ }^{9}$

\section{Conclusion}

Practices in the field of APS with a life-shortening intention are not transparent and represent a 'grey' area. In the decision-making process, consultation among physicians and nurses and caregivers is often lacking. Nurses and caregivers are not always informed about the intention of the treatment (namely ending the life of the patient), they are insufficiently aware of their responsibilities, and they perform activities that are principally illegal.

This practice is also maintained by nurses and caregivers, particularly in situations in which they and the physician have the same intention, namely to hasten a patient's death.

The boundaries are blurred among APS, euthanasia and the ending of life without an explicit request of the patient.

To improve transparency of the process of APS in the final stage of life, in particular APS with a life-shortening intention, institutional guidelines may play an important role.

Although embedded in a Dutch cultural context, the data derived from this study may stimulate international discussion about the role and responsibilities of nurses in APS with a life-shortening intention.

\section{References}

1. Van der Heide A, Deliens $L$, Faisst $K$ et al. End-of-life decision-making in six European countries: descriptive study. Lancet 2003; 362: 345-50.

2. Kuhse $H$, Singer $P$, Baume $P$, Clark $M$, Rickard $M$. End-of-life decisions in Australian medical practice. Med J Aust 1997; 166: 191-96.

3. Mitchell $\mathrm{K}$, Owens RG. National survey of medical decisions at the end of life made by New Zealand general practitioners. BMJ 2003; 327: 202-203.

4. Deliens $L$, Mortier $F$, Bilsen $J$ et al. End-of-life decisions in medical practice in Flanders, Belgium: a nationwide survey. Lancet 2000; 356: 1806-11.

5. Bilsen J, Vander Stichele R, Mortier F, Bernheim J, Deliens $L$. The incidence and characteristics of end-of-life decisions by GPs in Belgium. Fam Pract 2004; 21: 282-89.

6. Bilsen $J$, Norup $M$, Deliens $L$ et al. Drugs used to alleviate symptoms with life shortening as a possible side effect: end-of-life care in six European countries. J Pain Symptom Manage 2006; 31: 111-21.

7. Bilsen J, Vander Stichele R, Broeckaert B, Mortier F, Deliens L. Changes in medical endof-life practices during the legalization process of euthanasia in Belgium. Soc Sci Med 2007; 65: 803-808.

8. Van der Heide $A$, Onwuteaka-Philipsen BD, Rurup ML et al. End-of-life practices in the Netherlands under the Euthanasia Act. N Engl J Med 2007; 356: 1957-65.

9. Onwuteaka-Philipsen BD, Gevers JKM, van der Heide A ot al. Evaluatie wet toetsing levensbeëindiging op verzoek en hulp bij zelfdoding. (Evaluation of the law on the termination of life on request and assisted suicide.) Den Haag: ZonMw, 2007 (in Dutch).

10. Van Bruchem-van de Scheur $A$, van der Arend $A$, Spreeuwenberg $C$, van Wijmen F, ter Meulen $R$. De rol van verpleegkundigen bij medische beslissingen rond het levenseinde. Ver- 
slag van een landelijk onderzoek naar betrokkenheid en praktijken. (The role of nurses in medical end-of-life decisions. Report of a national study into involvement and practices.) Utrecht: Uitgeverij De Tijdstroom, 2004 (in Dutch).

11. Strauss $A$, Corbin J. Basics of qualitative research: techniques and procedures for developing grounded theory. Thousand Oaks, CA: SAGE, 1998.

12. Van der Wal G, van der Maas PJ. Euthanasie en andere medische beslissingen rond het levenseinde: de praktijk en de meldingsprocedure. (Euthanasia and other medical end-oflife decisions: practice and notification procedure.) Den Haag: Sdu, 1996 (in Dutch).

13. The A-M. 'Vanavond om 8 uur ...' Verpleegkundige dilemma's bij euthanasie en andere beslissingen rond het levenseinde. ('Tonight at eight o'clock ...' Nurses' dilemmas with euthanasia and other end-of-life decisions.) Houten/Diegem: Bohn Stafleu Van Loghum, 1997 (in Dutch).

14. V\&VN (Nurses and Caregivers Netherlands), NU'91 (New Union'91). Nationale Beroepscode van Verpleegkundigen en Verzorgenden. (National code of ethics for nurses and caregivers.) Hilversum: Van der Weij Drukkerijen BV, 2007 (in Dutch). 


\section{Chapter 8}

\section{Conclusions and discussion}

\section{Introduction}

The aim of the study was to investigate the role, perceptions, responsibilities, and problems of nurses in medical end-of-life decisions in order to advise the Dutch government in legislation and policy-making concerning the role of nurses. In November 2004, the results of the study were presented in an extensive Dutch report to the State Secretary of Health, Welfare and Sports (Van Bruchem-van de Scheur et al. 2004). It should be noted that between publication of this Dutch report and this thesis there is a time difference of four years, during which two important developments took place. First, in 2006 the fourth revised edition of the national joint guidelines of physicians and nurses/caregivers on the collaboration and demarcation of tasks in euthanasia between physicians and nurses/caregivers was published (AVV et al. 2006). Chapters 3 to 6 of this thesis refer regularly to these guidelines. Second, in 2007 the evaluation report of The Termination of Life on Request and Assisted Suicide Act was published (Onwuteaka-Philipsen et al. 2007). This report was published after chapters 3 to 6 of this thesis were published as articles. This chapter does make reference to this evaluation report.

In this chapter the conclusions are presented and discussed with regard to the role of nurses in and their attitudes towards euthanasia and physician-assisted suicide, the role of nurses in the alleviation of pain and symptoms with a life-shortening intention, and finally a discussion regarding the methodology of the study.

\section{Conclusions and discussion with regard to the role of nurses in euthanasia and physician-assisted suicide}

When speaking in general about the role of nurses in euthanasia/physician-assisted suicide, this study shows clearly that a number of distinctions are necessary:

1. The role of nurses needs specification by sector. There were considerable differences between the intramural sector (hospitals and nursing homes) on one hand, and the extramural sector (homecare) on the other. In the homecare sector, which 
has by far the largest reported number of cases of euthanasia/physician-assisted suicide in the Netherlands, the nurse is considerably less involved in the process of euthanasia/physician-assisted suicide than in both other sectors. In 2001, 2002 and 2003 the years in which the respondents cases took place, about $80 \%$ of the reports received by the Regional euthanasia review committees were performed in the patients' home (see Table 8.1). In subsequent years this remained approximately the same.

Table 8.1 The number of received reports by the Regional euthanasia review committees divided over the different sectors. ${ }^{1}$

\begin{tabular}{|c|c|c|c|c|c|c|c|}
\hline Year & $\begin{array}{c}2001 \\
\left(n^{2}=2054\right)\end{array}$ & $\begin{array}{c}2002 \\
\left(n^{2}=1882\right)\end{array}$ & $\begin{array}{c}2003 \\
\left(n^{2}=1815\right)\end{array}$ & $\begin{array}{c}2004 \\
\left(n^{2}=1886\right)\end{array}$ & $\begin{array}{c}2005 \\
\left(n^{2}=1933\right)\end{array}$ & $\begin{array}{c}2006 \\
\left(n^{2}=1923\right)\end{array}$ & $\begin{array}{c}2007 \\
\left(n^{2}=2120\right)\end{array}$ \\
\hline Setting & $\%$ & $\%$ & $\%$ & $\%$ & $\%$ & $\%$ & $\%$ \\
\hline Patients' homes & 82.7 & 82.0 & 81.4 & 81.1 & 82,0 & 79.5 & 79.5 \\
\hline Hospitals & 12.0 & 11.1 & 11.4 & 9.4 & 8.2 & 7.5 & 6.9 \\
\hline Nursing homes & $3.8^{3}$ & 2.2 & 2.6 & 3.4 & 3.8 & 4.1 & 3.9 \\
\hline Elderly care centres & - & 2.7 & 2.3 & 3.3 & 2.3 & 4.1 & 4.2 \\
\hline Elsewhere & $1.5^{3}$ & 2.0 & 2.4 & 2.8 & 3.7 & 3.6 & 5.5 \\
\hline
\end{tabular}

This table is borrowed from the annual reports 2001 to 2007 of the regional euthanasia review committees.

${ }^{2}$ The number of received reports by the Regional euthanasia review committees.

${ }^{3}$ In 2001, the sectors were divided differently compared to subsequent years. The percentage related to nursing homes included also the cases in elderly care centres. The percentage related to the cases 'elsewhere' included also the cases in old people's homes.

2. The role of nurses varied during the different stages which could be identified within the process of euthanasia/physician-assisted suicide and is characterised by:

- considerable disproportion in nurses' role throughout the stages. Although nurses were consulted in the majority of cases, in at least a quarter of the cases, there was a considerable lack of consultation between physician and nurses. In the administering of euthanatics, nurses were sometimes involved too strongly, as in $12.2 \%$ of cases nurses administered the euthanatics together with or without a physician.

- considerable fragmentation in the involvement of the nurse throughout the stages. For example, in $18.9 \%$ of cases, the nurse who was present during the administration of the euthanatics did not have a role in the decision-making process. An important reason for this 'fragmented' involvement might be the changing duties of nurses.

1. In most cases the patient did not first speak alone with a nurse about the option of euthanasia or physician-assisted suicide (see chapters 3-5)

Because nurses generally have an important role in the caring and guidance of incurably ill patients, it was assumed that patients would likely speak first with a nurse about the option of euthanasia or physician-assisted suicide. This assumption was refuted in this study. Patients discussed a request for euthanasia/physician-assisted suicide first with a nurse just as frequently as with a physician, respectively $37.0 \%$ and $36.8 \%$ of 799 cases (see chapter 3).

Factors contributing to this might be that the patient knows that the physician must first agree with the request and, therefore, first approaches the physician, or the patient speaks first with the physician due to their longstanding and confidential relationship, often from the beginning of the sickness process and treatment.

Nurses often become involved later, work part-time or have changing duties, all of which can obstruct building a confidential relationship with the patient. Although building a 
confidential relationship is not always a matter of availability or presence, according to Smits (2004), personal involvement is necessary to create trust.

It should be noted that the patient probably does not always deliberately choose to speak with the physician or the nurse. As well as the patient may suddenly be more inclined to talk about euthanasia/physician-assisted suicide, for example after receiving bad news or after sleeping poorly.

2. During the decision-making process, consultations between physician and nurse often took place in hospitals and nursing home and less frequently in homecare (see chapters 3-5)

In homecare (see chapters 3 and 4), the nurse is considerably less involved in the decision-making process $(41.2 \%$ ) than in hospitals $(78.8 \%$ ) (see chapters 3 and 5 ) and nursing homes $(81.3 \%$ ) (see chapter 3 ) These differences may be related to the different organisational structure in homecare, where physicians and nurses usually do not work within the same organisation, and do not generally encounter each other in the presence of the patient or elsewhere. Moreover, in this sector considerable upscaling of organizations has taken place, and as a result, the district nurse is confronted with physicians who barely know her and as a result could be reserved in their communication. Also other studies indicated large differences between institutions and homecare (De Bal et al. 2008; Inghelbrecht et al. 2007).

The joint guidelines of physicians and nurses (AVV ot al. 2006) state that it is highly desirable that the physician includes the nurse in the decision-making process when a nurse is involved in the daily care of a patient who has requested euthanasia. It appeared in this study that, this is not always the case. This does not mean that nurses experienced their non-involvement as problematic. In $39.3 \%$ of cases in which nurses were not involved in the decision-making process, they indicated that the patient's request was so obvious that consultation was unnecessary.

Before the physician can determine whether the situation of the patient complies with the due care requirements, information must be collected and evaluated. Given their involvement with the patient, nurses can provide a relevant contribution to this process of information collection and opinion development. Nurses could have insight into the degree that the request is voluntary and well-considered. They could give information about factors which confuse the situation, for example about a hidden appeal for a different kind of help behind the request or information about the influence of relatives on the patient's feelings and opinions about terminating his or her life.

She can help the patient with formulating or expressing the sorrows he or she might have or experience.

Moreover, consultation between physician and nurse corresponds to the nature of the decision-making process, which is not a snap decisison. It usually means developing insight through talk and observation over an extended period, collating all the different aspects of a request. The guidelines of the AVV et al. (2006) state about that: the need for the involved physician and other caregivers for time and space in order to form a judgement about the euthanasia request is clarified to the patient.

3. The role of nurses in the decision-making process is (also) dependent on the wishes of the patient (see chapters 4 and 5 )

So far the idea has predominated that the consultation between physician and nurse mainly depends on the willingness of the physician to consult the nurse or not. This study indicates that patients share responsibility for the non-involvement of nurses as in $30.8 \%$ of homecare cases (see chapter 4 ) and in $35.3 \%$ of hospital cases (see chapter 5) in which nurses were not involved in the decision-making process, the patient indicated that 
they did not want nurses to be involved in the decision-making process. According to Van Bruchem-van de Scheur et al. (2004), this concerned $35.7 \%$ of cases in nursing homes, giving an average of $32.3 \%$ over the three sectors.

The private and sensitive nature of the subject may mean that patients wish to involve as few persons as possible in their request, perhaps as they do not want to be exposed to their reactions and wish not to have to justify their choice to other persons than the physician. Another reason may be that patients still have not developed a relationship of mutual trust with one or more nurses, perhaps due to the changing duties of nurses, recent admission on the ward or care recently started at the patient's home.

Therefore it is important that physicians ask patients whether they want to involve nurses in the process. They, then, are complying with the joint euthanasia guidelines for physicians and nurses (AWV et al. 2006), which state that the physician should discuss with the patient which caregivers should be informed, and what information they should receive. Any objections expressed by patients should be taken into account.

This does not mean however that the total situation must remain secret, which is of course not possible in a hospital ward or nursing home, but which is possible in the home situation.

The study indicates that in homecare it occurs that the nurse is not informed about the patient's request for euthanasia/physician-assisted suicide and/or the performing of it (see chapter 4). Nurses have gone to patients' homes only to find out that death had aiready occurred. They expressed feelings of being misunderstood or being underestimated in their professionalism, not so much for having had no role in the decisionmaking process, but more because they were not informed about the situation and could not say farewell to the patient.

4. The role of nurses in the decision-making process is (also) dependent on the degree in which nurses took the initiative of raising the issue with physicians (see chapters 4 and 5)

If nurses would have to wait for physicians to initiate a consultation, the percentage of nurses involved in the decision-making process would probably be lower than the data presented in this study.

In $32.2 \%$ of the homecare cases (see chapter 4 ) and $29.5 \%$ of the hospital cases (see chapter 5 ) in which nurses were involved in the decision-making process, nurses initiated discussion of the patient's request with the physician. According to Van Bruchem-van de Scheur et al. (2004), this concerned $26.1 \%$ of cases in nursing homes, giving an average of $29.3 \%$ over the three sectors.

This development displays a professional attitude which is in accordance with the Dutch national code of ethics for nurses and caregivers (V\&VN \& NU'91, 2007). This code, which describes the moral aspects of professional practice, states in article 3.1: "as nurse/caregiver, I work together with other care providers, to give the necessary care to the patient.' This means among other things 'that I share my expertise, experience and vision with the other involved care givers with the intention of providing good care to the patient'.

The study indicates that one reason for nurses to initiate a consultation with the physician could be to find a balance between their emotions (having potentially strong emotional bonds with patients) and the objective aspects of the case. Another conceivabie reason is the awareness that they can act as an important source of information for physicians.

It is moreover conceivable that in a number of cases the patient him- or herself is able to successfully interact with the physician. However, in situations where this is not the case 
and nurses remained silent and did not initiate discussion with the physician, could be due to a variety of, and possibly overlapping reasons:

- Inavailability of the physician.

- Sensitivity of the subject. This might itself impose a barrier to raising the issue with the physician.

- Patient's request was obvious. The nurse might decide that consultation with the physician is not necessary.

- Medical end-of-life decision. Consequently, the nurse considered euthanasia/physician-assisted suicide as the domain of the physician.

- Physician coordinates the euthanasia procedure. In the guidelines (AVVV et al. 2006, p. 32) this is described as: 'The coordination of the euthanasia procedure lies in the hands of the physician. The physician coordinates as much as possible with the responsible nurse or caregiver.' This could result in a reticent attitude of nurses towards the physician.

- Personal demeanor of the physician. According to Chafey et al. (1998), who conducted a qualitative descriptive design to explore the characterizations of client advocacy by practicing nurses, the physician's demeanor such as throwing objects and intimidation, could be a reason for nurses not to approach the physician.

- Conscientious objections. The study of Van Bruchem-van de Scheur et al. (2004) indicate that $13.5 \%$ of 118 nurses did not want involvement in the decision-making process because of conscientious objections.

5. Nurses felt more satisfied when a request was granted than when it was denied (see chapters 3 and 4)

Nurses agreed with the physician's decision to grant a request in $88.6 \%$ of cases, while they agreed with the physician's decision to refuse a request in $60.1 \%$ of cases (see chapter 3).

When a request was not granted, the reason most mentioned for nurse's disagreement or doubts was that they found the request understandable (see chapters 3 and 4). This argument might be based on identification with the interest of the patient. Nurses often find themselves in the role of the patient's advocate, trying to represent the patient's interests.

An implicit argument which could play a role is that nurses do not want to put the slightest obstacle in the way of the patient, who is living his last weeks or days or sometimes even hours. However, this type of solidarity with the patient may be misleading if the request is not sufficiently assessed from different perspectives, for example as a hidden appeal for help.

However, the fact that nurses evaluate the situation from the position of the patient could be the result of a lack of knowledge about the due care requirements of the law (see also page 101). According to Thacker (2008), who conducted a comparative descriptive study focusing on acute care nurses' perceptions of advocacy behaviors in end-of-life nursing practice, one of the barriers to practicing advocacy in end-of-life nursing care is lack of knowledge.

An example of lack of knowledge is described in chapter 4 , where nurses stated that patients were 'entitled' to euthanasia or physician-assisted suicide as a matter of principle. This 'right' to euthanasia or physician-assisted suicide is an incorrect interpretation of the euthanasia law. Euthanasia and physician-assisted suicide are not usual medical activities and consequently physicians are not obliged to give their assistance to euthanasia and physician-assisted suicide. 
Of course it is possible that nurses regard patients, as stated by Verkerk (1999), as 'individuals who have a strong interest in (and a right to) freedom and non-interference'. However, respecting patients' autonomy must stay within the boundaries set by law.

In the guidelines of the AVW et al. (2006) much value is been attached to involvement of nurses in the decision-making process. However, if nurses present incorrect arguments during the decision-making process, they accept the risk that their opinion is not considered valuable by the physician and weaken their role in the decision-making process.

Furthermore, nurses may interpret the due care criteria differently from physicians. However, it may also be true that the physician grounds his/her decision on conscientious objections while the nurses' arguments are based on the due care criteria only. Physician and nurse may also interpret a request or the circumstances of a request differently because the patient may have expressed his/herself inconsistently to the various care providers. Patients may, for example, be positive about the request with the nurse, and express doubts to the physician.

The different opinions of the physician and nurse underline the importance of consultation between each other which is also recommended in the guidelines of the AVVV et al. (2006, p. 36): 'When the concerned nurse/caregiver disagrees with the decision or when other concerned care providers have indistinctness, it is preferable that they first contact the physician and/or their executives and/or colleagues. The physician has the responsibility to defend his decision among other care providers'.

This communication between physicians and nurses is of particular importance for guaranteeing mutual understanding while performing the care. A wrong interpretation of intentions of physicians by nurses can give uncomfortable discussion and commotion around the deathbed.

6. In a number of cases, nurses administered the euthanatics together with or without a physician (see chapters 3-5)

While the administration of euthanatics is by law exclusively reserved to the physician, in some cases $(12.2 \%)$ the nurse performed this act together with or without a physician (see chapter 3 ).

Sometimes this occurred because the physician was insufficiently experienced in adequately managing the infusion. As the moment of infusion is important to the patient and/or relatives, nurses may feel compelled at that very moment to take over the procedure. Despite the intentions of nurses to supply 'good care', such activities are illegal under the Dutch law.

As the last lawsuit in this area in the Netherlands dates from 1995, it is likely that physicians have not officially reported the administering of euthanatics by nurses. However, nurses who administer euthanatics or assist in a suicide risk both criminal prosecution and disciplinary measures.

Although the joint euthanasia guidelines of physicians and nurses (AVVV et al. 2006) state that the administration of euthanatics may only be performed by the physician, it is worrying that in the same guidelines the borders of what is punishable are stretched. It states: 'It is unlikely that if the border between preparatory activities and administering activities in euthanasia cases, which fall within the legal due care criteria, was crossed that the nurse or caregiver would be brought up on criminal or disciplinary charges' ( $p$. 20).

However, this latitude between both activities does not correspond with the legal rules and the professional responsibilities of nurses. Administration of euthanatics does not belong to regular medical practice. Consequently, nurses' activities in this area are not regular practice either. Such activity has an extraordinary moral character that, strictly 
speaking, makes it incompatible with the professional and legal competencies of physicians and nurses. Nevertheless, it may be practised under certain conditions, but it remains the exclusive task and responsibility of physicians.

One should be careful to initiate potential task shifts to nurses. All the more so, because the administration of medication is a common nursing activity and therefore a slippery slope is conceivable.

Moreover, nurses who administer euthanatics damage their social status and indirectly those of physicians. Society expects that the work of nurses and caregivers is aimed to promote and maintain health, to prevent illness and disability, to contribute to restoring health, and to relieve suffering and discomfort, such as described in the national code of ethics for nurses and caregivers (V\&VN \& NU'91, 2007). This description excludes the ending of life of patients as the task of nurses and caregivers.

Physicians should be aware of their responsibilities and not leave such activities to nurses. It is important that physicians and nurses discuss and review each other's responsibilities and tasks before taking action. It must be prevented that nurses come to the bed of the patient in a field of tension, and then feel compelled to manage the infusion.

7. Nurses in general have insufficient knowledge of legal aspects on euthanasia/ physician-assisted suicide (see chapters 3-5)

Nurses in general seem to have insufficient knowledge of law and regulations on euthanasia/physician-assisted suicide and their legal position, as became clear in several issues in the study. Some examples:

- When nurses disagreed with the physician's decision not to grant a request, a number of nurses argued that the patient has a 'right' to euthanasia or physicianassisted suicide (see chapter 4). This is an incorrect argument as euthanasia and physician-assisted suicide are not ordinary medical activities and consequently physicians are not obliged to give their assistance to euthanasia and physician-assisted suicide.

- When nurses were present during the administering of euthanatics, not all were convinced that the physician complied with the due care requirements of law, partly because they had insufficient knowledge (see chapter 5).

- When nurses performed administering tasks, a number of them were unaware of the limits to their professional authority (see chapter 4).

Moreover, the fact that nurses are inclined to prioritise the wishes and interests of patients over professional duties and legal restraints may be due to a lack of knowledge of the latter (see chapter 3 and 4 ).

Concerning the lack of knowledge among nurses, it must be pointed out that the majority of respondents in the present study had already completed their education when the euthanasia law was passed.

The study shows clearly that when nurses are not able to give euthanasia its proper meaning and to place its legality in the right context, the risk exists for misinterpretation of the physician's decision and of their own professional boundaries.

Nurses' poor knowledge concerning legal aspects might be due to a lack of experience because nurses are not regularly involved in requests for euthanasia or physicianassisted suicide, or may result from the fact that they are insufficiently supported by the euthanasia guidelines of their employer.

Van Bruchem-van de Scheur et al. (2004) indicated that it is not self-evident that organizations have guidelines concerning euthanasia and/or physician-assisted suicide and, if they are present $(57.5 \%)$, that they are within arm's reach and describe the nurse's role. 
According to the evaluation report of the euthanasia Law, in only half of the guidelines (originating from 5 sectors) the role which nurses could have in the administering of euthanasia was specified (Onwueaka-Philipsen et al. 2007).

According to Van Bruchem-van de Scheur et al. (2004), nurses are also insufficiently supported by the euthanasia guidelines of their profession. $86.4 \%$ of nurses do not have an opinion on the official joint guidelines for physicians and nurses from the national physicians' and nurses' professional organizations (KNMG \& NU'91, 1997) because they never heard about, never studied them, or do not remember anything of their content.

It is important that nurses be supported by guidelines, particularly since euthanasia and physician-assisted suicide are not frequently requested, and, consequently, nurses may not have relevant knowledge at hand (as showed in this study). Moreover, institutional guidelines may play an important role in preventing procedural misunderstandings that could lead to ethical problems and legal offences, such as the administration of euthanatics by nurses.

As described in the joint guidelines of the AVVV et al. (2006), it is important to have a clear view of the unique legal character of euthanasia and physician-assisted suicide compared to other end-of-life decisions, a clear view of the leeway within the legal framework for euthanasia and physician-assisted suicide in granting the wish of the patient, and thereby a clear view of the legal requirements which must be met.

\section{Conclusions and discussion with regard to attitudes of nurses concerning euthanasia/physician-assisted suicide}

1. A minority of nurses supported the membership of nurses in the Regional euthanasia review committees (see chapter 6 )

Although nurses' professional organizations strongly advised the membership of nurses in Regional euthanasia review committees (LCVV, 1998), the study showed that only a minority of nurses (45\%) was in favour of such membership and a relatively high percentage $(41.6 \%)$ of nurses had no opinion about this issue.

Interestingly, it should be noted that the discussion about the membership of nurses in Regional euthanasia review committees was the reason to commission the present study (see pages $10-11$ ).

It is not advisable to include nurses in the Regional euthanasia review committees, because of the following reasons. Firstly, indeed, only $45 \%$ of nurses supported membership of nurses in these committees. Secondly, the task of Regional euthanasia review committees is to answer only the question whether or not physicians have followed the legally-established requirements of due care, and not to evaluate the process of care and support of patients given by nurses. Their evaluation concerns the legal and moral assessment of a medical action, not the 'ethics of care'. Nurses may be involved in such committees but they have no specific tasks in law that would make social control necessary.

This last argument still applies since no legal tasks have been ascribed to nurses in the evaluation of the euthanasia law (Onwuteaka-Philipsen et al. 2007). Also the authors of this evaluation study concluded that there are insufficient grounds to modify the composition of the Regional euthanasia review committees. Their study indicated that all but one member of the review committees had no need for a nurse in the committee. Furthermore, they refer to earlier arguments of the legislator to abandon inclusion of nurses in regional euthanasia review committees:

- The involvement of the nurse within the reviewing process has been in other ways guaranteed, as such by means of the questions about nurses' invalvement in the 
Model report of the physician, and the possibility for the committee to obtain information later from the concerned caregiver.

- Not in all cases a nurse has been involved in euthanasia or physician-assisted suicide.

- A committee's even number of members would not facilitate its decision-making.

This last argument is mentioned here only for the sake of completeness, but it has nothing to do with the role of nurses.

2. A majority of the nurses did not consider it necessary to make consultation between a nurse and physician a legal requirement (see chapter 6)

Although the nurses' professional organizations recommended consultation with a nurse a legal requirement for the physicians' decision-making, a majority of nurses $(58.2 \%)$ did not consider it necessary. And although it was still unknown which nurses' responsibilities would ensue from this consultation, nurses showed that the decision to grant euthanasia or physician-assisted suicide is a medical one and that a line should be drawn between their areas of responsibility and those of physicians. Nurses were aware of the heavy responsibility of physicians in this instance and did not want to interfere by formalising their input in the decision-making process.

However, there are also practical objections to requiring physicians to consult a nurse. Such legal constructs may become problematic if the situations on which they are to decide constantly change. Problems of interpretation may easily arise, e.g. with regard to differences of opinion on who is the nurse 'involved' and whether he or she should represent only his or her own opinion or also those of other nurses who took part in the care for the patient, and how to act in case of differing opinions among nurses.

Other data from the present study show that nurses lack sufficient knowledge in general on the subject of euthanasia and physician-assisted suicide. This also forms an argument against formalizing their input in the decision-making process.

In the evaluation report of the Euthanasia Law (Onwuteaka-Philipsen et al. 2007) making consultation between a nurse and physician is not recommended as a legal requirement. The subject even remains unmentioned. One could argue that these authors did not consider it necessary to make consultation with a nurse a legal requirement for physician's decision-making.

Here the Dutch situation differs from the Belgian, where involvement of nurses in the decision-making is a legal requirement. In the Belgian Euthanasia Law of May 2002, this has been formulated as follows: 'Before carrying out euthanasia he/she [the physician] must in each case: if there is a nursing team that has regular contact with the patient, discuss the request of the patient with the nursing team or its members' (Minister of Justice, 2002).

A study, with data collection between 15 November 2005 to 28 February 2006, investigated the form and content of ethics policies on euthanasia in Flemish hospitals and the possible influence of religious affiliation on policy content, indicated that it is not selfevident that policies includes a description of the role of nurses in the decision-making process. Thirty-three of 42 policies $(78.6 \%)$ described the role of nurses in the decisionmaking process, either by being consulted or by participating in interdisciplinary teams specifically formed to handle euthanasia cases (Lemiengre et al. 2008).

In the Belgian registration form that physicians are required to fill in and send to the Federal Control and Evaluation Commission, the physician can tick whether the request for euthanasia has been discussed with the nursing team or its members. In contrary to the Dutch situation, physicians are not asked for the view of nurses nor the possible reason for not consulting nurses. 
3. The majority of nurses stated that preparatory activities for the administration of euthanatics are not part of their tasks (see chapter 6)

The majority of nurses stated that inserting an infusion needle $(54.1 \%)$ and preparing euthanatics $(62.9 \%)$ are not part of their tasks. These percentages were much lower in hospitals compared to homecare organizations and nursing homes. An explanation for this difference may be that such activities are more common nursing activities in hospitals than elsewhere.

While the administration of euthanatics is by law exclusively reserved to the physician, the competence with regard to preparatory activities has not been laid down legally. Physicians and nurses have established their views in joint guidelines (AVVV et al. 2006). In these guidelines (p. 20) the boundary between administering and preparatory activities is formulated as follows: 'As a rule of thumb the demarcation which can be used is that the nurse or caregiver does not perform activities which result directly in the ending of the patient's life. In other words: the nurse or caregiver may only do those things after which an essential activity towards ending the life of the patient still needs to follow, and which activity will be performed by the physician.'

Following the view of the State secretary of the Dutch Ministry of Health, Welfare and Sports (Ross-van Dorp, 2005), in the joint guidelines inserting an infusion needle can be a task for nurses.

Although preparing euthanatics is not considered a task for nurses, this remains unmentioned in the guidelines. This can raise uncertainty for care providers. All the more because nurses, according to Van Bruchem-van de Scheur et al. (2004) are involved in preparing euthanatics.

This distinction in preparatory activities in the guidelines is in conformity with the standpoint of Ross-van Dorp (2005). She states: the physician is responsible for the administration of medication and therefore the physician him/herself must prepare the medication. This prevents, for example, possible carelessness with regards to the dosage being attributed to the nurse. This juridical-defensive argument seems to have little to do with the professional competency of nurses and moreover the physician himself can make mistakes.

Furthermore this distinction in preparatory activities is in conformity with an earlier standpoint taken by the KNMG (2002), namely that the nurse may not have contact with euthanatics.

Concerning the legal security for nurses, the Board of Procurators General stipulated that inserting an infusion needle for performing euthanasia by ambulance nurses is allowed (De Vries \& Tax, 2003). Furthermore, in reply to questions of the members of the Parliament, the Minister of Health, Welfare and Sports and the Minister of Justice indicated that the due care requirements for euthanasia and physician-assisted suicide apply primarily to the physician who performs euthanasia. If the physician acts carelessly, it is not within reason to prosecute the nurse who has performed the usual preparatory activities. The nurse is an accessory when the physician and the nurse deliberately terminated together the patient's life. Also to be an accessory it has been required that talk is 'on purpose', aimed both at the care being provided and at the offence for which the care is provided (Tweede Kamer der Staten-Generaal, 2004).

With reference to the standpoint of the ministers, the guidelines (AVV et al. 2006) state: disciplinary measures or criminal prosecution of a nurse who performs preparatory activities are not impossible, but the chance of this is highly unlikely.

Though nurses' professional organizations indicated a preference for recording in the law of particular criminal exceptions for nurses and caregivers who give assistance to euthanasia by way of preparatory activities, the evaluation report of the euthanasia law thought that there was insufficient reason for such a change of the law (Onwuteaka- 
Philipsen et al. 2007). The authors of this evaluation report refer to the above-mentioned standpoint of the ministers and the Board of Procurators General, and the guidelines of the AVVV et al. (2006).

Because legislation in this area is lacking, guidelines will play an important role in case of a lawsuit, such as in 1995 when a nurse was judged for having administered euthanatics.

Although according to the guidelines (AVVV et al. 2006) nurses can perform preparatory activities aimed at the technical success of the performing of euthanasia, there are doubts whether this is morally acceptable. Euthanasia and physician-assisted suicide do not belong to regular medical practice. Consequently, nurses' activities in this area are not regular practice either, even when they concern only preparatory activities and even when they are done from a feeling of duty to the patient. Such activities have an extraordinary moral character and do not belong to the professional responsibility of nurses, such as expressed in the Individual Health Care Professions Act and the national code of ethics for nurses and caregivers (see chapter 6).

\section{Conclusions and discussion with regard to the role of nurses in the alleviation of pain and symptoms with a life-shortening intention}

The medical end-of-life decision alleviation of pain and symptoms with a life-shortening intention was included in this study because this is a 'grey area' where much uncertainty exists with regard to the role of nurses, as well as, it is likely that many nurses are confronted and even involved in the performing of this medical end-of-life decision.

Although the frequency has not been investigated, the study confirms that there is indeed a grey area between on the one side alleviation of pain and symptoms, and on the other side euthanasia and ending of life without an explicit request of the patient.

This became clear from results such as:

- In $23 \%$ of cases, nurses disagreed with or had doubts about the physician's decision to hasten the patient's death.

- In $27.3 \%$ of cases, the physician did not inform nurses about the aim of the medication (to hasten the patient's death).

- In $18.8 \%$ of cases, a part of the nursing team was not willing to administer the medication.

This concerns a non-transparent practice which is removed from social control. This has been confirmed in the evaluation report of the euthanasia law (Onwuteaka-Philipsen et al. 2007). This report stated that about $20 \%$ of all performed cases of termination of life on request in the year 2005 were not reported to the Regional euthanasia review comm mittees. Usually this concerned termination of life by means of Morphine which was not considered by the involved physician as a form of euthanasia, but at the same time according to the same physician the case complied with the criteria for euthanasia. The suspicion that the case did not comply with the due care requirements of the law or the fear of judicial prosecution was in $10 \%$ of cases reason for not reporting to a Regional euthanasia review committee (Onwuteaka-Philipsen et al. 2007).

it is important to note that in the Netherlands the number of decisions involving alleviation of pain and symptoms with a life-shortening intention has decreased from $4 \%$ of all deaths in 1990 to $1 \%$ in 2005 (Onwuteaka-Philipsen et al. 2007). An explanation could be the improvement of palliative care, and as a result the decrease of requests for hastening the patient's death. Another explanation, which is related to recent years, is the developing of other methods of alleviation of pain and symptoms, such as continuous deep sedation until death occurs (Onwuteaka-Philipsen et al. 2007). 
In 2005, the guideline palliative sedation of the Royal Dutch Medical Association was published (KNMG, 2005). Although in the guidelines the emphasis lies on the tasks and responsibilities of physicians, there is also attention given to other care providers, in particular nurses and caregivers. The guidelines state that: 'care for the care providers' requires good communication, reflection and guidance of care providers.

1. There is insufficient communication between physician and nurse about the alleviation of pain and symptoms with a life-shortening intention (see chapter 7)

Although there are differences in sectors with regard to the communication between physician and nurse, in general it can be stated that physician and nurse communicate insufficiently. For instance, in at least $34.8 \%$ of cases, the physician did not involve nurses in the decision-making process, and in $27.3 \%$ of cases, the physician did not inform nurses about the aim of the medication (to hasten the patient's death).

When the physician classifies his actions as normal pain and symptom alleviation, then the physician is probably under the assumption that this concerns, technically speaking, a normal nursing activity, which is moreover incorrect given the aim of the activity.

Another explanation for the limited communication may be that this seems a practice in which physician and nurse understand each other and where there is partially an implicit agreement concerning the performing of the alleviation of pain and symptoms with a lifeshortening intention.

The different care providers can also have their own unexpressed interests. For example the nurse finds it important to answer the dying wish of the patient, and the physician wants to avoid the euthanasia notification procedure. When nurses discussed their disagreements or doubts with the physician, the physician might respond nastily as they did occasionally. This would also not stimulate the communication between physician and nurse.

2. In case of alleviation of pain and symptoms with a life-shortening intention, a large number of nurses administered the medication, which is in principal illegal (see chapter 7)

By law it has been regulated that the administration of euthanatics is reserved to the physician, whereas it is described in guidelines which role the nurse can have. However, in the field of alleviation of pain and symptoms with a life-shortening intention, there is unclearness concerning the mutual responsibilities.

The study indicates that in the majority of cases (66.1\%), nurses administered the medication, especially in hospitals and nursing homes. From a technical point of view, nurses (if professionally competent) are authorised to administer medication. However, alleviation of pain and symptoms with a life-shortening intention does not belong to normal medical practice. Consequently, nurses' performing activities in this area are not regular practice either. In such cases, the administration of the medication by nurses is unacceptable from a moral and legal point of view. A nurse who administers medication with a life-shortening intention risks both criminal prosecution and disciplinary measures.

When nurses have clear indications that the intention of alleviation of pain and symptoms is to hasten the patient's death, they should demand an explanation from the physician, and, with persistent doubts, refuse their cooperation.

However, as could be noticed in a number of cases $(18.8 \%)$, when one or more nurses were not willing to administer the medication, this did not lead to stagnation of the administration of medication. In such cases, the medication was administered by nurses who agreed with the policy of the physician. 
3. Nurses contribute to blurring boundaries between on the one hand the alleviation of pain and symptoms, and on the other hand euthanasia and ending of life without request (see chapter 7)

The practice of the alleviation of pain and symptoms with a life-shortening intention is also maintained by nurses, particularly in situations in which physician and nurse had the same intention, namely to hasten the patients' death. Boundaries between on the one side the alleviation of pain and symptoms, and on the other side euthanasia and active ending of life without request are blurred.

In the majority of cases, nurses had agreed with the physician's decision to hasten the patient's death. Thereby, being inclined to prevail the wishes and interest of patients over professional practice, which results from the fact that nurses often let themselves be lead by arguments such as the dying wish of the patient, the hopelessness of the situation, and the meaninglessness of the patient's life.

From these arguments it becomes clear that nurses may involve or identify too much with the patient's situation. Smits (2004) calls this the 'pitfall of involvement'.

It is important to recognize that nurses are closely involved in the situation of the patient and the sorrow of the relatives. This might intensify emotions and feelings of impotence which in turn could change an objective view into a subjective one.

However, the risk is that the situation has not been sufficiently examined from other perspectives, for example determining whether the relatives have received sufficient information and direction. The results do indicate that relatives in about half $(48.8 \%)$ of cases requested to hasten the patients' death or made remarks in that direction. An explanation for the wish of relatives to see the agony ended could be that they are insufficiently supported when sitting around the deathbed of the patient, or that perhaps they received insufficient information about the anticipated course of the situation. Information from the physician such as: 'We connect the morphine pump and it will not last long' could arouse relatives' hope that the moment of death follows shortly. When this does not happen, frustration could arise.

According to Andershed (2006), who conducted a literature review focusing on the relatives' situation and needs in end-of-life care, one of the needs of close relatives is knowing and communicating. Relatives had a great need for information about issues such as the patient's condition, course of illness, symptoms and treatment. They needed information to know what to expect, to make decisions, to plan the day and to prepare for the care of the patient.

The (1997) describes another explanation for the insisting behaviour of the family, namely that the patient may have expressed him/herself differently to the relatives and care providers. The patient may, for example, be positive about the idea to start Morphine with the relatives and express doubts to the physician and/or nurses.

Although in $18.8 \%$ of cases nurses, who were part of the same nursing team, held opposing views with regard to the administering of the medication, this did not hamper the treatment. In such cases, nurses who agreed with the treatment of the physician administered the medication.

The performing or not performing of the physician's treatment was a matter up to the individual nurse. The physician was, with regard to the performing of the policy, dependent on the nurse who at that moment was caring for the patient. Multidisciplinary institutional guidelines can promote a department-wide policy. Where in case of disputes one can address each other on the guidelines. 


\section{Conclusions and discussion with regard to the methodology of the study}

The role of nurses in medical end-of-life decisions was investigated using both qualitative and quantitative methods (see chapter 2). Although qualitative and quantitative studies have their own methodology, it can be stated that the qualitative part of the study had a reinforcing effect on the quantitative part. The qualitative study provided important building blocks for the decisions with respect to the further development of the study and the construction of the questionnaire for the quantitative study. When explaining the results of the quantitative study, it was possible to rely on data of the qualitative study.

Both the qualitative and quantitative part of the study provided much, and often new information and contributed to obtaining insight into the role of nurses in medical end-oflife decisions. The qualitative study provided relevant preparation to the quantitative study.

During the interviews there was an open and confidential atmosphere and a large willingness to provide information. In the quantitative study respondents testified to their interest by the extensive answering of open questions and answer categories, frequently providing sensitive information. Also the time investment of about an hour did not detract from participation in the study.

Much attention was paid to the interpretation of the different types of medical end-of-life decisions, which led to the conclusion that not all types of medical end-of-life decisions appeared suitable for a quantitative approach, because of respondents' misunderstandings with regard to the interpretation of three medical end-of-life decisions. The interviews revealed namely much conceptual confusion about the ending of life without an explicit request of the patient, not starting or stopping treatments which are prospectless or futile in conformity with actual medical knowledge, and withholding artificial administration of fluids and nutrition.

In a qualitative study, misunderstandings with regard to the interpretation of medical endof-life decisions can be corrected immediately. When using a questionnaire, this correction is not possible and such ambiguities should be avoided at all costs. As a result, the questionnaire in the quantitative study focussed on three medical decisions: euthanasia, physician-assisted suicide, and alleviation of pain and symptoms with a life-shortening intention.

The study overran its time by nine months, which was mainly due to the large time investment in recruiting respondents and inputting and ordering data.

Although the study has been based on several types of data, the main focus lays on the quantitative part of the study. The articles in this thesis (chapters 3-7) are also based on this part of the study. As a result, the methodological conclusions will concentrate only on the quantitative study.

1. Answering questions within the context of an experienced case is a suitable research approach in the field of medical end-of-life decisions

Medical end-of-life decisions such as euthanasia and physician-assisted suicide are sensitive and complex issues to study through quantitative methods. Therefore, a practical approach was chosen, namely by asking respondents to place their responses within the context of their most recent case of a medical end-of-life decision within the last two years. Often these were cases which concerned nurses deeply and which were not easily forgotten.

Although this study sought contact with the work experience of respondents, it was obviously not possible in a questionnaire to capture all nuances of the practice. Due to the 
extensive answering of open questions and open answer categories, the results could be explained using these qualitative descriptions of respondents.

2. The recruitment of respondents by means of contact persons seemed a useful approach

It was important to recruit a large sample of nurses in order to obtain representative results. Therefore, much time was spent on the recruitment process of respondents. Contact persons in organizations were asked to recruit respondents. Contact persons formed an important link between the organisation and the researcher. Within the organization, they played an important stimulating role in the recruitment of respondents.

It was important to build up a good understanding with contact persons over the telephone, though this was not easy given the sensitivity of the subject.

Many contact persons were interested in the subject which resulted in a large number of respondents. Nevertheless, there were also contact persons who did not follow up on their commitment to recruit respondents.

To prevent selection bias, the contact persons were not informed about the procedure that respondents were asked to focus their answers on the most recent case.

3. Although the results cannot be generalised to all nurses in the three sectors, the quantitative results about euthanasia/physician-assisted suicide and the alleviation of pain and symptoms with a life-shortening intention can be considered representative of Dutch nurses who have had experience with this types of medical end-of life decisions

The study got high participation rates: a large number of organisations nationwide were involved, and a large number of cases of high quality (most recent cases) were included. Therefore, though a randomly drawn sample was lacking and non-response could have affected the results a little, the conclusion may be justified that the study was representative of Dutch nurses who have had experience with euthanasia/physician-assisted suicide and the alleviation of pain and symptoms with a life-shortening intention.

However, we acknowledge that the data are not representative of the whole population of nurses, as those with no experience with the above-mentioned medical end-of-life decisions were not included.

\section{References}

Andershed, B. (2004). Relatives in end-of-life care-part 1: a systematic review of the literature the five last years, January 1999-February 2004. Joumal of Clinical Nursing, 15, 1158-1169.

AVVV, NU'91, KNMG. (2006). Handreiking voor Samenwerking Artsen, Verpleegkundigen en Verzorgenden bij Euthanasie. (Directive for collaboration physicians, nurses, and caretakers in euthanasia). [4 $4^{\text {th }}$ Editlon]. Utrecht: AVVV/NU'91/KNMG. (In Dutch).

Chafey, K., Rhea, M., Shannon, A.M. \& Spencer, S. (1998). Characterizations of Advocacy by Practicing Nurses. Journal of Professional Nursing, 14, 43-52.

De Bal, N., Gastmans, C. \& Dierckx de Casterlé, B. (2008). Nurses' involvement in the care of patients requesting euthanasia: A review of the literature. International Journal of Nursing Studies, 45, 626-644.

De Vries, G.M.J. \& Tax, C.P.G. (2003). De ambulanceverpleegkundige (The ambulancenurse). Medisch Contact, 58, 524-525. (In Dutch).

Inghelbrecht, E., Bilsen, J., Mortier, F. \& Dellens, L. (2008). Factors related to the involvement of nurses in medical end-of-life decisions in Belgium: A death certificate study. International Journal of Nursing Studies, 45, 1022-1031. 
KNMG (Royal Dutch Medical Association). (2002). Duidelijkheid voorbereidende handeling euthanasie. (Clarity preparatory activity euthanasia). Medisch Contact, 57, 1215. (In Dutch).

KNMG (Royal Dutch Medical Association). (2005). KNMG-richtlijn palliatieve sedation. (KNMGguideline palliative sedation). Utrecht: KNMG. (In Dutch)

KNMG (Royal Dutch Medical Association) \& NU'91 (New Union '91). (1997). Euthanasierichtlijnen arts-verpleegkundigen. Richtlijnen samenwerking en taakafbakening arts en verpleegkundige bij de procedure rond euthanasie. (Euthanasia guidelines physician-nurses. Guidelines collaboration and task demarcation between physician and nurse in euthanasia procedures). [3 $3^{\text {lt }}$ Edition]. Utrecht: KNMG/NU'91. (In Dutch).

Lemiengre, J., Dierckx de Casterlé, B., Denier, Y., Schotsmans, P. \& Gastmans, C. (2008). How do hospitals deal with euthanasia requests in Flanders (Belgium)? A content analysis of policy documents. Patient Education and Counseling, 71, 293-301.

LCVV (National Centre Nursing \& Care). (1998). Verpleegkundigen in regionale toetsingscommissies voor euthanasie: Standpunt LCVV. (Nurses in Regional review committees for euthanasia. Point of view LCVV). Utrecht: LCVV. (In Dutch). The current name of the LCVV is LEVV (The Netherlands Centre for Excellence in Nursing).

Minister of Justice. (2002). The Belgian Act on Euthanasia of May, 28th 2002. Ethical Perspectives, $9,182-188$

Onwuteaka-Philipsen, B.D., Gevers, J.K.M., van der Heide, A., van Delden, J.J.M., Pasman, H.R.W. Rietjens, J.A.C. et al. (2007). Evaluatie Wet toetsing levensbeëindiging op verzoek en hulp bij zelfdoding. (Evaluation of the Law on the Termination of Life on Request and Assisted Suicide). Den Haag: ZonMw. (In Dutch).

Regionale toetsingscommissies euthanasie (Regional euthanasia review committees) (2002). Jaarverslag 2001. (Annual Report 2001). Arnhem: Regionale toetsingscommissies euthanasie. (In Dutch). [subsequent reports with similar titles for the following years up to 2007].

Ross-van Dorp, C. (March $4^{\text {th }}$ 2005). Rol van verpleegkundigen bij euthanasie: Kamerstuk. (Role of nurses in euthanasia: Letter to the chairman of the Dutch Lower Chamber). Den Haag: Ministerie van Volksgezondheid, Welzijn en Sport. (In Dutch).

Smits, M-J. (2004). Zorgen voor een draaglijk bestaan: Morele ervaringen van verpleegkundigen. (Providing for a bearable existence: Moral experiences of nurses). Universiteit Maastricht: thesis.

Thacker, K.S. (2008). Nurses' advocacy behaviors in end-of-life nursing care. Nursing Ethics, 15, 174-185.

Tweede Kamer der Staten-Generaal (The Dutch Lower Chamber). (2004). Aanhangsel van de Handelingen. Vragen gesteld door de leden der Kamer, met de daarop door de regering gegeven antwoorden. Vergaderjaar 2004-2005. (Appendix to the Hansards. Questions of the members of the Chamber with answers of the government. Meeting year 2004-2005). s'Gravenhage: Sdu Uitgevers.

Van Bruchem-van de Scheur, A., van der Arend, A., Spreeuwenberg, C., van Wijmen, F. \& ter Meulen, R. (2004). De rol van verpleegkundigen bij medische beslissingen rond het levenseinde. Verslag van een landelijk onderzoek naar betrokkenheid en praktjken. (The role of nurses in medical end-of-life decisions. Report of a national study into involvement and practices). Utrecht: Uitgeverij De Tijdstroom. (In Dutch).

Verkerk, M. (1999). A care perspective on coercion and autonomy. Bioethics, 13, 358-368.

V\&VN (Nurses \& Caregivers Netherlands) \& NU'91 (New Union'91). (2007). Nationale Beroepscode van Verpleegkundigen en Verzorgenden. (National code of ethics for nurses and caregivers). Hilversum: Van der Weij Drukkerijen BV. (In Dutch). 


\section{Chapter 9}

\section{Recommendations}

\section{Introduction}

This thesis is based on a study commissioned by the Ministry of Health, Welfare and Sports on the role of nurses in medical end-of-life decisions. The Dutch report of this study (Van Bruchem-van de Scheur et al. 2004) contained a number of recommendations on legislation and policy-making regarding the role of nurses in medical decisionmaking at the end of life. A part of these recommendations is presented, discussed and further developed in this chapter. Moreover this chapter includes the recommendations that are part of chapters 3 through 8 of this thesis.

In view of the lapse between the publication of the Dutch report (2004) and the present thesis (2008), it is important to know that a number of recommendations in the Dutch report have been taken over and/or implemented. Such developments are reported in this chapter.

Recommendations are described with regard to euthanasia and physician-assisted sulcide. They are related to nursing practice, nursing education, institutional guidelines and legislation. Furthermore, recommendations are given with regard to the alleviation of pain and symptoms with a life-shortening intention. Finally, recommendations are given for further research.

\section{Recommendations with regard to euthanasia and physician- assisted suicide}

\section{Nursing practice}

1. Communication with regard to the decision-making process

During the decision-making process, consultations between physicians and nurses were more frequent in hospitals $(78.8 \%)$ and nursing homes $(81.3 \%)$ than in homecare $(41.2 \%)$ (see page 97 ). These differences are substantial and might be explained by the fact that in Dutch homecare collaboration between general practitioners and district nurses is problematic. In spite of these difficulties, improved communication between 
physicians and nurses in homecare is recommended, particularly because this sector has the largest number of reported cases of euthanasia/physician-assisted suicide (see Table 8.1 on page 96). Preferably, these agreements are part of institutional guidelines (see also pages 114-115 for suggestions about the development of guidelines). However, one must know that general practitioners and district nurses do not usually work in the same organisation which can be a hindrance to formulating joint agreements about communication.

Improved communication does not only concern the role of nurses in the decisionmaking process, but also the need to inform each other about the current state of affairs so that physician and nurse can tailor the care to the needs of the patient. In case a euthanasia request is not-granted physicians should inform nurses of their arguments to decline the request. Nurses should be encouraged to raise their questions or doubts with the physician, but on the condition of respect of the confidentiality if asked by the patient. Not only in homecare, but in hospitals and nursing homes as well, communication between physician and nurse could be improved. In these institutions, physicians and nurses usually work together as part of the institutional workforce and, because of this it should be easier to formulate joint guidelines.

\section{Communication concerning the administration of euthanatics}

Prior to the administration of the euthanatics there should be a clear understanding of the responsibilities and tasks when administering the euthanatics. When a physician is insufficiently experienced in managing the infusion, he should ask the nurse in advance for instructions or involve an experienced co-physician. By no means nurses should be requested, or even compelled at the final moment to perform tasks which they are legally not allowed to. Such 'last minute' request may create uncomfortable tensions which could affect the care for the patient. The nurse should make clear to the physician the responsibility of the nursing profession and her refusal to cooperate in activities which are illegal under the Dutch law.

\section{The position of the patient}

In a number of cases, it was the patients' wish not to involve the nurse in the decisionmaking process. The private and sensitive nature of the subject may mean that patients wish to limit discussion to a small and intimate circle of people. Another reason may be that patients still have not developed a relationship of mutual trust with one or more nurses, perhaps due to the changing duties of nurses, recent admission on the ward, or care being recently started at the patient's home. Therefore it is advisable that physicians ask patients whether they want to involve nurses. This is also recommended in the joint euthanasia guidelines for physicians and nurses (AVVV et al. 2006) This guideline states that the physician should discuss with the patient which caregivers should be informed, and what information they should receive. Any objections expressed by patients should be taken into account.

\section{Nursing education}

In the study, a lack of knowledge among nurses has been observed concerning law and regulations on euthanasia/assisted suicide and their legal position (see page 101). This resulted among other things in carelessness concerning the legal consequences of participation in the performing of euthanasia. It is advisable that nurses be better educated in the field of the laws and legislation pertinent to their own role.

Also the Secretary of Health. Welfare and Sports underlined the importance of education. In expressing her viewpoint on the Dutch report she indicated that she would take up the lack of education among nurses issue in her annual letter to the educational or- 
ganisations. It is her opinion that during education sufficient attention must be given to the legal position of nurses (Ross-van Dorp, 2005).

In the education of nurses there should be explicit attention to issues such as communication between physician and nurse, the privacy of the patient, handling one's own emotions and feelings, interests and rights of the patient, the difference between preparatory and administering activities, and observation points which are specific to euthanasia/physician-assisted suicide requests, such as, hidden appeals for help and the degree to which the request is well-considered and voluntary.

The results of the present study could be used in the development of such educational material. Courses could be given by an organisation or institution itself, but it seems more productive that the General Association of Nurses and Caretakers (AWV) organises national education courses. These national courses could be given to implement the revised euthanasia guidelines of the AVVV et al. (2006). Advantage of the latter option is that nurses from different institutions can exchange and compare experiences, and that methods that are producing good results elsewhere can be adopted for one's own practice.

As a result of this recommendation in the Dutch report, the AVVV (current Nurses \& Caregivers Netherlands (V\&VN)) and the Royal Dutch Medical Association (KNMG) have developed a training program 'decisions around the end of life' for nurses. In a pilot in 2006 twenty hospitals were offered the training including opportunities of incorporating the wishes of the organization into the program. Because only one hospital responded, the training was adapted for a broader target group, including physicians, nurses, (legal) policy employees, and caregivers to patients with mental problems. This training is still offered twice annually, where it is observed that only a few nurses take part.

Following of the Cabinet's response to the evaluation of the euthanasia law (Bussemaker \& Hirsch Ballin, 2007) the V\&VN took the initiative to reinvigorate the education of nurses. The Cabinet's response indicated that the education of physicians in the field of euthanasia and other medical end-of-life decisions is very important. The V\&VN believes that it is particularly important that nurses and care-givers also have sufficient knowledge of the different medical end-of-life decisions. For this reason, the V\&VN and the KNMG would like to establish an information point, which nurses could contact directly to get help with questions concerning euthanasia and other medical end-of-life decisions. Physicians already have such an information line. Furthermore, the V\&VN now encourages colleges and Regional Education Centers (ROC's) to give attention to the law and palliative care within their courses.

\section{Institutional guidelines}

Institutional guidelines may play an important roie in improving cooperation between physicians and nurses while preventing procedural misunderstandings that might lead to ethical problems and legal offences. Therefore, guidelines should include a description of the law and regulations, and the roles of physicians, nurses and other care providers, as well as rules for the communication between them. In short, institutional guidelines can provide an important support to (the role of) nurses. It is important that nurses be supported by guidelines because of two reasons. First, euthanasia and physician-assisted suicide do not belong to regular medical practice. Second, euthanasia and physicianassisted suicide are usually not frequently requested and consequently nurses may not have relevant knowledge at hand.

However, it should not be taken for granted that hospitals have such guidelines and, if present, that they are easily reachable or that they describe the nurse's role. This is even more true for homecare organizations and nursing homes (Van Bruchem-van de Scheur et al. 2004). 
During the developing or renewing of institutional guidelines, the national joint guidelines of physicians and nurses can be helpful (AVW et al. 2006). In these guidelines, tasks and responsibilities of both physicians and nurses are clarified and demarcated. In 2006, the fourth revised edition was published, partly adapted on the basis of the Dutch report of the present study.

In the homecare sector, it is probably more difficult to develop joint guidelines of physicians and nurses, because they do not usually work in the same organization. Nevertheless, particularly in this sector nurses benefit from guidelines in which their role and responsibilities are clearly described. Meanwhile, specific guidelines for homecare have been developed (Van Bruchem-van de Scheur et al. 2005). These guidelines have been included in a loose-leaf handbook, to which homecare organisations can subscribe.

\section{Legislation}

1. The membership of nurses in the Regional euthanasia review committees.

It is not advisable to include nurses in the regional euthanasia review committees. Firstly, only $45 \%$ of nurses supported membership of nurses in these committees (see page 102). The task of Regional euthanasia review committees is to answer the question whether or not physicians have followed the due requirements of care, and not to evaluate the process of care and support of patients given by nurses. Their evaluation concerns the legal and moral assessment of a medical action, not the 'ethics of care'. For this reason there is no ethical or legal argument to include nurses in such committees.

This recommendation in the Dutch report of this study not to include nurses in the Regional euthanasia review committees was also adopted in the evaluation report of the euthanasia Act (Onwuteaka-Philipsen et al. 2007). The authors of that study concluded that there were insufficient grounds to structurally modify the composition of the committees. Their study indicated that all but one member of the Regional euthanasia review committees saw no need for a nurse in the committee. Furthermore, they refer to earlier arguments of the legislator to abandon inclusion of nurses in Regional euthanasia review committees:

- The involvement of the nurse in the review process has been guaranteed in other ways, particularly by means of Question 12 in the Model report of the physician concerning nurses' involvement, as well as by the possibility for the committee to request information from the concerned caregiver later on.

- A nurse has not been involved in all cases of euthanasia or physician-assisted suicide.

- A committee's even number of members would not facilitate its decision-making.

It is advisable that the Regional euthanasia review committees pay attention in their Annual Reports to what extent physicians answer the questions in the Model report concerning nurses' involvement in the decision-making. More specifically that they analyse the physicians' answers to the questions: Did you consult the nursing staff/the patient's carers about terminating the patient's life? If so, who did you consult and what was their view? If not, why not?'

Also the committees should be more attentive to the involvement of nurses in the administration of euthanatics.

2. To make consultation of a nurse a legal requirement for the physicians' decisionmaking

There is no sufficient ground to add a due care requirement to the euthanasia law in which it is stated that "if the nurse is involved in the care of the patient, the physician is obliged to consult a nurse in the decision-making". This proposal can be rejected on the 
basis of three reasons. Firstly, on the basis of the opinion of nurses represented in this study, only $22.6 \%$ found it a worthwhile proposal, and $58.2 \%$ did not consider it necessary to give a legally binding character to nurses' consultation (see page 103). These nurses indicated implicitly that it concerns a medical decision

Secondly, there are practical objections to requiring physicians to consult a nurse. Such legal constructs may become problematic if the situations on which they are to decide are fluid and in constant change. Problems of interpretation may easily arise, e.g. with regard to differences of opinion on who is the nurse 'involved' and whether he or she should represent only his or her own opinion or also those of other nurses who took part in the care for the patient, and how to act in case of differing opinions among nurses.

Thirdly, the lack of knowledge among nurses with regard to the euthanasia law and regulations forms a contraindication to formalize their input in the decision-making process.

Nevertheless the desirability to involve the nurse in the decision-making process, particularly for providing information on the psychosocial situation of the patient, remains intact. As it is stated in the guidelines of the AVVV et al. (2006): When nurses are involved in the daily care of patients who make a request for euthanasia, it is highiy desirable that they are involved in the decision-making process. This because they, by their daily involvement and specific expertise, can contribute to careful decision-making by the physician.

Also in the evaluation report of the Euthanasia Law (Onwuteaka-Philipsen et al. 2007) no recommendation is formulated with regard to making consultation of a nurse a legal requirement for the physicians' decision-making. The subject even remains unmentioned.

\section{Preparatory activities for the administration of euthanatics}

Concerning preparing euthanatics, this was not seen as a nursing task by a majority $(62.9 \%)$ of nurses (see pages 103-104). It is advisable to leave this task to the physician or pharmacy. When the physician has insufficient expertise, the pharmacist can be asked to prepare the euthanatics solution. The workability of this seems beyond doubt.

Also with regard to inserting an infusion needle, a majority $(54.1 \%)$ of nurses did not see this as a nursing task (see pages 103-104). Here it is also recommended to let the physician perform this activity.

There may be practical problems implementing this, such as when physicians are insufficiently skilled in this activity, particularly in the Dutch homecare sector. However, the medical profession should not shift this practical problem to the nursing profession but resolve it within their own profession.

Euthanasia and physician-assisted suicide do not belong to regular medical practice. Therefore, nurse's activities in this area are not regular practice either, even when they concern only preparatory activities. Those activities have an extraordinary moral character which, strictly speaking, fall outside the professional domain of physicians and nurses. Nevertheless, although they may be practised under certain conditions (see the due care requirements on page 13), it remains the exclusive task and responsibility of the physician.

This recommendation done in the Dutch report of this study has been partly taken over by the Government. Following the response by the State Secretary of Health, Welfare and Sports (Ross-van Dorp, 2005) to the report, the joint guidelines of physicians and nurses (AVV et al. 2006) include a distinction between various preparatory activities: inserting an infusion needle may be considered a task for nurses, while preparing euthanatics may not be. This latter activity remains moreover unmentioned in the guideline. 


\section{Recommendations with regard to alleviation of pain and symptoms with a life-shortening intention}

The practice of alleviation of pain and symptoms with a life-shortening intention is not transparent and represents a large 'grey' area of activities. Nurses are often not informed about the intention of the treatment (namely ending the life of a patient), are insufficiently aware of their responsibilities, perform activities which are in principal illegal, insufficiently voice their objections and concerns within the own organisation, and are insufficiently supported within their organisational guidelines. Therefore, it is advisable to improve the clarity on these issues, first by promoting better communication between physician and nurse (and patient/relatives).

The conceptual and intentional boundaries of this medical decision should be clearly defined and the responsibility and task of the concerned care providers, particularly nurses, should be communicated clearly by means of guideline development. This task should be undertaken by the concerned professional groups, following euthanasia guideline development. Those guidelines should include a conceptual definition of alleviation of pain and symptoms with a life-shortening intention and also other medical end-of-life decisions in order to clarify the differences between the various types of medical decisions. Furthermore, the guidelines should include a description of the law and regulations, the roles of physicians, nurses and other care providers as well as rules for the communication between them, and an ethical framework on which the acceptability of a proposed treatment can be evaluated.

The most important purpose of this recommendation is in general to improve the transparency of the process of alleviation of pain and symptoms in the last stage of the patient's life, and in particular the alleviation of pain and symptoms with a life-shortening intention.

Four years after publication of the Dutch report of this study, this guideline is still not implemented on a national level. It is unknown to what extent institutions have developed their own guidelines or directives in this area.

A positive point is that in the Netherlands the number of decisions regarding alleviation of pain and symptoms with a life-shortening intention has declined from $4 \%$ of all deaths in 1990 to $1 \%$ in 2005 (Onwuteaka-Philipsen et al. 2007). An explanation could be the improvement of palliative care, and as a result the decrease of requests for hastening the patient's death. Another explanation may be the recent development of and emphasis on other methods of alleviation of pain and symptoms, such as continuous deep sedation until death occurs (Onwuteaka-Philipsen et al. 2007).

\section{Follow-up research}

1. Perception of the role of nurses by physicians

It is recommended to include in quantitative follow-up studies concerning medical end-oflife decisions among physicians a number of questions concerning the role of nurses, in particular concerning the physician's perception of the role of nurses. Such research produces important comparison material with respect to results from this present research.

\section{The physicians' report to the Regional euthanasia review committee}

There is need for research concerning the question in the physicians' report to the Regional euthanasia review committee about the role of the nurses, and in particular how often this question has been answered by the physician and what the content is of the 
answers. Also the actual desirability of the question from the perspective of the physician could be the subject of further study.

\section{Institutional guidelines}

An interesting point for research concerns the role which guidelines play in euthanasia/physician-assisted suicide and other medical end-of-life decisions. Institutional guidelines could be analyzed on a large number of points, among which, the role granted to nurses in the various phases of the euthanasia process. The data from such research can be used for the revision of guidelines and/or consensus meetings with special attention to the establishment of 'best practices'.

Meanwhile the evaluation study of the euthanasia law (Onwuteaka-Philipsen et al. 2007) analysed 107 guidelines (originating from 5 sectors). The analysis focused mainly on the aspects of due care requirements. The role of nurses was analysed as well on the following points: preparatory activities, consultation concerning the time of administering and the administration.

At present, the research group 'Public health at the end of life' at the VU University Medical Centre in Amsterdam is studying euthanasia guidelines in health care institutions. This study also includes the role of nurses in euthanasia. To date (November 2008) no data have been published.

\section{Wishes of patients}

Another point for further research is to inquire among patients to what extent they value involvement of the nurse in the various phases of the euthanasia/physician-assisted suicide process. An important research question could be what reasons patients would have to not involve the nurse in the decision-making process. This could provide important additional data to this study.

5. Medical decisions, not (yet) quantitative studied

With respect to the role of the nurse, in a number of medical end-of-life decisions (ending of life without an explicit request of the patient, not starting or stopping treatments which were without prospect or futile in conforming to actual medical knowledge, withholding artificial administration of fluids and food), this study did not come further than the preliminary qualitative study. This was mainly due to absence of univocal conceptual definitions in the nursing practice (see page 26). It is recommended to do further studies into the role of nurses in these medical end-of-life decisions.

In this study palliative sedation was not included because the discussion on this type of medical end-of-life decision has only recently got underway. It was only during the performing of the present study that the first research results about the practice of palliative sedation among Dutch physicians were published (Van der Wal et al. 2003). Meanwhile palliative sedation has been added to the spectrum of medical end-of-life decisions (KNMG, 2005). The role of nurses in palliative sedation, therefore, would also be an interesting point for further research.

\section{References}

AVWV, NU'91, KNMG. (2006). Handreiking voor Samenwerking Artsen, Verpleegkundigen en Verzorgenden bij Euthanasie. (Directive for collaboration physicians, nurses, and caretakers in euthanasia). [4" Edition]. Utrecht: AVVV/NU'91/KNMG. (In Dutch).

Bussemaker, J. \& Hirsch Ballin, E.M.H. (14 november 2007). Kabinetsstandpunt op de evaluatie van de Wet Toetsing levensbeäindiging op verzoek en hulp bij zelfdoding (Euthanasiewet): 
118 | Chapter 9

Kamerstuk. (Cabinet's point of view concerning the termination of life on request and assisted suicide Act (Euthanasia Law): Letter to the chairman of the Dutch Lower Chamber). Den Haag: Ministerie van Volksgezondheid en Sport. (In Dutch).

KNMG (Royal Dutch Medical Association). (2005). KNMG-richtlijn palliatieve sedation. (KNMGguideline palliative sedation). Utrecht: KNMG. (In Dutch).

Onwuteaka-Philipsen, B.D., Gevers, J.K.M., van der Heide, A., van Delden, J.J.M., Pasman, H.R.W. Rietjens, J.A.C. et al. (2007). Evaluatie Wet toetsing levensbeëindiging op verzoek en hulp bij zelfdoding. (Evaluation of the Law on the Termination of Life on Request and Assisted Suicide). Den Haag: ZonMw. (In Dutch).

Ross-van Dorp, C. (4 Maart 2005). Rol van verpleegkundigen bij euthanasie: Kamerstuk. (Role of nurses in euthanasia: Letter to the chairman of the Dutch Lower Chamber). Den Haag: Ministerie van Volksgezondheid, Welzijn en Sport. (In Dutch).

Van Bruchem-van de Scheur, A., van der Arend, A., Spreeuwenberg, C., van Wijmen, F. \& ter Meuten, R. (2004). De rol van verpleegkundigen bij medische beslissingen rond het levenseinde. Verslag van een landelijk onderzoek naar betrokkenheid en praktijken. (The role of nurses in medical end-of-life decisions. Report of a national study into involvement and practices). Utrecht: Uitgeverij De Tijdstroom. (In Dutch).

Van Bruchem-van de Scheur, G.G., van der Arend, A.J.G. \& Spreeuwenberg, C. (2005). Euthanasie en hulp bij zelfdoding in de thuissituatie: De rol van wijkverpleegkundigen en andere zorgverleners (Euthanasia and physician-assisted suicide in the home situation: The role of district nurses and other care providers). In Handboek Zorg Thuis, B 3.8-1 - B 3.8-24. Amsterdam/Maarssen: Reedbusiness. (In Dutch).

Van der Wal, G., van der Heide, A., Onwuteaka-Philipsen, B.D. \& van der Maas, P.J. (2003). Medische besluitvorming aan het einde van het leven: De praktik en de toetsingsprocedure euthanasie. (Medical decision-making at the end of live: The practice and the notification procedure euthanasia). Utrecht: Uitgeverij De Tijdstroom. (In Dutch). 


\section{English summary}

This thesis focuses on the main outcomes of the Dutch study into the role of nurses in medical end-of-life decisions. The study was commissioned by the minister of Health, Welfare and Sports as a result of discussion points concerning the role of nurses in euthanasia/physician-assisted suicide. The aim of the study was to investigate the role, perceptions, responsibilities, and problems of nurses in medical end-of-life decisions in order to advise the Dutch government in legislation and policy-making regarding the role of nurses. In November 2004 the results of the study were presented in a Dutch report to the State Secretary of Health, Welfare and Sports.

This thesis is based on this report and is compiled of five articles (chapters 3-7). Three articles focus on the role of nurses in euthanasia/physician-assisted suicide. One article focuses on the attitudes of nurses towards euthanasia/physician-assisted suicide, and one article focuses on the role of nurses in alleviation of pain and symptoms with a lifeshortening intention.

Chapter 1 provides an introduction to the subject of the study. The chapter begins with an overview of the most important events which mark the role of nurses from 1985 to 2001 , the year in which the present research began.

A year of particular meaning was 1998 when five Regional euthanasia review committees were established in the Netherlands and discussion arose concerning the inclusion of nurses in these committees. The minister of Health considered this not yet necessary, but promised a study into the role of nurses in medical end-of-life decisions.

In the introduction the aim and research method of the study are described, followed by definitions of the different medical end-of-life decisions, and some points of the Dutch euthanasia law.

The national relevance of the study is described from scientific, social and nursing perspective. The relevance for the nursing profession is among others the quality improvement of the activities of nurses and the further development of guidelines in this field.

From an international point of view, the study is relevant because it brings up new issues in the discussion concerning the role of nurses, such as their role in preparing euthanatics and inserting an infusion needle to administer the euthanatics. The Dutch data presents useful information for nurses in other countries to help them define their (future) role in euthanasia and physician-assisted suicide.

Finally, the outline of the thesis is given.

Chapter 2 describes the method of the study, which consists of two parts: qualitative and quantative. First a qualitative study was conducted to explore the subject. This consists of 14 individual semi-structured in-depth interviews with nurses/caregivers and 6 focus group interviews in which a total of 42 nurses/ caregivers took part, as well as, 9 nonnurses were interviewed individually among which physicians.

The results of the qualitative part of the study were important for constructing a questionnaire to be used during the quantitative study. 
Because a randomly drawn sample would give a limited response, the study adopted a purposed sampling approach, seeking to recruit nurses with experience with euthanasia or physician-assisted suicide.

Contact persons in organizations recruited 1509 nurses who each received a questionnaire. The absolute response rate was $82.0 \%$, and $78.1 \%(1179)$ sufficient to be used for analysis.

Both the qualitative and the quantitative parts of the study are described on the basis of the following topics: recruitment of participants, data collection, data analysis, validity and reliability, and ethical considerations.

Although the articles in this thesis (chapters 3-7) are based on the quantitative study, a summary of the results of the qualitative study is included, mentioning the areas relevant to the medical end-of-life decisions in the quantitative study, namely: euthanasia/ physician-assisted suicide and the alleviation of pain and symptoms with a lifeshortening intention.

Choices are also discussed with regard to the changeover from the qualitative to the quantitative part of the study. Not all medical decisions appeared suitable for a quantitative approach because of conceptual confusion among nurses.

Chapter 3 describes the role of nurses with respect to the request by the patient for euthanasia or physician-assisted suicide, the decision-making process and the administration of euthanatics.

The role of nurses is reported in three settings (hospitals, homecare and nursing homes) and shows substantial differences between the intramural (hospitals and nursing homes) and the extramural (homecare) sector.

Unlike cases in hospitals and nursing homes, in homecare the physician was more often the first person with whom patients discussed their request for euthanasia/physicianassisted suicide. An explanation might be that in homecare the physician-patient relationship is, generally speaking, more longstanding and confidential than in the other sectors.

Consultation between physicians and nurses during the decision-making process took place quite often in hospitals and nursing homes and less frequently in homecare. These differences may be related to the different organisational structure in homecare, where physicians and nurses usually do not work in the same organisation, and do not generally encounter each other in the presence of the patient or elsewhere.

While the administration of euthanatics is by law exclusively reserved to the physician, in some cases $(12.2 \%)$ the nurse performed this act together with or without a physician. Sometimes this occurred because the physician was insufficiently experienced in adequately managing the infusion. Nurses who administer euthanatics or assist in a suicide risk both criminal prosecution and disciplinary measures.

Chapter 4 focuses on the role of district nurses in euthanasia/physician-assisted suicide in homecare. The nurses' role is presented in four stages, with respect to: requests for euthanasia/physician-assisted suicide, the decision-making process, the administration of euthanatics, and aftercare.

Characterising for the role of district nurses is that they have a limited role in euthanasia/physician-assisted suicide in the home situation, with exception of the aftercare.

In $22.3 \%$ of 278 cases, patients spoke first to a nurse about their request for euthanasia/ physician-assisted suicide. This may be the result of the fact that general practitioners typically have a longer and more confidential relationship with the patient than the district nurse. District nurses on the other hand change frequently, caused by an increasing number of part-time posts, which is not favourable for building a confidential relationship with the patient. 
In fewer than half $(41.2 \%)$ of 267 cases, district nurses were involved in the decisionmaking process. This rather low percentage is possibly explained by the fact that they usually work separately form general practitioners and do not often see each other.

The presence of a district nurse during administration of euthanatics was more the exception ( $13.3 \%$ of 264 cases) than the rule. In two cases ( $8.3 \%$ of 24 cases), a district nurses administered the euthanatics together with the physician.

In $80.3 \%$ of 264 cases, district nurses provided some degree of aftercare to the surviving relatives, among which most frequently a personal talk during a home visit. This high rate of aftercare probably stems, at least partly, from a desire to prevent problems arising through early observation of developing issues.

Chapter 5 focuses on the role of nurses in euthanasia/physician-assisted suicide in hospitals, and presents the role of nurses during the request for euthanasia/physicianassisted suicide, the decision-making process, and the administration of euthanatics. Subsequently, the article discusses the role of existing euthanasia guidelines in hospitals.

In $45.1 \%$ of 381 cases, nurses were the first person with whom patients discussed their request for euthanasia or physician-assisted suicide.

Consultation between physicians and nurses during the decision-making process took place in $78.8 \%$ of 359 cases. This high percentage of consultation may be related to the organisational structure of hospitals, where collaboration between physicians and nurses is usually formalised in several scheduled consultation moments.

In $15.4 \%$ of 143 cases, nurses administered the euthanatics together with or without a physician.

It is not self-evident that hospitals have guidelines concerning euthanasia and/or physician-assisted suicide and, if they are present (65.3\%) that they are 'within arm's reach' or describe the nurses' role. Therefore, in many cases nurses are not supported by such guidelines.

It is important that nurses be supported by guidelines, particularly when euthanasial physician-assisted suicide are not frequently requested, and consequently, nurses may not have relevant knowledge at hand. Moreover, institutional guidelines may play an important role in improving collaboration between physicians and nurses and in preventing procedural misunderstandings that may cause ethical problems and legal infringements.

Chapter 6 presents the attitudes of 1172 nurses towards three issues concerning their role in euthanasia and physician-assisted suicide, and discusses the findings in the context of common practices and policies in the Netherlands.

Nurses held diverging opinions about membership of Regional euthanasia review committees: $45 \%$ supported membership of nurses on these committees, $8.9 \%$ were against, and $41.6 \%$ had no opinion about the issue.

Almost a quarter $(22.6 \%)$ of the nurses approved the proposal to regulate the physicians' obligation to consult a nurse before making their decisions about situations where a nurse is involved in the daily care of the patient. More than half of nurses $(58.2 \%)$ found this too far-reaching, and $14.0 \%$ had either an unclear opinion or an opinion with an unclassifiable meaning.

A minority $(40.8 \%)$ of nurses stated that inserting an infusion needle to administer euthanatics could be an acceptable nursing task. A majority $(54.1 \%)$ believed that this should not be part of their role. Almost one third $(31.9 \%)$ of the nurses stated that preparing euthanatics could be an acceptable nursing task, while the majority $(62.9 \%)$ were opposed to this.

The findings indicated that nurses hesitated to extend their role into the issues described. Also the research team did not discern any necessity to extend the role of 
nurses, partly because the professional responsibility of Dutch nurses is laid down by law.

Chapter 7 describes the role of nurses in 330 cases of alleviation of pain and symptoms (APS) with a life-shortening intention. The reasons for APS with a life-shortening intention are described and the role of nurses is presented with respect to the decisionmaking, and the administration of medication in hospitals, homecare and nursing homes. In about half (48.8\%) of cases, relatives requested to hasten the patients' death or made remarks in that direction. In a number of these cases, relatives regarded themselves responsible for taking care of the patients' interests, particularly when the patient had either moderate or no means of communication.

During the decision-making preceding APS with a life-shortening intention, consultation between physician and nurse was more frequent in hospitals $(62.6 \%)$ and nursing homes $(65.9 \%)$ than in homecare $(44.3 \%)$.

In almost a quarter $(23.0 \%)$ of cases, nurses either disagreed with or had doubts about the physician's decision, for example because of the absence of pain and/or other symptoms.

Although not obliged, it is desirable that the physician consult the nurse during the decision-making, especially when involving nurses in administering the medication, which is frequently $(81.5 \%)$ the case, especially in hospitals and nursing homes.

APS with a life-shortening intention does not belong to normal medical practice. Consequently, nurses' involvement in administering the medication could mean involvement of nurses in a criminal act.

In $18.8 \%$ of cases, nursed held opposing views with regard to the administration of medication; some were not willing to administer the medication, but some were. In general, nurses respected each other's point of view and the medication was administered by nurses who agreed with the physician's policy.

Chapter 8 discusses the main conclusions of the thesis. One conclusion is that the role of nurses in euthanasia/physician-assisted suicide needs specification by sector. There were considerable differences between the intramural sector (hospitals and nursing homes) and the extramural sector (homecare). In the homecare sector, which has by far the largest reported number of cases of euthanasia/physician-assisted suicide in the Netherlands, the nurse is considerably less involved.

Another conclusion is that the role of nurses varied during the different stages identified within the process of euthanasia/physician-assisted suicide. Firstly, considerable fragmentation in the involvement of the nurse throughout the stages was witnessed. For example, in $18.9 \%$ of cases, the nurse who was present during the administration of the euthanatics did not have a role in the decision-making process. An important reason for this 'fragmented' involvement might be the changing duties of nurse. Secondly, considerable disproportion in nurses' role throughout the stages was witnessed. During decision-making, their role could be expanded. Although nurses were consulted in the majority of cases, in at least a quarter of the cases, there was a considerable lack of consultation between physician and nurses. In the administering of euthanatics, nurses were sometimes involved too strongly, as in $12.2 \%$ of cases nurses administered the euthanatics together with or without a physician.

Although the study focused on actual practice, the nurses were additionally asked for their opinions on three particular issues: their participation in the reviewing process, their role in the physician's decision-making process and their involvement in preparatory activities in the administration of euthanatics. There was no majority point of view among nurses to include these three issues in new regulations regarding the role of nurses in euthanasia and physician-assisted suicide. The research team also saw no reason to do so. 
The medical end-of-life decision alleviation of pain and symptoms with a life-shortening intention was included in this study because this is a 'grey area' where much uncertainty exists with regard to the role of nurses. As well as it is likely that many nurses are confronted and even involved in the performing of this medical end-of-life decisions.

Although the frequency has not been investigated, the study confirms that there is indeed a grey area between on the one side alleviation of pain and symptoms, and on the other side euthanasia and active ending of life without request. This became clear from results where: nurses disagreed with or had doubts about the physician's decision to hasten the patient's death (23\% of cases), the physician did not inform nurses about the aim of the medication (to hasten the patient's death) $(27.3 \%$ of cases), and a part of the nursing team was not willing to administer the medication ( $18.8 \%$ of cases).

This unclear practice of the alleviation of pain and symptoms with a life-shortening intention is also maintained by nurses, particularly in situations in which physician and nurse had the same intention, namely to hasten the patients' death.

Finally, conclusions with regard to the methodology of the study are discussed.

Medical end-of-life decisions such as euthanasia and physician-assisted suicide are sensitive and complex issues to study through quantitative methods. Therefore, a practical approach was chosen, namely by asking respondents to place their responses within the context of their most recent case of a medical end-of-life decision within the last two years.

The recruitment of respondents by means of contact persons seemed a useful approach. The study got high participation rates: a large number of organisations nationwide were involved, and a large number of cases of high quality (most recent cases) were included. Therefore, though a randomly drawn sample was lacking and non-response could have affected the results a little, the conclusion may be justified that the study was representative of Dutch nurses who have had experience with euthanasia/physician-assisted suicide and the alleviation of pain and symptoms with a life-shortening intention.

Chapter 9 describes the recommendations. Also the development/implementation in recommendations between the period of publication of the Dutch report (2004) and the present thesis (2008) are reported.

Concerning euthanasla and physician-assisted suicide the recommendations are related to nursing practice, nursing education, institutional guidelines, and legislation.

Improved communication between physicians and nurses is recommended, particularly in homecare. This does not only concern the role of nurses in the decision-making process and in the administration of euthanatics, but also the need to inform each other about the current state of affairs so that physician and nurse can tailor the care to the needs of the patient.

It is advisable that nurses be educated in the field of the laws and legislation. In the education of nurses there should be explicit attention to issues such as communication between physician and nurse, the privacy of the patient, handling one's own emotions and feelings, interests and rights of the patient, the difference between preparatory and administering activities.

With regard to legislation, there is an insufficient interest base among nurses to include nurses in Regional euthanasia review committees. Also there is no ethical or legal argument to include nurses in such committees; their evaluation concerns the legal and moral assessment of a medical action, not the 'ethics of care'.

There is no sufficient ground to add a due care clause to the euthanasia law in which it is stated that "if the nurse is involved in the care of the patient, the physician is obliged to consult a nurse in the decision-making". This proposal can be rejected on the basis of: only $22.6 \%$ of nurses found it a worthwhile proposal, and the lack of knowledge among nurses with regard to the euthanasia law and regulations. 
Concerning preparing euthanatics, this was not seen as a nursing task by a majority $(62.9 \%)$ of nurses. It is advisable to leave this task to the physician or pharmacy. Also with regard to inserting an infusion needle, a majority $(54.1 \%)$ of nurses did not see this as a nursing task. Here it is also recommended to let the physician perform this activity.

Along with an insufficient interest base among nurses, another important argument is that euthanasia and physician-assisted suicide do not belong to regular medical practice. Therefore, nurse's activities in this area are not regular practice either, even when they concern only preparatory activities.

With regard to alleviation of pain and symptoms with a life-shortening intention, it is advisable to improve the clarity of this 'grey' practice by promoting better communication between physician and nurse (and patient/relatives). The conceptual and intentional boundaries of this medical decision should be clearly defined and the responsibility and task of the concerned care providers, particularly nurses, should be communicated clearly by means of guideline development.

Concerning further research, it is recommended to research in quantitative follow-up studies concerning medical end-of-life decisions among physicians, the role of nurses and in particular the physician's perception of their role.

There is also need for research concerning the question in the physicians' report to the Regional euthanasia review committee about the role of the nurses, and the wishes of the patient concerning the involvement of the nurse in the various phases of the euthanasia process.

An other point for research concerns the role which guidelines play in euthanasia/physician-assisted suicide and other medical end-of-life decisions. Institutional guidelines could be analyzed on a large number of points, among which, the role granted to nurses in the various phases of the euthanasia process.

Finally, it is recommended to do further studies into the role of nurses in the medical endof-life decisions, which were not (yet) quantitatively studied in this research (ending of life without an explicit request of the patient, not starting or stopping treatments which were without prospect or futile in conforming to actual medical knowledge, withholding artificial administration of fluids and food). Also the role of nurses in palliative sedation would be an interesting point for further research. 


\section{Nederlandse samenvatting}

Dit proefschrift bevat de belangrijkste resultaten van de studie naar de rol van verpleegkundigen bij medische beslissingen rond het levenseinde. Deze studie werd ingesteld door de minister van Volksgezondheid, Welzijn en Sport naar aanleiding van discussie over de rol van verpleegkundigen bij euthanasie/hulp bij zelfdoding. Met het onderzoek werd beoogd inzicht te verschaffen in de rol, opvattingen en verantwoordelijkheden van verpleegkundigen bij medische beslissingen rond het levenseinde en de knelpunten die zich daarbij voordoen. Het doel was om de Nederlandse regering te adviseren over wetgeving en beleidsvorming ten aanzien van de rol van verpleegkundigen. In november 2004 werd het Nederlandstalige onderzoeksrapport aangeboden aan de Staatssecretaris van Volksgezondheid, Welzijn en Sport.

Het proefschrift is gebaseerd op boven bedoeld rapport en is voornamelijk samengesteld uit artikelen (hoofdstukken 3-7). Drie artikelen gaan over de rol van verpleegkundigen bij euthanasie/hulp bij zelfdoding. Eèn artikel gaat in op de meningen van verpleegkundigen ten aanzien van euthanasie/hulp bij zelfdoding, en éen artikel betreft de rol van verpleegkundigen bij pijn- en symptoombestrijding met een levensbekortende intentie.

Hoofdstuk 1 bevat een introductie in het onderwerp van de studie. Dit hoofdstuk begint met een overzicht van de belangrijkste momenten die de rol van verpleegkundigen markeren vanaf 1985 tot 2001, het jaar waarin onderhavig onderzoek van start ging.

Een jaar van bijzondere betekenis was 1998 toen vijf Regionale toetsingscommissies euthanasie werden ingesteld en discussie rees over het al dan niet zitting nemen van verpleegkundigen in deze commissies. De minister van Volksgezondheid, Welzijn en Sport achtte dit vooralsnog niet noodzakelijk, maar zegde wel een onderzoek toe naar de rol van verpleegkundigen bij medische beslissingen rond het levenseinde.

Verder worden het doel en de vraagstelling van de studie beschreven, gevolgd door omschrijvingen van de verschillende medische beslissingen rond het levenseinde en enkele aspecten van de Nederlandse euthanasiewetgeving.

De nationale relevantie van de studie wordt beschreven vanuit wetenschappelijk, maatschappelijk en verpleegkundig perspectief. De relevantie voor de verpleegkundige professie is onder meer de kwaliteitsverbetering van het verpleegkundig handelen en de verdere ontwikkeling van richtlijnen op dit gebied. Vanuit internationaal oogpunt is de studie relevant doordat zij nieuwe vraagstukken aansnijdt in de discussie over de rol van verpleegkundigen, zoals hun rol bij het klaarmaken van euthanatica en het inbrengen van een infuusnaald ten behoeve van het toedienen ervan. Verder kunnen de resultaten behulpzaam zijn voor verpleegkundigen in andere landen in het vaststellen van hun (toekomstige) rol bij euthanasie.

Ten slotte wordt een overzicht van het proefschrift gegeven.

Hoofdstuk 2 beschrijft de methode van de studie, die bestond uit twee delen. Eerst werd een kwalitatieve studie verricht om het onderwerp te verkennen. Deze bestond uit 14 halfgestructureerde diepte-interviews met verpleegkundigen en 6 focusgroepinterviews waaraan totaal 42 verpleegkundigen/verzorgenden IG deelnamen. Verder werden 9 nietverpleegkundigen individueel geïnterviewd waaronder artsen. 
De resultaten van deze verkenning waren belangrijk voor het ontwikkelen van een vragenlijst voor het kwantitatieve deel van de studie.

Omdat een ad random steekproef een te beperkte respons zou geven, werd ervoor gekozen om doelgericht verpleegkundigen te werven die ervaring hadden met verzoeken tot euthanasie/hulp bij zelfdoding. Contactpersonen in organisaties wierven 1509 verpleegkundigen/verzorgenden welke allen een vragenlijst ontvingen. De absolute respons was $82 \%$ en $78,1 \%$ (1179) was bruikbaar voor analyse.

Zowel de kwalitatieve als de kwantitatieve studie worden beschreven op basis van de volgende onderwerpen: werving van respondenten, dataverzameling, data-analyse, validiteit en betrouwbaarheid, en ethische overwegingen.

Dit hoofdstuk bevat ook een samenvatting van de resultaten van het kwalitatieve onderzoek van de medische beslissingen die in het kwantitatieve onderzoek aan bod komen, namelijk: euthanasie/hulp bij zelfdoding en pijn- en symptoombestrijding met een levensbekortende intentie.

Ook worden keuzes bediscussieerd met betrekking tot de overgang van de kwalitatieve naar de kwantitatieve studie. Niet alle medische beslissingen bleken geschikt voor een kwantitatieve benadering vanwege conceptuele verwarring onder respondenten.

Hoofdstuk 3 beschrijft de rol van verpleegkundigen met betrekking tot het verzoek van de patiënt om euthanasie/hulp bij zelfdoding, het besluitvormingsproces en de toediening van euthanatica. De rol van verpleegkundigen wordt gerapporteerd voor drie settings: ziekenhuizen, thuiszorg en verpleeghuizen.

Er blijken grote verschillen te bestaan tussen de intramurale (ziekenhuizen en verpleeghuizen) en de extramurale (thuiszorg) sector. In tegenstelling tot ziekenhuizen en verpleeghuizen, was in de thuiszorg de arts het vaakst de eerste persoon met wie patiënten hun verzoek tot euthanasie/hulp bij zelfdoding bespraken. Een verklaring kan zijn dat in de thuiszorg de arts-patiënt relatie in het algemeen langduriger en vertrouwelijker is dan in de andere sectoren.

Overleg tussen artsen en verpleegkundigen in het besluitvormingsproces vond in ziekenhuizen en verpleeghuizen vaak plaats, maar minder frequent in de thuiszorg. Deze verschillen kunnen worden gerelateerd aan de andere organisatiestructuur in de thuiszorg, waar artsen en verpleegkundigen in het algemeen niet in dezelfde organisatie werken en elkaar doorgaans niet ontmoeten in aanwezigheid van de patiënt of elders.

Hoewel het toedienen van euthanatica volgens de wet een exclusieve taak van de arts is, voerde in sommige gevallen $(12,2 \%)$ de verpleegkundige deze handeling uit, al dan niet samen met de arts. Soms gebeurde dit doordat de arts onvoldoende ervaren was in het bedienen van het infuussysteem. Verpleegkundigen die euthanatica toedienen of assisteren bij zelfdoding riskeren zowel strafrechtelijke als tuchtrechtelijke vervolging.

Hoofdstuk 4 spitst zich toe op de rol van wijkverpleegkundigen bij euthanasie/hulp bij zelfdoding in de thuiszorg. De rol van verpleegkundigen wordt beschreven met betrekking tot het verzoek van de patiënt om euthanasie/hulp bij zelfdoding, het besluitvormingsproces, de toediening van euthanatica en de nazorg.

Kenmerkend voor wijkverpleegkundigen is dat zij een beperkte rol hebben bij euthanasie/hulp bij zelfdoding in de thuissituatie. In $22,3 \%$ van 278 gevallen spraken patiënten ais eerste met de wijkverpleegkundige over hun verzoek tot euthanasie/hulp bij zelfdoding. Dit hangt waarschijnlijk samen met het feit dat huisartsen doorgaans een langdurige en vertrouwelijke relatie hebben met de patiënt. Wijkverpleegkundigen daarentegen wisselen frequent. Dat wordt veroorzaakt door de toename van het aantal parttime werkenden, hetgeen niet bevorderlijk is voor het opbouwen van een vertrouwensrelatie met de patiënt. 
In minder dan de helft $(41,2 \%)$ van 267 gevallen waren wijkverpleegkundigen betrokken bij het besluitvormingsproces. Dit tamelijk lage percentage is verklaarbaar doordat zij doorgaans gescheiden werken van huisartsen en deze niet vaak ontmoeten.

De aanwezigheid van een wijkverpleegkundige bij het toedienen van euthanatica was eerder uitzondering (13,3\% van 264 gevallen) dan regel. In twee gevallen dienden wijkverpleegkundigen de euthanatica toe samen met de arts.

In $80,3 \%$ van de 264 gevallen boden wijkverpleegkundigen enigerlei vorm van nazorg aan nabestaanden, waaronder meestal een persoonlijk gesprek tijdens een huisbezoek. Deze hoge mate van nazorg komt, tenminste gedeeltelijk, voort uit de wens problemen te voorkomen door vroegtijdige observatie van zich ontwikkelende kwesties.

Hoofdstuk 5 spitst zich toe op de rol van verpleegkundigen bij euthanasie/hulp bij zelfdoding in de ziekenhuizen en beschrijft de rol van verpleegkundigen met betrekking tot het verzoek van de patiënt om euthanasie/hulp bij zelfdoding, het besluitvormingsproces en de toediening van euthanatica. Verder komt de betekenis van bestaande euthanasierichtlijnen in ziekenhuizen aan bod.

Kenmerkend voor verpleegkundigen in ziekenhuizen is dat zij frequent een rol hebben bij euthanasie/hulp bij zelfdoding. In $45,1 \%$ van de 381 gevallen waren verpleegkundigen de eerste persoon met wie patiënten hun verzoek tot euthanasie/hulp bij zelfdoding bespraken. In $78,8 \%$ van de 359 gevallen waren verpleegkundigen betrokken in het besluitvormingsproces. In $15,4 \%$ van de 143 gevallen dienden verpleegkundigen de euthanatica toe al dan niet samen met de arts.

Het is niet vanzelfsprekend dat ziekenhuizen richtlijnen hebben over euthanasie/hulp bij zelfdoding en, als ze aanwezig zijn, dat ze binnen handbereik zijn en de rol van verpleegkundigen beschrijven. Dientengevolge worden veel verpleegkundigen niet ondersteund door dergelijke richtlijnen. Toch is zo'n ondersteuning belangrijk, vooral wanneer de euthanasie/hulp bij zelfdoding niet vaak wordt gevraagd, en bijgevolg, verpleegkundigen geen relevante/actuele kennis hebben. Voorts kunnen de instellingsrichtlijnen een belangrijke rol spelen bij het verbeteren van de samenwerking tussen artsen en verpleegkundigen en bij het voorkomen van procedurele misverstanden die kunnen leiden tot ethische problemen en wettelijke overtredingen.

Hoofdstuk 6 presenteert de mening van 1172 verpleegkundigen over drie vraagstukken met betrekking tot hun rol bij euthanasie/hulp bij zelfdoding en bediscussieert de bevindingen in de context van algemene praktijken en het beleid in Nederland.

Verpleegkundigen hadden uiteenlopende meningen over het lidmaatschap van de Regionale toetsingcommissies euthanasie: $45 \%$ ondersteunde het lidmaatschap van verpleegkundigen in deze commissies, $8,9 \%$ was tegen en $41,6 \%$ had geen mening over dit vraagstuk.

Bijna een kwart $(22,6 \%)$ van de verpleegkundigen vond het een goed voorstel om artsen te verplichten een verpleegkundige te consulteren in de besluitvorming wanneer zij betrokken zijn bij de dagelijkse zorg van de patiënt. Meer dan de helft $(58,2 \%)$ van de verpleegkundigen vond dit te ver gaan en $14,0 \%$ had een onduidelijke of een niet classificeerbare mening.

Een minderheid $(40,8 \%)$ van de verpleegkundigen stelde dat het inbrengen van een infuusnaald ten behoeve van het toedienen van euthanatica een verpleegkundige taak zou kunnen zijn. Een meerderheid $(54,1 \%)$ was van mening dat deze taak geen deel van hun rol zou moeten uitmaken. Bijna een derde $(31,9 \%)$ van de verpleegkundigen stelde dat het klaarmaken van euthanatica een verpleegkundige taak zou kunnen zijn, terwijl de meerderheid $(62,9 \%)$ daar tegen was.

De bevindingen wijzen erop dat verpleegkundigen terughoudend zijn om hun rol in de beschreven kwesties uit te breiden. Ook het onderzoeksteam zag geen noodzaak om de 
rol van verpleegkundigen uit te breiden, mede vanwege de professionele verantwoordelijkheid van Nederlandse verpleegkundigen die wettelijk is vastgelegd.

Hoofdstuk 7 beschrijft de rol van verpleegkundigen in 330 gevallen van pijn- en symptoombestrijding met een levensbekortende intentie. Nadat de aanleiding tot pijn- en symptoombestrijding met een levensbekortende intentie is uiteengezet, wordt de rol van verpleegkundigen beschreven in het besluitvormingsproces en het toedienen van medicatie in ziekenhuizen, thuiszorg en verpleeghuizen.

In ongeveer de helft $(48,8 \%)$ van de gevallen verzochten naasten om het overlijden van de patiënt te bespoedigen of maakten opmerkingen in die richting. In een aantal gevallen voelden naasten zich verantwoordelijk om de belangen van de patiënt te behartigen, vooral als deze matig of niet aanspreekbaar was.

Tijdens het besluitvormingsproces vond overleg tussen arts en verpleegkundige vaker plaats in ziekenhuizen $(62,6 \%)$ en verpleeghuizen $(65,9 \%)$ dan in de thuiszorg $(44,3 \%)$. In bijna een kwart $(23,0 \%)$ van de gevallen waren verpleegkundigen het oneens met het besluit van de arts of twijfelden daaraan, bijvoorbeeld vanwege de afwezigheid van pijn en/of andere symptomen.

Hoewel niet verplicht, is het wel wenselijk dat de arts de verpleegkundige consulteert in de besluitvorming. Dat geldt des te meer wanneer artsen verpleegkundigen betrekken bij het toedienen van medicatie hetgeen frequent $(81,5 \%)$ aan de orde is, vooral in ziekenhuizen en verpleeghuizen. Pijn- en symptoombestrijding met een levensbekortende intentie behoort niet tot de normale medische praktijk. Dientengevolge kan betrokkenheid van verpleegkundigen bij het toedienen van medicatie betekenen dat verpleegkundigen worden betrokken bij een strafbare handeling.

In $18,8 \%$ van de gevallen bestond een meningsverschil onder verpleegkundigen en was een deel wel en een deel niet bereid tot het toedienen van de medicatie. In het algemeen respecteerden zij elkaars mening en werd de medicatie toegediend door een verpleegkundige die achter het beleid van de arts stond.

Hoofdstuk 8 bediscussieert de belangrijkste conclusies uit het proefschrift. Met betrekking tot de rol van verpleegkundigen bij euthanasie/hulp bij zelfdoding is een van de conclusies dat hun rol specificatie behoeft per sector. Er werden grote verschillen aangetroffen tussen de intramurale sector (ziekenhuizen en verpleeghuizen) en de extramurale sector (thuiszorg). In de thuiszorgsector, met het grootste aantal gemelde gevalien van euthanasie/hulp bij zelfdoding, is de verpleegkundige aanzienlijk minder betrokken bij euthanasie/hulp bij zelfdoding dan in beide andere sectoren.

Een andere conclusie is dat de rol van verpleegkundigen varieert in de verschillende fasen die bij euthanasie kunnen worden onderscheiden. In de eerste plaats bestaat een aanzienlijke fragmentatie in de betrokkenheid van verpleegkundigen in de verschillende fasen. Bijvoorbeeld, 18,9\% van de verpleegkundigen die aanwezig waren bij de uitvoering, hadden geen rol in het besluitvormingsproces. Een belangrijke reden voor deze 'gefragmenteerde' betrokkenheid kunnen de wisselende diensten van verpleegkundigen zijn. In de tweede plaats is er een aanzienlijke disproportie in de rol van verpleegkundigen in de verschillende fasen. In het besluitvormingsproces zouden zij vaker betrokken kunnen worden. Hoewel in het merendeel van de gevallen werd overlegd tussen artsen en verpleegkundigen, bleef dit in minstens een kwart van de gevallen achterwege. In het toedienen van euthanatica waren verpleegkundigen soms te sterk betrokken, doordat zij in $12,2 \%$ van de gevallen de euthanatica toedienden al dan niet samen met de arts.

Hoewel de studie zich toespitste op de feitelijke praktijk, werden verpleegkundigen ook naar hun mening gevraagd over drie vraagstukken: hun deelname in de toetsingscommissies, hun rol in het besluitvormingsproces van de arts en hun betrokkenheid in voorbereidende handelingen ten behoeve van het toedienen van euthanatica. Onder ver- 
pleegkundigen was geen meerderheidsstandpunt om deze vraagstukken vast te leggen in nieuwe regelgeving. Ook het onderzoeksteam zag daartoe geen reden.

De medische beslissing pijn- en symptoombestrijding met een levensbekortende intentie werd in dit onderzoek opgenomen omdat in dit zogeheten 'grijze' gebied veel onduidelijkheid bestaat over de rol van verpleegkundigen, terwijl alleszins aannemelijk is dat verpleegkundigen frequent worden geconfronteerd en zelfs betrokken in de uitvoering van deze medische beslissing rond het levenseinde.

Hoewel geen onderzoek is verricht naar de frequentie, bevestigt dit onderzoek dat het inderdaad gaat om een 'grijsachtige' praktijkvoering tussen enerzijds pijn- en symptoombestrijding en anderzijds euthanasie en levensbeëindiging zonder verzoek. Dit blijkt uit resultaten zoals: bijna een kwart $(23,0 \%)$ van de verpleegkundigen was het niet eens met, of had twijfels bij het besluit van de arts het levenseinde te bespoedigen. In ongeveer een kwart $(27,3 \%)$ van de gevallen werd de verpleegkundige door de arts niet geïnformeerd over het doel van de medicatie (bespoedigen van het levenseinde) en in $18,8 \%$ van de gevallen was een deel van het verpleegkundige team niet bereid tot het toedienen van de medicatie.

Deze onheldere praktijk van pijn- en symptoombestrijding met een levensbekortende intentie wordt mede in stand gehouden door verpleegkundigen, met name in situaties waarin arts en verpleegkundigen dezelfde intentie voor ogen hebben, namelijk het bespoedigen van het levenseinde.

Ten slotte worden de belangrijkste conclusies met betrekking tot de methodologie van de studie besproken. Medische beslissingen rond het levenseinde zoals euthanasie en hulp bij zelfdoding zijn gevoelige en complexe vraagstukken om kwantitatief te benaderen. Daarom werd gekozen voor een praktische insteek, namelijk het beantwoorden van vragen aan de hand van een meegemaakte situatie in de praktijk, niet langer dan twee jaar geleden.

De werving van respondenten door contactpersonen bleek een bruikbare aanpak.

De studie kende een hoge participatie vanwege het grote aantal deelnemende organisaties met landelijke spreiding en de analyse van een groot aantal casussen van hoge kwaliteit (meest recente casus). Hoewel een ad random steekproef ontbrak en nonrespons de resultaten enigszins beïnvloed kan hebben, is de conclusie gerechtvaardigd dat de resultaten representatief zijn voor Nederlandse verpleegkundigen die ervaring hebben met euthanasie/hulp bij zelfdoding en pijn- en symptoombestrijding met een levensbekortende intentie.

Hoofdstuk 9 bevat de aanbevelingen. Ook de ontwikkelingen/implementatie van aanbevelingen in de periode tussen het verschijnen van het Nederlandstalige onderzoeksrapport (2004) en van dit proefschrift (2008) worden beschreven.

De aanbevelingen over euthanasie/hulp bij zelfdoding hebben betrekking op de praktijk van verpleegkundigen, scholing voor verpleegkundigen, instellingsrichtlijnen en wetgeving.

Het verdient aanbeveling het overieg tussen arts en verpleging te verbeteren, vooral in de thuiszorg. Het gaat daarbij niet alleen over de rol van verpleegkundigen in het besluitvormingsproces en in het toedienen van euthanatica, maar evenzeer om het informeren van elkaar over de stand van zaken, zodat arts en verpleegkundige zorg kunnen verlenen afgestemd op de situatie van dat moment.

Aanbevolen wordt om verpleegkundigen te scholen op het gebied van wet- en regelgeving. In de scholing dient expliciet aandacht besteed te worden aan kwesties als de communicatie tussen arts en verpleegkundige, de privacy van de patiënt, het omgaan met eigen emoties en gevoelens, belangen en rechten van de patiënt en het verschil tussen voorbereidende en uitvoerende taken. 
Met betrekking tot wetgeving, is onder verpleegkundigen onvoldoende draagvlak om hen toe te voegen aan de Regionale toetsingscommissies euthanasie. Ook ontbreken ethische of wettelijke argumenten om verpleegkundigen toe te voegen aan deze commissies; hun evaluatie betreft de wettelijke en morele beoordeling van een medische handeling en niet de 'ethiek van de zorg'.

$\mathrm{Er}$ is onvoldoende grond om een zorgvuldigheidseis toe te voegen aan de euthanasiewet waarin wordt gesteld dat 'als de verpleegkundige bij de zorg van de patiënt betrokken is, de arts verplicht is een verpleegkundige te consulteren in de besluitvorming'. Dit voorstel kan op basis van verscheidene redenen worden verworpen, zoals: slechts $22,6 \%$ van de verpleegkundigen vond het een waardevol voorstel, en het gebrek aan kennis onder verpleegkundigen met betrekking tot wet- en regelgeving.

Met betrekking tot het klaarmaken van euthanatica bestaat geen meerderheid onder verpleegkundigen om deze taak tot de hunne te rekenen $(62,9 \%$ vindt dit geen taak voor de verpleegkundige). Aanbevolen wordt om deze taak voor rekening van de arts of apotheker te laten.

Ook met betrekking tot het inbrengen van een infuusnaald is er geen meerderheid onder verpleegkundigen om dit tot hun taak te rekenen $(54,1 \%$ vindt dit geen taak voor de verpleegkundige). Ook op dit punt geldt de aanbeveling deze handeling door de arts te laten verrichten.

Naast onvoldoende draagvlak onder verpleegkundigen is een belangrijk argument dat euthanasie en hulp bij zelfdoding niet-normale medische handelingen zijn, waaruit voortvloeit dat het om niet-normale verpleegkundige handelingen gaat, ook al gaat het hier om handelingen in voorbereidende zin.

Met betrekking tot pijn- en symptoombestrijding met een levensbekortende intentie is het aan te bevelen de helderheid van deze 'grijze' praktijk te verbeteren door bevordering van een betere communicatie tussen arts en verpleegkundige (en patiënt/verwanten). De conceptuele en intentionele grenzen van deze medische beslissing dienen helder gedefinieerd te worden en de verantwoordelijkheden en taken van de betrokken beroepsgroepen kunnen worden verduidelijkt door middel van richtlijnen.

Met betrekking tot verder onderzoek verdient het aanbeveling om in kwantitatief (vervolg)onderzoek onder artsen inzake medische beslissingen rond het levenseinde de rol van verpleegkundigen te betrekken en in het bijzonder de beleving van artsen inzake hun rol. Ook is er behoefte aan onderzoek over de vraag in het meldingsformulier aan de Regionale toetsingscommissies euthanasie die gaat over de rol van de verpleegkundige, en de wensen van de patiënt over de betrokkenheid van de verpleegkundige in de verschillende fasen van het euthanasieproces.

Een ander punt voor onderzoek betreft de rol die richtlijnen spelen bij euthanasie/hulp bij zelfdoding en andere medische beslissingen rond het levenseinde. Instellingsrichtlijnen zouden op een groot aantal punten geanalyseerd kunnen worden, waaronder de rol die aan verpleegkundigen wordt toegekend in de verschillende fasen van het euthanasieproces.

Tenslotte wordt aanbevolen om verdere studie te verrichten naar de rol van verpleegkundigen in de medische beslissingen rond het levenseinde die in dit onderzoek niet kwantitatief werden onderzocht (levensbeëindiging zonder uitdrukkelijk verzoek, niet instellen of staken van behandelingen die naar heersend medisch inzicht kansloos of zinloos zijn, niet kunstmatig toedienen van vocht en voeding). Ook de rol van verpleegkundigen bij palliatieve sedatie zou een interessant punt voor verder onderzoek kunnen zijn. 


\section{Dankwoord}

'Als ik elke werkdag enkele regels schrijf, komt het proefschrift vanzelf af'. Met deze gedachte begon ik in januari 2005 met het schrijven van dit proefschrift, wat aangeduid kan worden als de tweede fase van het totale traject. De eerste fase begon in 2001 met een opdracht van het Ministerie van VWS aan het Instituut voor Gezondheidsethiek (IGE) te Maastricht voor een onderzoek naar de rol van verpleegkundigen bij medische beslissingen rond het levenseinde. Dit onderzoek mondde uit in een onderzoeksrapport dat in november 2004 werd aangeboden aan staatssecretaris Ross-van Dorp.

Dit proefschrift is gebaseerd op het Nederlandstalige onderzoeksrapport. Ik wil allereerst diegenen bedanken die bij dat onderzoek en de rapportage betrokken waren, in het bijzonder de honderden verpleegkundigen/verzorgenden die bereid waren tot een interview of tot het invullen van de vragenlijst. Zonder jullie medewerking was het onderzoek niet van de grond gekomen en zeker niet op deze wijze. Jullie mondelinge en schriftelijke verhalen maakten veel indruk, waardoor ik soms een moment van stilte in acht nam door mijn handen op het toetsenbord te laten rusten als een vorm van nagedachtenis aan de vele patiënten die jullie zeer nabij stonden. Ook de vele gezondheidszorginstellingen en de contactpersonen die de respondenten wierven wil ik hartelijk danken.

Daarnaast ben ik de leden van de klankbordgroep van het WWS-onderzoek, met mw. prof. dr. M. Verkerk als voorzitter, erkentelijk voor hun constructieve besprekingen, aanvullende bijdragen en opbouwende kritiek. Tevens voorzagen zij het onderzoek en de rapportage van een maatschappelijk draagvlak.

$\mathrm{Na}$ de rapportage volgde de fase van het schrijven van een proefschrift op basis van Engelstalige artikelen in peer reviewed journals, waarin de veschillende onderdelen van het onderzoek voor een internationaal publiek werden gepresenteerd. Hoewel het schrijven van deze artikelen en andere hoofdstukken van het proefschrift iets weg had van 'de traagheid van een pad', maakte ik steeds een klein sprongetje voorwaarts en werden de artikelen en hoofdstukken c.q. het proefschrift in zijn totaliteit voltooid zonder dips. Dank aan God voor de gave van gezondheid, kracht en verstand.

Het proefschrift werd grotendeels thuis geschreven terwijl mijn promotoren en copromotor zich in de loop der jaren over de wereld verspreidden. Toch heb ik het karwei niet ervaren als een eenzame bezigheid, dankzij de voelbare betrokkenheid via e-mails.

Promotor Prof. dr. R.H.J. ter Meulen, beste Ruud, jij zag in 1998 het nut in van mijn voorstel om een landelijk onderzoek te verrichten naar de rol van verpleegkundigen bij euthanasie. Nu, tien jaar later, ligt er het proefschrift. Jouw goede begeleiding en het vertrouwen dat je me gaf hebben mij zeker geholpen om gemotiveerd te blijven. Je gaf me vrijheid een eigen weg te zoeken in het onderzoek. Hartelijk dank voor de plezlerige samenwerking, ook nadat je vertrok naar Bristol.

Promotor Prof. dr. H. .Huijer Abu-Saad, beste Huda, hoewel je verhuisde naar Libanon, bleef je onverminderd betrokken bij het onderzoek en later het proefschrift. Dank voor je constructieve opmerkingen, je steun en stimulans.

Copromotor Dr. A.J.G. van der Arend, beste Arie, ik kan niet anders dan mijn grote waardering uitspreken voor jouw ondersteuning, dus: duizendwerf dank! Onze samen- 
werking dateert al uit 1996 toen je mijn doctoraalscriptie begeleidde. Je voorzag mijn concepten minutieus van doordacht commentaar. Ik heb veel van je geleerd. Dank voor de productieve samenwerking, ook nadat je verhuisde naar Finland. Je hebt me ontzettend gehoipen door het opmaakwerk van het proefschrift voor je rekening te nemen.

Ook aan de overige leden van de begeleidingscommissie en later medeauteurs van artikelen in dit proefschrift past een woord van dankbaarheid.

Prof. dr. C. Spreeuwenberg, beste Cor, dank voor je nuttige suggesties en opbouwende commentaar. Ook je betrokkenheid heb ik zeer gewaardeerd.

Prof. mr. F.C.B. van Wijmen, beste Frans, dank voor je meedenken vanuit gezondheidsrechtelijk oogpunt en je meeleven.

Hoewel het proefschrift grotendeels werd geschreven buiten de muren van het IGE en later de vakgroep Health, Ethics \& Society van de Universiteit Maastricht was er met name contact met enkele (oud) vakgroepleden: Josy Ubachs-Moust, Ireen Proot en Angelique Heijnen. Hartelijk dank voor jullie meeleven. Angelique, jij ook hartelijk dank voor je praktische ondersteuning op verschillende punten.

Mijn huidige collega's van de Hogeschool Rotterdam ben ik erkentelijk voor hun betrokkenheid en meeleven.

Graag wil ik ook Vicki van Tuijl-Gay ontzettend bedanken die met veel enthousiasme en ijver mijn Engelstalige teksten corrigeerde. Je betekende veel voor mij!

Verder past een woord van dank aan Dick en Frieda de Bijl voor de coverfoto van het proefschrift. Ook dank aan huisartspraktijk Van den Dool voor het lenen van een deel van de afgebeelde attributen.

Verder wil ik zussen, broers, zwagers, schoonzussen, verdere familieleden, vrienden, kennissen en buren danken voor hun meeleven.

Moeder Anna, hartelijk dank voor al je goede zorgen door de jaren heen. Jammer dat vader Marinus (†1989) dit niet meemaakt. Hij zou er ongetwijfeld trots op zijn geweest.

Schoonzus Aline, veel dank voor je wekelijkse oppasdag zodat ik een aantal aaneengestoten uren kon werken.

Jans van Hemert, heel hartelijk dank voor de niet aflatende ijver waarmee je ons gezin ter zijde staat.

Mijn lieve Cees, dank voor je steun en vertrouwen en niet te vergeten je geduld, want het bleek een kwestie van lange adem.

Het schrijven over het levenseinde werd afgewisseld met de komst van nieuw leven toen onze dochters Hanna (2004) en Annemarie (2005) werden geboren. Gelukkig zijn jullie goede slaapsters, zodat ik tijdens jullie middagdut steeds enkele regels kon toevoegen aan mijn proefschrift.

Hoewel het opvoeden van kinderen de voortgang van het proefschrift aanzienlijk vertraagde, relativeerde het tegelijkertijd de totstandkoming ervan: een titel is dan per slot van rekening maar bijzaak!

Ik veronderstelde dat het schrijven van het proefschrift aan jullie voorbij ging, maar dat bleek niet geheel waar. Toen ik enkele maanden geleden aan Hanna vroeg wat ze ging doen op de basisschool zei ze: 'knutselen en een proefschrift maken'. En die beiden sluiten elkaar niet uit, er moet immers heel wat geknutseld worden voordat er een proefschrift ligt.

Bruchem, november 2008

Ada van Bruchem-van de Scheur 


\section{Curriculum Vitae}

Ada van de Scheur was born in June 1965 in 's-Hertogenbosch and grew up in Hurwenen, the Netherlands.

After primary school, she completed in 1981 her secondary education (MAVO) at the Christian School for MAVO in Zaltbommel, followed by higher secondary education (HAVO) at the Queen Wilhelmina College in Culemborg in 1983.

In 1987 she obtained her Associate Degree in Nursing at the Bleuland Hospital in Gouda. Subsequently she specialised in oncology nursing in the cancer center Dr. Daniel den Hoedkliniek in Rotterdam, where in 1988 she completed the theoretical and practical Oncology for Nurses courses.

She finished her Bachelor's degree in Social Haalthcare at The Hague University of Applied Sciences in 1992. During this study she worked as district nurse at Rotterdam Homecare.

Subsequently she studied Health Sciences at Maestricht Universify (1992-1997), focusing on Nursing Science. During this study she continued her work as district nurse.

After graduation she worked at Rotterdam homecare as district nurse, indication advisor and staff nurse respectively. She worked also for a brief period as researcher at the Prof. dr. G. A. Lindeboom Institute (Centre for medical ethics) in Ede, where she conducted a literature study into Spiritual Care.

In 2001 she started her PhO study at Maastricht University. This concerned a study into the role of nurses in medical end-of-life decisions. In November 2004, the results of the study were presented in a (Dutch) report to the principal, the Ministry of Health. Welfare and Sports.

Since February 2008 she is working at the Rotterdam University of Applied Sciences as lecturer in the Master's Advanced Nursing Program.

Ada is married to Cees van Bruchem, agriculture economist, and lives in Bruchem, the Netherlands. Together they have two daughters, Hanna and Annemarie. 


\section{List of publications}

Van de Scheur, A. \& van der Arend, A. (1998). The role of nurses in euthanasia: a Dutch study. Nursing Ethics, 5, 497-508.

Van de Scheur, G.G. \& van der Arend, A.J.G. (1998). De rol van verpleegkundigen bij euthanasie. Het Richtsnoer, 3, 1,4-7.

Cusveller, B.S. \& van de Scheur, G.G. (1998). Versterven, levensbeëindigend handelen en euthanasie. Het Richtsnoer, 3, 12-14.

Van de Scheur, A. (1999). Beroepsverantwoordelijkheid rond het levenseinde. In B.S. Cusveller (Red.). Volwaardige verpleging: Morele beroepsverantwoordelijkheid in de zorgverlening. Amsterdam: Buijten \& Schipperheijn.

Van de Scheur, G.G. \& van der Arend, A.J.G. (1999). De rol van verpleegkundigen bij euthanasie. Verpleegkunde, 14, 46-57.

Van de Scheur G.G., van der Arend, A.J.G \& ter Meulen, R.H.J. (2003). Hulp van verpleegkundigen: Wet toetsing levensbeëindiging roept nieuwe vragen op. Medisch Contact, 58, 522-524.

Van de Scheur, G.G. \& van der Arend, A.J.G. (2003). Voorbereidende handelingen bij euthanasie en hulp bij zelfdoding: een taak voor verpleegkundigen? Verpleegkunde, 18, 123-125.

Van Bruchem-van de Scheur, G.G., Cusveller B.S. \& Jochemsen, H. (2004). Spiritualiteit en spirituele zorg: Een literatuuroverzicht. Nederlands Tijdschrift voor Palliatieve Zorg, 5, 25-40.

Van Bruchem-van de Scheur, G.G. \& van der Arend, A.J.G. (2004). Euthanasierichtilinen van do KNMG en NU'91: Expertrapport met betrekking tot het voorstel tot wijziging van de euthanasierichtlijnen arts-verpleegkundigen. Universiteit Maastricht.

Van Bruchem-van de Scheur, A. (2004). Professional Responsibility at the End of Life: Euthanasia and palliative care. In B. Cusveller, A. Sutton \& D. O'Mathúna (Eds). Commitment and Responsibility in Nursing: A Faith-Based Approach. Sioux Center, lowa: Dordt College Press.

Van Bruchem-van de Scheur, A., van der Arend A., Spreeuwenberg, C., van Wijmen, F. \& ter Meulen, R. (2004). De rol van verpleegkundigen bij medische beslissingen rond het levenseinde. Verslag van een landelijk onderzoek naar betrokkenheid en praktijken. Utrecht: Uitgeverij De Tijdstroom.

Van Bruchem-van de Scheur, A \& van der Arend, A. (2005). De rol van verpleegkundigen bij euthanasie en hulp bij zelfdoding. TVZ Tijdschrift voor Verpleegkundigen, 115(1), 32-36.

Van Bruchem-van de Scheur, A \& van der Arend, A. (2005). Kennis en opvattingen van verpleegkundigen over euthanasie en hulp bij zelfdoding. TVZ Tijdschrift voor Verpleegkundigen, 115(2), 34-39.

Van Bruchem-van de Scheur, A \& van der Arend, A. (2005). Pijn- en andere symptoombestrijding met de dood als nevenbedoeling. TvZ Tijdschrift voor Verpleegkundigen, 115(3), 32-37.

Van Bruchem-van de Scheur, G.G. \& van der Arend A.J.G. (2005). Gewetensbezwaren bij euthanasie en hulp bij zelfdoding. RMU Katern, 10, 9-13.

Van Bruchem-van de Scheur, G.G. \& van der Arend, A.J.G. (2005). De rol van verpleegkundigen in het besluitvormingsproces en de ultvoering van euthanasie en hulp bij zelfdoding. Pro Vita Humana, 12, 129-133. 
Van Bruchem-van de Scheur, G.G. \& van der Arend, A.J.G. (2005). De rol van verpleegkundigen bij pijn-en andere symptoombestrijding met de dood als nevenbedoeling. Pro Vita Humana, 12, 153-157.

Van Bruchem-van de Scheur, G.G. \& van der Arend, A.J.G. \& Spreeuwenberg, C. (2005). Euthanasie en hulp bij zelfdoding in de thuissituatie. De rol van wijkverpleegkundigen en andere zorgverleners. Handboek Zorg Thuis, B 3.8-1 - B 3.8-24.

Nieuwe Unie'91. (2006). Rapport Evaluatie Euthanasiewet: Reactie NU'91 op functioneren euthanasiewet. Utrecht: NU'91 [Bi]dragen van A. van Bruchem-van de Scheur \& A. van der Arend].

Van Bruchem-van de Scheur, G.G., van der Arend, A.J.G., Spreeuwenberg, C., Huijer Abu-Saad, H. \& ter Meulen, R.H.J. (2007). Euthanasia and physician-assisted suicide in the Dutch homecare sector: the role of the district nurse. Journal of Advanced Nursing, 58, 44-52.

Van Bruchem-van de Scheur, G.G., van der Arend, A.J.G., Huijer Abu-Saad, H., Spreeuwenberg C., van Wijmen, F.C.B. \& ter Meulen, R.H.J. (2008). The role of nurses in euthanasia and physician-assisted suicide in the Netherlands. Journal of Medical Ethics, 34, 254-258.

Van Bruchem-van de Scheur, G.G. \& van der Arend, A.J.G., Hijer Abu-Saad, H., van Wijmen F.C.B., Spreeuwenberg, C. \& ter Meulen, R.H.J. (2008). Euthanasia and physician-assisted suicide in Dutch hospitals: the role of nurses. Journal of Clinical Nursing, 17, 1618-1626.

Van Bruchem-van de Scheur, A., van der Arend, A., van Wijmen, F., Huijer Abu-Saad, H. \& ter Meulen, R. (2008). Attitudes of Dutch nurses towards euthanasia and physician-assisted suicide. Nursing Ethics, 15, 186-198.

Van Bruchem-van de Scheur, G.G., van der Arend, A.J.G., Huijer Abu-Saad, H., van Wijmen, F.C.B., Spreeuwenberg, C. \& ter Meulen, R.H.J. (2008). Alleviation of pain and symptoms with a life-shortening intention. Nursing Ethics, 15, 682-695.

Jochemsen, H., Klaasse-Carpentier, M., Cusveller, B.S., van de Scheur, A. \& Bouwer, J. (2008). Questions of life and death in the terminal phase towards quality criteria for spiritual care in the terminal palliative care from the patient's perspective. In J. Bouwer (Ed.). Spirituality and' meaning in health care: A Dutch contribution to an ongoing discussion. Leuven/Paris/Dudley(MA): Peeters. [Titus Brandsma Institute, Studies in spirituality, Supplement 17]. 